\title{
Ultrasound guidance for interventional pain management of cervical pain syndromes : an anatomical and clinical study
}

Citation for published version (APA):

Narouze, S. N. (2012). Ultrasound guidance for interventional pain management of cervical pain syndromes : an anatomical and clinical study. [Doctoral Thesis, Maastricht University]. Datawyse / Universitaire Pers Maastricht. https://doi.org/10.26481/dis.20120613sn

Document status and date:

Published: 01/01/2012

DOI:

10.26481/dis.20120613sn

Document Version:

Publisher's PDF, also known as Version of record

Please check the document version of this publication:

- A submitted manuscript is the version of the article upon submission and before peer-review. There can be important differences between the submitted version and the official published version of record.

People interested in the research are advised to contact the author for the final version of the publication, or visit the DOI to the publisher's website.

- The final author version and the galley proof are versions of the publication after peer review.

- The final published version features the final layout of the paper including the volume, issue and page numbers.

Link to publication

\footnotetext{
General rights rights.

- You may freely distribute the URL identifying the publication in the public portal. please follow below link for the End User Agreement:

www.umlib.nl/taverne-license

Take down policy

If you believe that this document breaches copyright please contact us at:

repository@maastrichtuniversity.nl

providing details and we will investigate your claim.
}

Copyright and moral rights for the publications made accessible in the public portal are retained by the authors and/or other copyright owners and it is a condition of accessing publications that users recognise and abide by the legal requirements associated with these

- Users may download and print one copy of any publication from the public portal for the purpose of private study or research.

- You may not further distribute the material or use it for any profit-making activity or commercial gain

If the publication is distributed under the terms of Article $25 f a$ of the Dutch Copyright Act, indicated by the "Taverne" license above, 


\section{Ultrasound Guidance for Interventional Pain Management of Cervical Pain Syndromes}

An anatomical and clinical study 
Ultrasound Guidance for Interventional Pain Management of Cervical Pain Syndromes An anatomical and clinical study

Thesis Maastricht University Medical Centre, 2012

\section{ISBN: 9789461591357}

The work was performed at the Center for Pain Medicine at Summa Western Reserve Hospital, 1900 23rd Street, Cuyahoga Falls, OH, 44223 USA.

Copyright (C) Samer Narouze, Akron, OH, 2012

All rights reserved. No part of this publication may be reproduced in any form or by any means, electronically, mechanically, by print, or otherwise, without written permission of the copyright owner.

The copyright of the articles and publications that have been published or accepted for publication has been transferred to the respective journals.

Layout and print: Datawyse | Universitaire Pers Maastricht 


\title{
Ultrasound Guidance for Interventional Pain Management of Cervical Pain Syndromes
}

\section{An anatomical and clinical study}

\author{
PROEFSCHRIFT \\ ter verkrijging van de graad van doctor aan de Universiteit Maastricht, \\ op gezag van de Rector Magnificus, \\ Prof. mr. G.P.M.F. Mols \\ volgens het besluit van het College van Decanen, \\ in het openbaar te verdedigen \\ op woensdag 13 juni 2012 om 16.00 uur \\ door \\ Samer Nabil Narouze \\ Geboren op 14 september 1966 - Cairo, Egypte
}

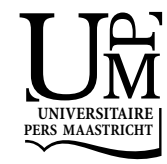




\section{Promotores}

Prof. dr. M. van Kleef

Prof. dr. A. van Zundert

\section{Copromotor}

Dr. M. Sommer

\section{Beoordelingscommissie}

Prof. dr. J. Wildberger (voorzitter)

Prof. dr. F. Huygen (Rotterdam)

Prof. dr. C. de Jong

Prof. dr. L. van Rhijn

Prof. dr. K. Vissers (Nijmegen) 
To my family; Mira, John, Michael, and Emma - the true love and joy of my life. 


\section{List of Abbreviations}

AAJ Atlanto-axial joint

at Anterior tubercle

CA Carotid artery

CT CAT scan

DRG Dorsal root ganglion

Es Esophagus

ITA Inferior thyroid artery

Lcol Longus colli muscle

MB Medial branch

MRI Magnetic Resonance Imaging

pt Posterior tubercle

SGB Stellate ganglion block

Th Thyroid

TON Third occipital nerve

Tp Transverse process

US Ultrasound

USPM Ultrasound in pain medicine

USRA Ultrasound in regional anesthesia

VA Vertebral artery 


\section{Table of Contents}

Chapter 1 Introduction and aim of the study 9

$\begin{array}{lll}\text { Chapter } 2 \text { Sonoanatomy of the cervical spine } & \mathbf{1 5}\end{array}$

$\begin{array}{lll}\text { Chapter } 3 & \text { Sonoanatomy of the cervical sympathetic chain } & \mathbf{3 1}\end{array}$

Chapter $4 \quad$ Ultrasound-guided cervical nerve root block $\quad \mathbf{4 5}$

Chapter 5 Ultrasound-guided stellate ganglion block $\quad \mathbf{5 9}$

Chapter 6 Atlanto-axial joint injection for cervicogenic headache $\quad 69$

$\begin{array}{lll}\text { Chapter } 7 & \text { Ultrasound-guided Atlanto-axial joint injection } & \mathbf{7 7}\end{array}$

$\begin{array}{lll}\text { Chapter } 8 & \text { USPM education and training recommendations } & \mathbf{8 5}\end{array}$

$\begin{array}{lll}\text { Chapter } 9 & \text { Summary } & 111\end{array}$

$\begin{array}{lll}\text { Chapter } 10 & \text { Samenvatting } & 115\end{array}$

$\begin{array}{lll}\text { Chapter } 11 \text { Acknowledgements } & 119\end{array}$

$\begin{array}{lll}\text { Chapter } 12 & \text { Curriculum Vitae } & 121\end{array}$

List of Publications 



\section{Chapter 1 \\ Introduction and Aim of the Study}

Samer Narouze, MD, MSc

Narouze S. Ultrasound-guided Interventional Procedures in Pain Management: Evidence Based Medicine. Reg Anesth Pain Med 2010; 35(S2):S55-8. 
Ultrasound guidance for peripheral nerve blocks is now well established in the field of Regional Anesthesia (USRA). ${ }^{1}$ Recently, we started to see a growing interest in using ultrasound to guide different procedures in interventional pain management (USPM). ${ }^{2-4}$

The difference between USRA and USPM is obvious. In USRA, we are comparing ultrasound guidance to other "blind" nerve localization techniques e.g. nerve stimulation or surface landmarks. On the other hand, in USPM we are comparing ultrasound guidance to other "imaging" techniques e.g. fluoroscopy (or CT scan). So, to advocate the use of ultrasound (US) in interventional pain management, US had to offer more advantages than what the traditional fluoroscopy can offer. ${ }^{5,6}$

The advantages of ultrasonography over fluoroscopy/CT are; no radiation exposure to both the patient and health care providers, visualization of soft tissues (nerves, muscles, vessels, etc), and real-time visualization of needle tip advancement relevant to surrounding structures. As the major advantage of US is soft tissue visualization, ultrasonography is particularly relevant in the cervical area with the multitude of vessels and other vital soft tissue structures compacted in a small area. ${ }^{7}$

One of the best examples is stellate ganglion block. The anatomy of the stellate ganglion being in close proximity to various critical structures, results in a number of complications potentially associated with its blockade, some of which are life-threatening. ${ }^{8}$ Fluoroscopy is a reliable method for identifying bony structures; however the adjacent anatomical structures can't be identified. Ultrasound-guided SGB may improve the safety of t,he procedure by direct visualization of the related anatomical structures and accordingly the risk of thyroid gland and vessels, vertebral artery, or esophagus injury may be minimized. 9-11 Will the application of ultrasonography in selective cervical nerve root injections revive the diminishing art? The major reported adverse events after cervical transforaminal injections, currently performed under fluoroscopic guidance, are related to the proximity to critical vessels. Reports of intravascular injection even after confirmation by contrast fluoroscopy have led some to question the safety of the procedure. ${ }^{12,13}$

Currently the guidelines for cervical transforaminal injection technique involve introducing the needle under fluoroscopic guidance into the posterior aspect of the intervertebral foramen just anterior to the superior articular process in the oblique view to minimize the risk of injury to the vertebral artery or the nerve root. ${ }^{14,15}$ Despite strict adherence to these guidelines adverse outcomes have been reported. ${ }^{16,17}$ A potential shortcoming to these current guidelines would be the presence of a critical feeder vessel to the anterior spinal artery in the posterior aspect of the intervertebral foramen that could be injured in the pathway of the needle. ${ }^{18}$ Here the ultrasonography may come to play; as it allows for visualization of soft tissues, nerves and vessels and also facilitates visualization of the injectate around the nerve thus it may be advantageous to 
fluoroscopy. With cervical selective nerve root block (cervical transforaminal epidural injection) there is really no safe zone, however there may be a safer tool, the ultrasound. ${ }^{19}$

Another area of interest that ultrasound may play a difference is the atlantoaxial joint (AAJ). Because of its close proximity to the vertebral artery and as fluoroscopy can't directly identify the vertebral artery, some advocate to abandon AAJ injections. ${ }^{20}$ As ultrasound can easily identify the vertebral artery as it courses from $\mathrm{C} 2$ to $\mathrm{C} 1$ foramina, ultrasound guidance can increase the safety of this much needed procedure in selected patients with cervicogenic headache. ${ }^{21-23}$

The aim of this thesis is to review the feasibility and demonstrate the potential advantages of US in visualizing various vessels and other soft tissue structures in the neck relevant to the performance of various interventional pain management procedures.

Specifically we will address the following questions:

1. What is the sonoanatomy of the cervical spine relevant to cervical spine injections for the treatment of various neck and upper extremity pain syndromes? (Chapter 2)

2. Is ultrasound feasible in visualizing various arteries and other vital soft tissues in the vicinity of the cervical sympathetic chain relevant to stellate ganglion block procedure? (Chapter 3 and 5)

3. Does ultrasound improve the safety of cervical selective nerve root block by visualizing critical radicular arteries in the vicinity of the cervical neuroforamen? (Chapter 4)

4. Are we able to visualize the vertebral artery as it courses through the C2 and $\mathrm{C} 1$ foramina to insure a safer atlanto-axial joint (AAJ) injection? Is there a role for $\mathrm{AAJ}$ injection in the treatment of cevicogenic headache? (Chapter 6 and 7)

5. What are the required skills to learn and master ultrasound guided pain procedure? What are the educational and training recommendations? (Chapter 8)

In summary; ultrasound is a very useful tool to identify the complex vasculature and other critical soft tissue structures in the neck relevant to various cervical spine procedures in interventional pain management. This thesis should help pain physician learn the applications of ultrasound in various cervical spine injections and should open the door to design more controlled studies comparing ultrasound to other imaging modalities in performing cervical spine injections. 


\section{References}

1. Hopkins PM. Ultrasound guidance as a gold standard in regional anesthesia. Br J Anaesth 2007; 98:299-301.

2. Narouze, SN. (Ed.) Atlas of ultrasound guided procedures in interventional pain management, 1st ed. New York, NY: Springer; 2011.

3. Narouze S, Peng PWH. Ultrasound-guided Interventional Procedures in Pain Medicine: A Review of Anatomy, Sonoanaotmy and Procedures. Part II: Axial structures. Reg Anesth Pain Med 2010; 35:386-396.

4. Peng PWH, Narouze S. Ultrasound-guided Interventional Procedures in Pain Medicine: A Review of Anatomy, Sonoanaotmy and Procedures. Part I: Non-axial structures. Reg Anesth Pain Med 2009; 34:458-474

5. Narouze S. Ultrasound-guided Interventional Procedures in Pain Management: Evidence Based Medicine. Reg Anesth Pain Med 2010; 35(S2):S55-58.

6. Neal JM, Brull R, Chan VW, Grant SA, Horn JL, Liu SS, McCartney CJ, Narouze SN, Perlas A, Salinas FV, Sites BD, Tsui BC. The ASRA evidence-based medicine assessment of ultrasound-guided regional anesthesia and pain medicine: Executive summary. Reg Anesth Pain Med 2010; 35(S2):S1-9.

7. Narouze S. Ultrasonography in pain medicine: a sneak peak at the future (editorial). Pain Pract 2008; 8:223-225

8. Higa K, Hirata K, Hirota K, Nitahara K, Shono S: Retropharyngeal hematoma after stellate ganglion block. Anesthesiology 2006; 105:1238-1245.

9. Narouze S, Vydyanathan A, Patel N. Ultrasound-guided stellate ganglion block successfully prevented esophageal puncture. Pain Physician 2007; 10:747-752.

10. Kapral S, Krafft P, Gosch M, Fleischmann D, Weinstabl C. Ultrasound imaging for stellate ganglion block: Direct visualization of puncture site and local anesthetic spread. Reg Anesth 1995; 20:323-328.

11. Narouze S. Beware of the "serpentine" inferior thyroid artery while performing stellate ganglion block. Anesth Analg 2009; 109:289-290.

12. Provenzano DA, Fanciullo G. Cervical transforaminal epidural steroid injections: should we be performing them? Reg Anesth Pain Med 2007; 32:168.

13. Wallace MA, Fukui MB, Williams RL, Ku A, Baghai P. Complications of cervical selective nerve root blocks performed with fluoroscopic guidance. AJR 2007; 188:1218-1221.

14. Rathmal JP, Aprill C, Bogduk N. Cervical transforaminal injection of steroids. Anesthesiology 2004; 100:1595-1600.

15. Hoeft MA, Rathmell JP, Monsey RD, Fonda BJ. Cervical transforaminal injection and the radicular artery: Variation in anatomical location within the cervical intervertebral foramina. Reg Anesth Pain Med 2006; 31:270-274.

16. Tiso RL, Cutler T, Catania JA, Whalen K. Adverse central nervous system sequelae after selective transforaminal block: the role of corticosteroids. The Spine J 2004; 4:468-474.

17. Baker R, Dreyfuss P, Mercer S, Bogduk N. Cervical transforaminal injections of corticosteroids into a radicular artery: a possible mechanism for spinal cord injury. Pain 2002; 103:211-215.

18. Huntoon MA. Anatomy of the cervical intervertebral foramina: vulnerable arteries and ischemic neurologic injuries after transforaminal epidural injections. Pain 2005; 117:104-111.

19. Narouze S, Vydyanathan A, Kapural L, Sessler DI, Mekhail N. Ultrasound-guided Cervical Selective Nerve Root Block: A Fluoroscopy-controlled Feasibility Study. Reg Anesth Pain Med 2009; 34:343-348.

20. Edlow BL, Wainger BJ, Frosch MP, Copen WA, Rathmell JP, Rost NS. Posterior circulation stroke after C1-C2 intraarticular facet steroid injection: evidence for diffuse microvascular injury. Anesthesiology 2010; 112:1532-1535.

21. Narouze S. Ultrasound-guided Lateral Atlanto-axial Joint Injection for the Treatment of Cervicogenic Headache. Pain Med 2009; 10: 222. 
22. Narouze S. Ultrasonography in pain medicine: Future directions. Tech Reg Anesth Pain Manage 2009; 13:198-202.

23. Narouze S, Casanova J, Mekhail N. The longitudinal effectiveness of lateral atlantoaxial intraarticular steroid injection in the management of cervicogenic headache. Pain Medicine 2007; 8:184-188. 



\section{Chapter 2 \\ Sonoanatomy of the Cervical Spine}

Samer Narouze, MD, MSc

Philip WH Peng, MBBS FRCPC

Narouze S, Peng P. Ultrasound-guided Interventional Procedures in Pain Medicine: A Review of Anatomy, Sonoanatomy, and Procedures. Part II: Axial structures. Reg Anesth Pain Med 2010; 35:386-96. 


\begin{abstract}
There is a growing trend in using ultrasonography in pain medicine (USPM) as evident by the plethora of published reports. Ultrasound provides direct visualization of various soft tissues, real-time needle advancement and avoids exposing both the healthcare provider and the patient to the risks of radiation. The ultrasound machine is more affordable and transferrable than a fluoroscopy, CT scan or MRI machine. In a previous review, we discussed the challenges and limitations of ultrasound, anatomy, sonoanatomy, and techniques of interventional procedures of peripheral structures. In the present review, we will discuss the anatomy, sonoanatomy, and ultrasound guided techniques of interventional pain procedures for axial structures and will review the pertinent literature.
\end{abstract}




\section{Introduction}

Ultrasonography in pain medicine (USPM) is a rapidly growing medical field in interventional pain management. Traditionally, spine interventional procedures for pain management are performed with imaging guidance such as fluoroscopy and computed tomography (CT) scan. In the last few years, there has been tremendous growth in USPM interest as evidenced by the remarkable increase in the publication of literature on ultrasound-guided injections. ${ }^{1}$ A search of the Medline $\AA$ database revealed only 3 publications published in ultrasound-guided or ultrasound-assisted injection techniques (excluding peri-operative, intraarticular, interlaminar and trigger point injections) between 1982 and 2002 but there have been nearly 50 publications since 2003. The first objective of this review is to describe the relevant anatomy and sonoanatomy of those specific interventional techniques. The second objective is to describe and summarize various reports and feasibility data published in the literature on axial USPM procedures.

\section{Methods}

We performed a literature search of the MEDLINE database from January 1982 to June 2009 using the search terms "ultrasound", "ultrasound-guided", "pain management", "spine injections" and different selected nerves or structures relevant in this review such as "transforaminal injections", "facet intraarticular injections", "medial branch nerve block", "caudal epidural", and "sacroiliac joint".

We excluded those publications that described the use of the peripheral nerve blocks in peri-operative setting, and those describing intra-articular, interlaminar and trigger point injections.

\section{Ultrasound versus Conventional Imaging Techniques}

The advantages and shortcomings of ultrasound relative to other imaging modalities were described in details in the previous review (non-axial procedures, part I). ${ }^{1}$

Ultrasonography allows direct real time visualization of soft tissue structures. Thus, it is an attractive alternative in non-axial applications when most of the conventional techniques are landmark-based or "blinded". However USPM faces unique challenges in the spine or axial injections when most of the established techniques require the use of fluoroscopy. Although CT or MRI guidance have been described, these procedures are by far commonly performed with fluoroscopic guidance (which will be discussed below). 
Ultrasonography provides good visualization of bony surfaces that may make it useful in various superficial axial or spine injections such as the medial branch block, facet intraarticular injections, nerve root blocks, and sacroiliac joint injection. However ultrasound is not as useful in neuraxial (epidural or intrathecal) blocks in adults as the major shortcomings of USPM are the limited resolution at deep levels and bony artifacts which affect image quality. If one can not visualize the real time spread of the injectate in the epidural space under ultrasonography or rule out intravascular injection (contrary to the commonly used fluoroscopy in pain medicine practice), then it is a "partially blind technique". Nevertheless, ultrasound-assisted neuroaxial block may be more advantageous than the traditional "blind" surface-landmark approach that is used in regional and obstetric anesthesia.

The present article will focus on various ultrasound-guided axial (spine) interventional procedures in pain management excluding neuroaxial applications for the aforementioned reasons.

\section{Cervical selective nerve root (transforaminal) injection}

\section{Anatomy}

The cervical spinal nerve occupies the lower part of the foramen with the epiradicular veins in the upper part. The radicular arteries arising from the vertebral, ascending cervical and deep cervical arteries lie in close approximation to the spinal nerve. ${ }^{2}$

Huntoon showed that the ascending and deep cervical arteries may contribute to the anterior spinal artery (not only the vertebral artery). In more than $20 \%$ of the foramina dissected (21/95), either the ascending or deep cervical artery or a large branch were found within $2 \mathrm{~mm}$ of the needle path for a cervical transforaminal procedure. One third of these vessels entered the foramen posteriorly potentially forming a radicular or a segmental feeder vessel to the spinal cord, making it vulnerable to unintentional injury or injection even during correct needle placement. Variable anastomoses between the vertebral and cervical arteries were found; therefore it is possible to introduce steroid particles into the vertebral circulation via the cervical arteries. ${ }^{3}$

Also, in a single cadaver dissection study, Hoeft et al. ${ }^{4}$ showed that radicular artery branches from the vertebral artery lie over the most anteromedial aspect of the foramen, while those that arise from the ascending or deep cervical arteries are of greatest clinical significance as they must course medially transversing the entire extent of the foramen.

Cervical transforaminal injections have been traditionally performed with the use of fluoroscopy or CT. However, there have been reports of fatal complications as a result of vertebral artery injury5,6, and/or infarction of the spinal 
cord and the brain stem ${ }^{7-11}$. The mechanism of injury was contended to be either vasospasm or accidental arterial injection of the particulate steroid injectate and embolus formation in critical arteries. ${ }^{12,13}$

Currently the guidelines for cervical transforaminal injection technique involve introducing the needle under fluoroscopic guidance into the posterior aspect of the intervertebral foramen just anterior to the superior articular process in the oblique view to minimize the risk of injury to the vertebral artery or the nerve root. ${ }^{2}$ Despite strict adherence to these guidelines adverse outcomes have been reported. ${ }^{7,8}$ A potential shortcoming of the described fluoroscopicguided procedure is that the needle may puncture a critical feeder vessel to the anterior spinal artery in the posterior aspect of the intervertebral foramen. ${ }^{3}$ Here ultrasonography may have potential utility, as it allows for visualization of soft tissues, nerves and vessels and the spread of the injectate around the nerve thus it may be potentially advantageous to fluoroscopy. The fact that the ultrasound allows real-time recognition of an artery prior to needle puncture is one distinct advantage over fluoroscopic guidance, wherein this complication can only be recognized after aberrant arterial flow is noted when contrast agent is injected.

\section{Literature review of ultrasound guided cervical nerve root block}

Galiano et al. ${ }^{12}$ described the use of ultrasound-guided periradicular injections in the middle and lower cervical spine in cadavers and were later confirmed with computed tomography. The needles were positioned within $5 \mathrm{~mm}$ dorsal to the spinal nerve and 5 of the 40 positioning attempts could not depict the spinal nerve due to reduced imaging conditions. They were not able to comment on the relevant blood vessels in the vicinity of the vertebral foramen and this raised some concerns about the safety of performing the procedure with ultrasound at that time ${ }^{13}$. With the introduction of high-resolution ultrasound transducers and gaining more experience, we were able to visualize small critical arteries with ultrasonography.

Narouze et al. ${ }^{14}$ reported a pilot study of 10 patients who received cervical nerve root injections using ultrasound as the primary imaging tool with fluoroscopy as the control. The radiologic target point was the posterior aspect of the intervertebral foramen just anterior to the SAP in the oblique view, and at the midsagittal plane of the articular pillars in the anteroposterior (AP) view. The needle was exactly at the target point in 5 patients in the oblique view and in 3 patients in the AP views. The needle was within $3 \mathrm{~mm}$ in all patients in the lateral oblique view and in 8 patients in the AP view. In the other 2 patients the needle was within $5 \mathrm{~mm}$ from the radiologic target. In 4 patients they were able to identify vessels at the anterior aspect of the foramen, while 2 patients had critical vessels at the posterior aspect of the foramen and in one patient this artery continued medially into the foramen most likely forming a segmental 
feeder artery. In these 2 cases such vessels could have been easily injured in the pathway of a correctly placed needle under fluoroscopy.

\section{Sonoanatomy and ultrasound guided technique for cervical selective nerve root block}

With the patient lying in the lateral decubitus position, an ultrasound examination of the cervical spine is performed using a high-resolution linear array transducer. The transducer is applied transversely to the lateral aspect of the neck to obtain a short axis view of the cervical spine. One can easily identify the cervical transverse process with the anterior and posterior tubercles as hyperechoic structures "two-humped camel" sign and the hypoechoic round to oval nerve root in-between (Fig. 1). ${ }^{14}$ First the cervical level is determined by identifying the transverse process of the seventh and sixth cervical vertebrae ( $\mathrm{C} 7$ and C6). The seventh cervical transverse process (C7) differs from the above levels as it usually has a rudimentary anterior tubercle and one prominent posterior tubercle ${ }^{15}$. Then by moving the transducer cranially the transverse process of the sixth cervical spine comes into the image with the characteristic sharp anterior tubercle (Fig. 2,3), and then after the consecutive cervical spinal level can be easily identified. Another way to determine the cervical spinal level is by following the vertebral artery, which runs anteriorly at the C7 level before it enters the foramen of C6 transverse process in about $90 \%$ of cases. However it enters at C5 or higher in the remaining cases (Fig. 2B). ${ }^{16}$

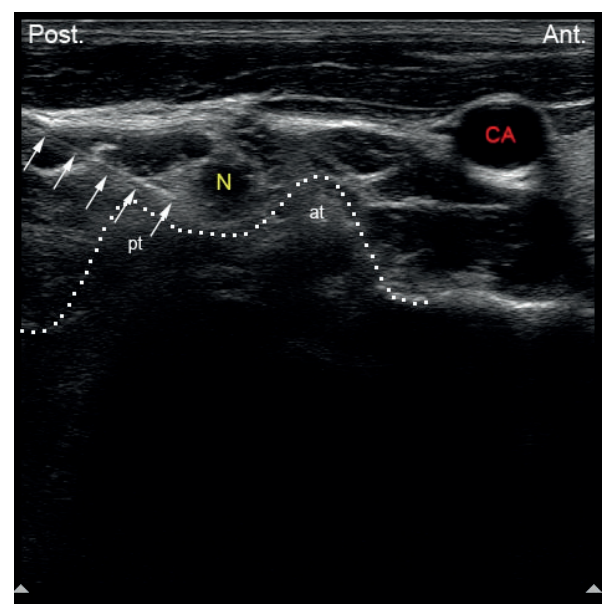

Figure 1: C5 level

Short-axis transverse ultrasound images showing the anterior tubercle (at) and the posterior tubercle (pt) of the C5 transverse process as the "two-humped camel" sign. $\mathrm{N}$, nerve root; CA, carotid artery. Solid arrows are pointing to the needle in place at the posterior aspect of the intervertebral foramen. 

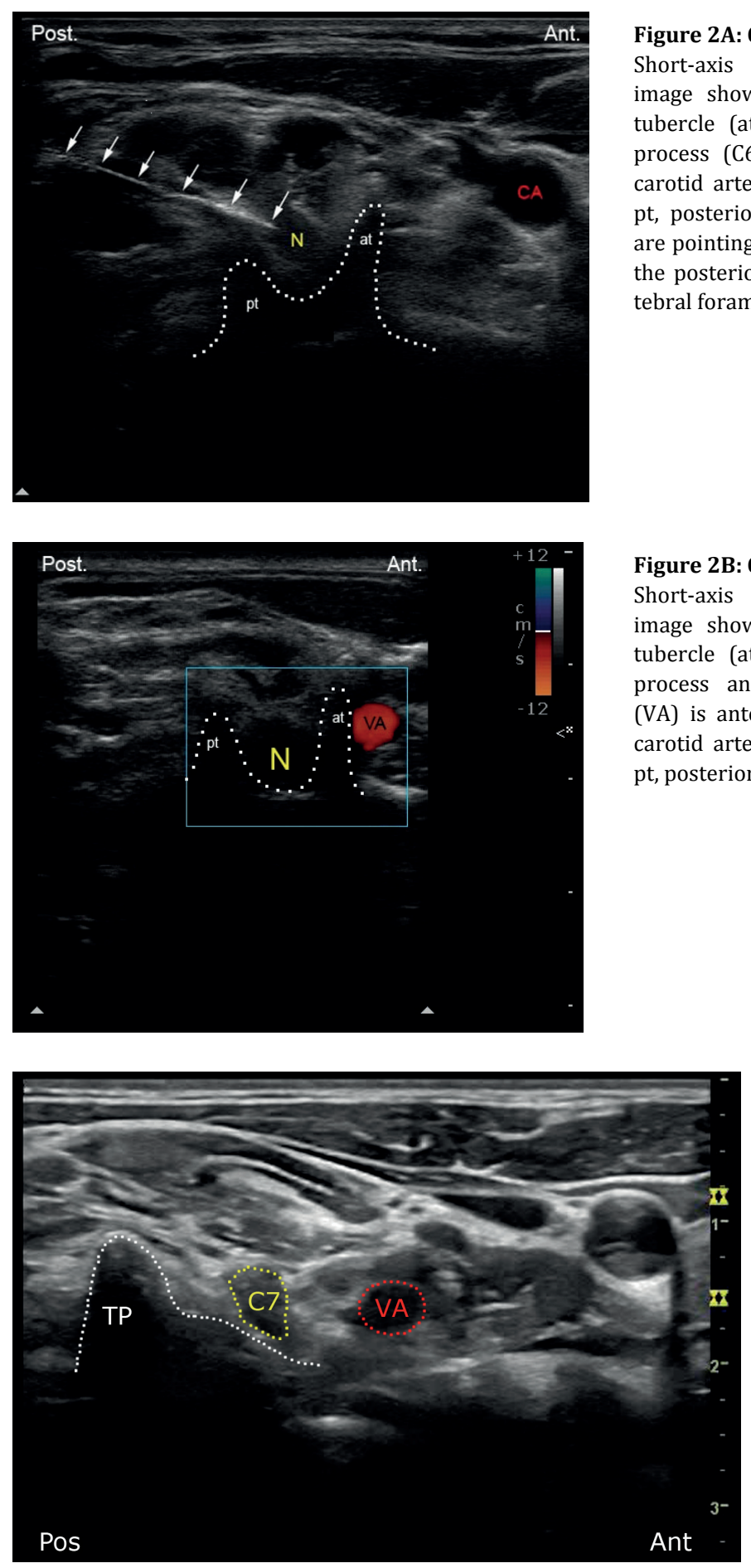

\section{Figure 2A: C6 level}

Short-axis transverse ultrasound image showing the sharp anterior tubercle (at) of the C6 transverse process (C6tp). N, nerve root; CA, carotid artery; at, anterior tubercle; pt, posterior tubercle. Solid arrows are pointing to the needle in place at the posterior aspect of the intervertebral foramen.

\section{Figure 2B: C6 level}

Short-axis transverse ultrasound image showing the sharp anterior tubercle (at) of the C6 transverse process and the vertebral artery (VA) is anterior. $\mathrm{N}$, nerve root; CA, carotid artery; at, anterior tubercle; pt, posterior tubercle.

\section{Figure 3: C7 level}

Short-axis transverse ultrasound image showing the characteristic transverse process (TP) of C7. Note no sharp anterior tubercle as the case in C6. C7, nerve root; VA, vertebral artery. 
Once the appropriate spinal level is identified, a 22-gauge blunt-tip needle can be introduced under real-time ultrasound guidance from posterior to anterior with an in-plane technique to target the corresponding cervical nerve root (from C3-C8) at the external foraminal opening between the anterior and posterior tubercles of the transverse process. One can successfully monitor the spread of the injectate around the cervical nerve with real time ultrasonography and the absence of such spread around the nerve root may suggest unsuspected or unintentional intravascular injection. However it is difficult to monitor the spread of the injectate through the foramen into the epidural space because of the bony drop out artifact of the transverse process. We therefore refer to this approach as a "cervical selective nerve root block" rather than cervical transforaminal epidural injection.

The authors believe that visualization of very small vessels (radicular arteries) may be very challenging especially in obese patients and requires special training and expertise. Real time fluoroscopy with contrast injection and digital subtraction -when available- should remain the standard of care.

\section{Cervical medial branch and facet joint injections}

\section{Anatomy}

Cervical zygapophyseal (facet) joints are diarthrodial joints formed by the superior articular process of one cervical vertebra articulating with the inferior articular process of the vertebra above at the level of the junction of the lamina and the pedicle. The angulation of the facet joint increases caudally, being about 45 degrees superior to the transverse plane at the upper cervical level to assume a more vertical position at the upper thoracic level. The superior articular process also faces more posteromedial at the upper cervical level and this changes to more posterolateral at the lower cervical level, with C6 being the most common transition level 17,18

The cervical zygapophyseal joints are innervated by articular branches derived from the medial branches of the cervical dorsal rami. The C4-C8 dorsal rami arise from their respective spinal nerves and pass dorsally over the root of their corresponding transverse process. The medial branches of the cervical dorsal rami curve medially, around the corresponding articular pillars, and have a constant relationship to the bone at the dorsolateral aspect of the articular pillar as they are bound to the periosteum by an investing fascia and held in place by the tendon of the semispinalis capitis muscle. ${ }^{19}$

This area is easily identified fluoroscopically where the medial branches are safely located away from the spinal nerve and the vertebral artery. The articular branches arise as the nerve approaches the posterior aspect of the articular pillar, one innervating the zygapophyseal joint above, and the other innervating 
the joint below. Consequently, each typical cervical zygapophyseal joint has dual innervation, from the medial branch above and below its location..$^{20}$

The medial branches of the C3 dorsal ramus differ in their anatomy. A deep medial branch passes around the waist of the $\mathrm{C} 3$ articular pillar similar to other typical medial branches and supplies the C3-C4 zygapophyseal joint. The superficial medial branch of $\mathrm{C} 3$ is large and known as the third occipital nerve. It curves around the lateral and then the posterior aspect of the C2-C3 zygapophyseal joint giving articular branches to the joint. Articular branches may also arise from a communicating loop that crosses the back of the joint between the third occipital nerve and the $\mathrm{C} 2$ dorsal ramus. Beyond the $\mathrm{C} 2-\mathrm{C} 3$ zygapophyseal joint, the third occipital nerve becomes cutaneous over the suboccipital region. So pain derived from the $\mathrm{C} 2-\mathrm{C} 3$ zygapophyseal joint can be addressed by blocking the ipsilateral third occipital nerve as it crosses the lateral aspect of the joint, and pain derived from joints below $\mathrm{C} 2-\mathrm{C} 3$ can be addressed by blocking the cervical medial branches as they pass around the waists of the articular pillars above and below the corresponding joint ${ }^{21}$

\section{Literature review of ultrasound guided third occipital nerve (TON) and cervical medial branch block}

Eichenberger et al. ${ }^{22}$ reported the use of ultrasound guidance in blockade of the third occipital nerve in volunteers. The needles were placed under ultrasound guidance and then confirmed by fluoroscopy. The third occipital nerve was visualized in all volunteers and showed a median diameter of $2.0 \mathrm{~mm}$. The C2C3 facet joint was identified correctly by ultrasound in 27 of 28 cases and 23 needles were placed correctly into the target zone. They defined the radiologic target point arbitrarily as the intersection of a vertical line passing through the middle of the $\mathrm{C} 2-\mathrm{C} 3$ zygapophyseal joint and an oblique line passing directly over the joint line. They reported accuracy of needle position as confirmed by fluoroscopy in $82 \%$ of insertions and a $90 \%$ success of nerve blockade.

Although they reported the feasibility of identifying the medial branch of $\mathrm{C} 3$, there are no other feasibility studies regarding ultrasound guided lower cervical medial branch block. Nevertheless the technique has been described. ${ }^{23,24}$

\section{Literature review of ultrasound guided cervical facet intraarticular injections}

Galiano et al. ${ }^{25}$ studied the feasibility of ultrasound as a guiding tool for simulated cervical facet joint intraarticular injections in cadavers using a lateral approach. They were able to accurately identify the facet joints from C2-3 to C6-7 in 36 of 40 attempts. All needle tips were located inside the joint space as verified by CT. Subsequently they have studied and advocated the use of an ultrasound-guided CT-assisted navigation system as a teaching tool for performing facet injections. ${ }^{20}$ 


\section{Sonoanatomy and ultrasound guided technique for cervical facet intraarticular injection}

\section{Lateral approach}

The patient is placed in the lateral position and the correct cervical level is identified as mentioned above. A high frequency linear transducer is used and a short axis view is obtained and the superior articular and the inferior articular processes forming the facet joint appear as a hyperechoic signals and the joint space in between as anechoic gap. The needle is inserted just lateral to the transducer and advanced from posterior to anterior -in plane- under real time ultrasonography to the target (joint space). The target was defined as the midpoint of the joint space on the lateral surface at the middle of the facet joint cranio-caudal extension. 25

\section{Posterior approach}

The authors prefer the posterior approach for several reasons. It is easier to identify the correct cervical level while the patient in the prone position. We start counting from cranial to caudal (C1 spine has no or only a rudimentary spinous process and the first identified bifid spinous process belongs to C2). Another advantage of this approach is that the needle will be advanced in a caudal to cranial direction and this is matching the caudal angulation of the cervical facet joint, making it easier for the needle to get into the joint space atraumatically. Also, bilateral injections can be performed without the need for position change. ${ }^{26}$

A linear or a curved transducer may be used depending on the size of the patient. A longitudinal scan is obtained initially at the midline (spinous process) and then by scanning laterally one can easily see the lamina and further laterally the facet column will appear in the image as the characteristic "saw sign" (Fig. 4). If in doubt, one can scan even more laterally until the facet joints are no longer in the image and then come back medially towards the facet joints. The inferior articular processes of the level above and the superior articular process of the level below appear as a hyperechoic signals and the joint space appears as anechoic gap in between. The needle is then inserted inferior to the caudal end of the transducer and advanced from caudad to cephalad -in plane- to enter the inferior part of the joint under real time ultrasonography (Fig. 4). 


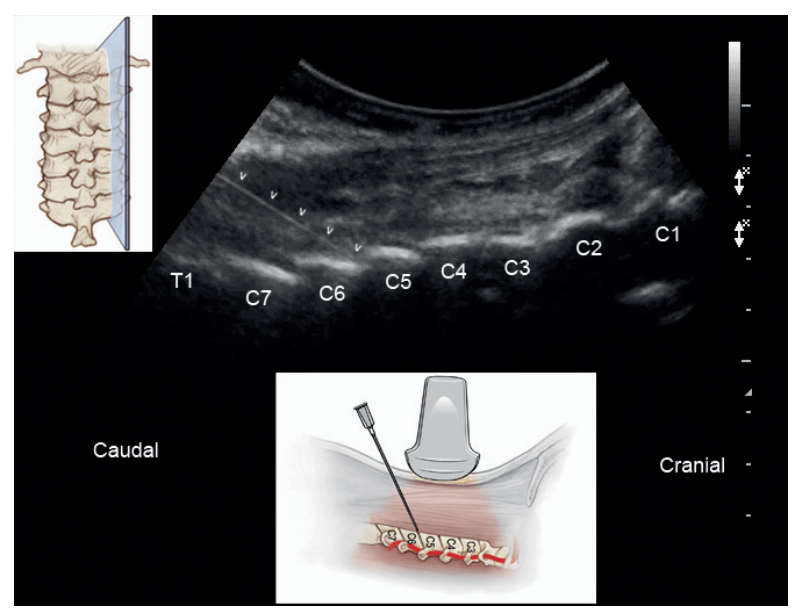

Figure 4:

Sagittal (longitudinal) ultrasonographic view showing the hypoechoic articular processes of the facet joints as the "saw sign" and the anechoic facet joint space in between. Needle is introduced caudal to the transducer and advanced inplane into the caudal part of the C5-C6 facet joint (arrow heads). Inset: Illustration showing the paramedian position of the ultrasound transducer to obtain a longitudinal scan through the facet column.

\section{Sonoanatomy and ultrasound guided technique for third occipital nerve (TON) and cervical medial branch block}

\section{Third occipital nerve}

Eichenberger et al. ${ }^{21}$ described the technique in detail. The patient is placed in the lateral position and a high frequency linear transducer is applied, just caudal to the mastoid process exactly perpendicular to the lateral aspect of the neck in a transverse plane, to obtain a short axis view.

Moving the transducer slowly caudally, the lateral mass of the axis and the transverse process of $\mathrm{C} 1$, are easily visible. Moving the transducer only 1-3 $\mathrm{mm}$ more caudally, the vertebral artery appears and by following this artery caudally, the vertebral artery disappears in the transverse foramen of $\mathrm{C} 2$, and the C2-C3 joint appears posteriorly. It presents as a convex density covered by the laminated densities of the overlying neck muscles. The apex of the convexity of the joint was identified and constituted the target point for the needle insertion.

The needle is introduced from immediately below the ultrasound probe and advanced perpendicular to the beam (out-of-plane) under ultrasound guidance toward the apex of the convexity of the joint, until bony resistance was encountered. The transducer is then rotated to the longitudinal plane because the nerve is best visualized in this view (Fig. 5). The third occipital nerve is identified with the typical sonomorphologic appearance of a small peripheral nerve just lateral to the C2-3 joint, and the needle was adjusted as needed to lie closer to the nerve. 


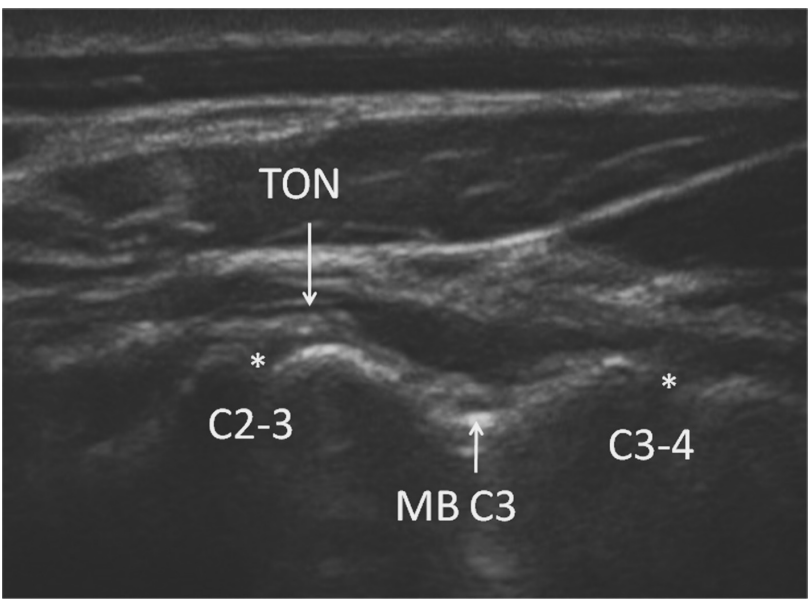

Figure 5:

Sagittal (longitudinal) view at $\mathrm{C} 2 / 3$ level showing the third occipital nerve (TON) crossing $\mathrm{C} 2-3$ joint and the C3 medial branch (MB C3) as a hypoechoic oval structure at the deepest point (waist) of the articular pillar. * Joint space.

\section{Cervical medial branch block}

The patient is placed in the lateral position and a high frequency linear transducer is applied longitudinally with its upper end just below the mastoid process to obtain a longitudinal view of the cervical spine. Once the C2-3 joint is identified as above, the transducer is slowly moved in a caudal direction to view the lower facet joints until the desired level of the cervical facet joint is reached. The highest points in the bony reflex of the articular pillars represent the facet articulations and the medial branches can be visualized at the deepest point over the articular pillars between the two articulations in contrast to the TON which runs over the highest point of the articulation (Fig. 6) . 23

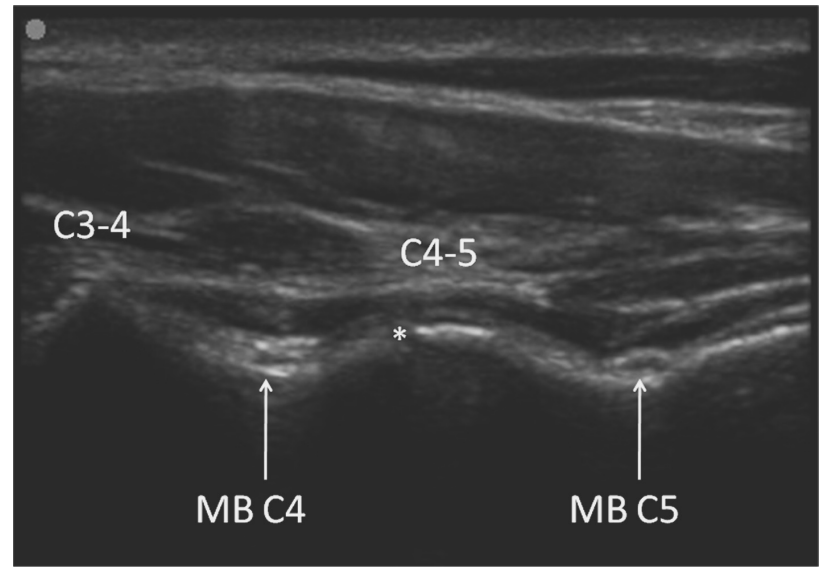

\section{Figure 6:}

Sagittal (longitudinal) view at $\mathrm{C} 2 / 3$ level showing the $\mathrm{C} 4$ and $\mathrm{C} 5$ medial branch (MB C4 and MB C5) as a hypoechoic oval structure at the deepest point (waist) of the articular pillar. * Joint space.

The needle can be introduced just caudal to the ultrasound transducer and advanced under real time ultrasonography to the target nerve (in-plane). Alternatively, once the correct level is identified the transducer is rotated to obtain a short axis view and the needle is advanced perpendicular to the beam (out-of- 
plane) under ultrasound guidance toward the articular pillar until bony resistance was encountered. Then the transducer can be rotated to the longitudinal plane, as the nerve is better visualized in this view, and the needle is adjusted as needed to lie closer to the nerve in the same manner described above for TON block. ${ }^{21}$

The authors believe that visualizing such small nerves (cervical medial branches and third occipital nerve) is usually very challenging specially in obese patients and requires special training and experience. Fluoroscopy may be superior in this application especially in radiofrequency ablation of the medial nerves as this requires precise needle placement along the targeted nerve.

\section{Conclusion}

Ultrasound is a welcomed addition to other imaging techniques in interventional pain management. It is a valuable tool for imaging soft tissue structures and bony surfaces, guiding needle advancement and confirming the spread of injectate around the target, all without exposing healthcare providers and patients to the risks of radiation. There is a rapidly growing interest in USPM as evidenced by the surging number of publications in the last few years. The published reports suggest a useful role for ultrasound in soft tissue injections, joint injections, and cervical spine injections; and only limited role in lumbar spine injections. More studies on the efficacy and safety of ultrasound-guided techniques are required. 


\section{References}

1. Peng PWH, Narouze S. Ultrasound-guided interventional procedures in pain medicine: A review of anatomy, sonoanaotmy and procedures. Part I: non-axial structures. Reg Anesth pain Med 2009; 34:458-474.

2. Rathmell JP, Aprill C, Bogduk N. Cervical transforaminal injection of steroids. Anesthesiology 2004; 100:1595-1600.

3. Huntoon MA: Anatomy of the cervical intervertebral foramina: vulnerable arteries and ischemic neurologic injuries after transforaminal epidural injections. Pain 2005; 117:104-111.

4. Hoeft MA, Rathmell JP, Monsey RD, Fonda BJ. Cervical transforaminal injection and the radicular artery: Variation in anatomical location within the cervical intervertebral foramina. Reg Anesth Pain Med 2006; 31:270-274.

5. Wallace MA, Fukui MB, Williams RL, Ku A, Baghai P. Complications of cervical selective nerve root blocks performed with fluoroscopic guidance. AJR 2007; 188:1218-1221.

6. Rozin L, Rozin R, Koehler SA, Shakir A, Ladham S, Barmada M, Dominick J, Wecht CH. Death during transforaminal epidural steroid nerve root block (C7) due to perforation of the left vertebral artery. Am J Forensic Med Pathol 2003; 24:351-355.

7. Tiso RL, Cutler T, Catania JA, Whalen K. Adverse central nervous system sequelae after selective transforaminal block: the role of corticosteroids. Spine J 2004; 4:468-474.

8. Baker R, Dreyfuss P, Mercer S, Bogduk N. Cervical transforaminal injections of corticosteroids into a radicular artery: a possible mechanism for spinal cord injury. Pain 2003; 103:211-215.

9. Muro K, O'Shaughnessy B, Ganju A. Infarction of the cervical spinal cord following multilevel transforaminal epidural steroid injection: case report and review of the literature. J Spinal Cord Med 2007; 30:385-388.

10. Brouwers PJ, Kottink EJ, Simon MA, Prevo RL. A cervical anterior spinal artery syndrome after diagnostic blockade of the right C6-nerve root. Pain 2001; 91:397-399.

11. Beckman WA, Mendez RJ, Paine GF, Mazzilli MA. Cerebellar herniation after cervical transforaminal epidural injection. Reg Anesth Pain Med 2006; 31:282-285.

12. Galiano K, Obwegeser AA, Bodner G, Freund MG, Gruber H, Maurer H, Schatzer R, Ploner F. Ultrasound-guided periradicular injections in the middle to lower cervical spine: An imaging study of a new approach. Reg Anesth Pain Med 2005; 30:391-396.

13. Narouze SN. Ultrasound-guided cervical periradicular injection: cautious optimism [letter]. Reg Anesth Pain Med 2006; 31:87.

14. Narouze S, Vydyanathan A, Kapural L, Sessler D, Mekhail N. Ultrasound-guided Cervical Selective Nerve Root Block: A Fluoroscopy-Controlled Feasibility Study. Reg Anesth Pain Med 2009; 34:343-348.

15. Martinoli C, Bianchi S, Santacroce E, Pugliese F, Graif M, Derchi LE. Brachial plexus sonography: a technique for assessing the root level. AJR Am J Roentgenol 2002; 179:699-702.

16. Matula C, Trattnig S, Tschabitscher M, Day JD, Koos WT. The course of the prevertebral segment of the vertebral artery: Anatomy and clinical significance. Surg Neurol 1997; 48:125-131.

17. Pal GP, Routal RV, Saggu SK. The orientation of the articular facets of the zygapophyseal joints at the cervical and upper thoracic region. J Anat 2001; 198: 431-441.

18. Yoganandan N, Knowles SA, Maiman DJ, Pintar FA. Anatomic study of the morphology of human cervical facet joint. Spine 2003; 28:2317-2323

19. Bogduk N: The clinical anatomy of the cervical dorsal rami. Spine 1982; 7: 19-330.

20. Galiano K, Obwegeser AA, Bodner G, Freund MC, Gruber H, Maurer H, Schatzer R, Fiegele T, Ploner F. Ultrasound-guided facet joint injections in the middle to lower cervical spine: a CTcontrolled sonoanatomic study. Clin J Pain 2006; 22:538-543.

21. Lord SM, Barnsley L, Bogduk N. Percutaneous radiofrequency neurotomy in the treatment of cervical zygapophyseal joint pain: a caution. Neurosurg 1995; 36: 732-739. 
22. Eichenberger U, Greher M, Kapral S, Marhofer P, Wiest R, Remonda L, Bogduk N, Curatolo M. Sonographic visualization and ultrasound-guided block of the third occipital nerve: prospective for a new method to diagnose C2-C3 zygapophyseal joint pain. Anesthesiology 2006; 104:303308.

23. Gofeld M. Ultrasonography in pain medicine: a critical review. Pain Pract 2008; 8:226-240.

24. Siegenthaler A, Narouze S, Eichenberger U. Ultrasound-guided third occipital nerve and cervical medial branch nerve blocks. Tech Reg Anesth Pain Manag 2009; 13:128-132.

25. Galiano K, Obwegeser AA, Bale R, Harlander C, Schatzer R, Schocke M, Gruber H. Ultrasoundguided and CT-navigation-assisted periradicular and facet joint injections in the lumbar and cervical spine: a new teaching tool to recognize the sonoanatomic pattern. Reg Anesth Pain Med 2007; 32:254-257.

26. Narouze S. Ultrasound guided cervical facet intraarticular injections. Tech Reg Anesth Pain Manag 2009; 13:133-136. 



\section{Chapter 3 \\ Sonoanatomy of the Cervical Sympathetic Chain}

Philip WH Peng, MBBS FRCPC

Samer Narouze, MD, MSc

Peng PWH, Narouze S. Ultrasound-Guided Interventional Procedures in Pain Medicine: A Review of Anatomy, Sonoanatomy, and Procedures. Part I: Non-axial Structures. Reg Anesth Pain Med 2009; 34:458-474. 


\begin{abstract}
Application of ultrasound in pain medicine is a rapidly growing medical field in interventional pain management. Ultrasound provides direct visualization of various soft tissues and real-time needle advancement and avoids exposing both the health care provider and the patient to the risks of radiation. The machine itself is more affordable than a fluoroscope, computed tomography scan, or magnetic resonance imaging machine. In the present review, we discuss the challenges and limitations of ultrasound-guided procedures for pain management, anatomy, and sonoanatomy of selected pain management procedures and the literature on those selected procedures.
\end{abstract}




\section{Introduction}

Application of ultrasound in pain medicine (USPM) is a rapidly growing component of interventional pain management. Traditionally, interventional procedures for pain management are performed either according to the description of surface landmarks or with imaging guidance such as fluoroscopy or computed tomography (CT) scan. In the last 5 years, there has been a tremendous growth in interest in USPM, as evidenced by the remarkable increase in the literature on ultrasound-guided injections. A search of the MEDLINE database revealed only 3 publications of ultrasound-guided or ultrasound-assisted injection techniques (excluding perioperative and various intraarticular, interlaminar, and triggerpoint injections) between 1982 and 2002,1-3 but there have been 42 publications since 2003. The first objective of this review was to describe and summarize the anatomy and sonoanatomy that are relevant to those specific interventional techniques e.g. stellate ganglion block. The second objective was to describe the limited reports and feasibility data published in the literature.

\section{Methods}

We performed a literature search of the MEDLINE database from January 1982 to December 2008 using the search terms ultrasound, ultrasound-guided, pain management, and different selected nerves or structures relevant in this review such as intercostal nerve, lateral femoral cutaneous nerve, pudendal nerve, piriformis muscle, and stellate ganglion. We excluded those publications that described the use of the nerve blocks in the perioperative setting and those of intra-articular, interlaminar, and trigger-point injections.

\section{Ultrasound versus Conventional Imaging Techniques}

One of the major problems with procedures relying on landmarks is the presence of anatomic variation, which can lead to a high failure rate. ${ }^{4-5}$ Ultrasound provides direct visualization and imaging of various soft tissues: muscles, ligaments, vessels, nerves, joints, and bony surfaces. With the use of a highresolution probe, thin nerves $(<2 \mathrm{~mm})$ can be visualized. Unlike fluoroscopy and CT scan, ultrasound does not expose the health care provider or the patient to the risks of radiation. ${ }^{6}$

Fluoroscopy provides clear images of bone but not soft-tissue structures, limiting its use in those procedures involving peripheral structures or nerves. An ultrasound machine is generally more affordable than a fluoroscopy, CT scan, or magnetic resonance imaging machine. Unlike other imaging modalities, ultrasound equipment is portable and has limited supportive resource needs. More- 
over, ultrasound imaging allows real-time needle advancement and appreciation of the spread of injectate, which improves the accuracy of the technique and minimizes the risk of intravascular injection. An added benefit of ultrasound is that it aids in the potential diagnosis of associated conditions that may be related to the patient's pain syndrome. These would include shoulder disorders, ${ }^{7}$ various nerve entrapment syndromes, ${ }^{8}$ joint pathology, ${ }^{9}$ and pneumothorax (following intercostal nerve block). ${ }^{10}$

\section{Limitations and Challenges of Ultrasound}

Despite various advantages, ultrasound imaging also has several limitations. The technique and the image are quite operator dependent. The practitioner requires experience to obtain a good image and direct the needle safely to the target structure. Furthermore, the quality of the image in certain areas is poor. This is particularly true in the visualization of axial or spine structures where an acoustic shadow artifact is produced by bone, which has a high attenuation coefficient. Visualization of deep structures is also suboptimal because a lowfrequency probe is commonly used in these situations, and the resolution is inferior to that provided by a high-frequency probe.

Another limitation is the visualization of a thin needle or a needle inserted at a steep angle. ${ }^{11}$ With the development of echogenic needles, this limitation may be overcome.12

Compared with ultrasound application in regional anesthesia, USPM is confronted with unique challenges. The targets are not limited to nerve structures (plexus or peripheral nerves) in the upper or lower limbs. Muscles, joints, ligaments, tendons, and bony structures (eg, the spine) are other anatomic structures that are targeted in USPM. For interventional techniques guided toward axial structures, the areas of interest are not limited to the interlaminar space for spinal or epidural injection. Structures of interest include the facet joints, facet (medial branch) nerves, spinal nerve roots, sacroiliac joint (SIJ), and caudal canal. Ultrasound in pain medicine demands extensive knowledge of the anatomy of different systems of the body, not to mention an extensive understanding of echogenicity and echotextures of various tissues and organs.

Similar to ultrasound-guided regional anesthesia, USPM is going through 2 phases. The first phase is a rapid increase in the reports of new USPM techniques and feasibility data in the literature. The second phase is an increase in publications of studies on efficacy and safety. Currently, USPM is in its infancy, and more studies on efficacy and safety are needed. In general, the USPM techniques can be categorized as those belonging to nonaxial and axial structures. The former injection techniques mainly involve imaging of soft tissues, and in this respect, it is easy to see the advantage that ultrasound confers over the conventional techniques. The latter are used in patients with pain from the 
spine structures and are commonly performed by interventional practitioners under fluoroscopic guidance. At the present stage, the imaging capability provided by ultrasound is limited because of the acoustic shadow cast by bone and the limited window allowed visualizing the target structures for injections. In addition, fluoroscopy is the established technique, having been subjected to rigorous investigation.

The present article focuses on the sonoanatomy relevant to cervical sympathetic chain and review the evidence for ultrasound guided stellate ganglion block.

\section{Stellate Ganglion (Cervical Sympathetic) Block}

Stellate ganglion block (SGB) is performed for the management of patients for a variety of pain conditions. ${ }^{13,14}$ The most widely practiced approach to SGB is the paratracheal approach, in which the needle is inserted toward the anterior tubercle of cervical sixth vertebra (Chassaignac tubercle). ${ }^{15}$ However, this landmark is actually in proximity to the middle cervical ganglion instead of the stellate ganglion, which is located opposite to the neck of first rib (Fig. 1). ${ }^{16}$

\section{Anatomy}

The sympathetic fibers for the head, neck, and upper limbs arise from the first few thoracic segments, ascend through the sympathetic chains, and synapse in the superior, middle, and inferior cervical ganglia. The stellate ganglion, formed by fusion of the inferior cervical and first thoracic ganglion, is located adjacent to the neck of the first rib, lateral to the longus colli muscle, and posterior to the vertebral artery (Fig. 1). The postganglionic fibers are sent from the stellate ganglion to the cervical nerves (seventh and eighth) and first thoracic nerve to provide sympathetic innervation to the upper limbs..$^{16-19}$

The preganglionic fibers of the head and neck region continue to travel cephalad to the superior and middle cervical ganglion through the cervical sympathetic trunk, which is located anterior to the prevertebral fascia. ${ }^{20,21}$ 


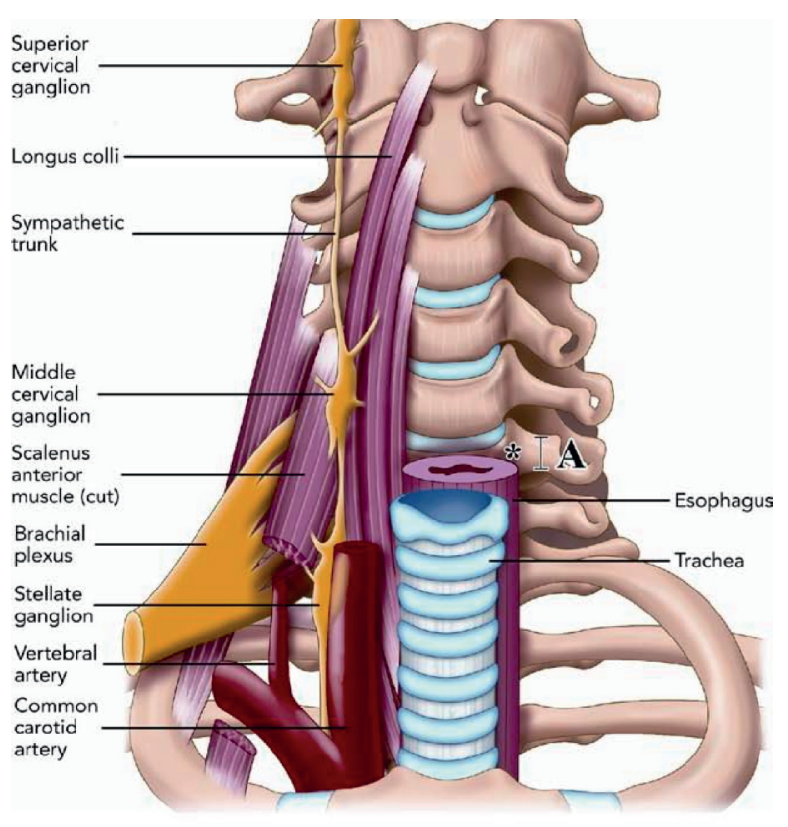

\section{Figure 1:}

Prevertebral region of the neck. The target site for needle insertion in classic approach is marked as asterisk. The breadth of the transverse process is marked as A.

\section{Limitations of the Existing Techniques}

The dominant approach is an anterior paratracheal approach at the sixth cervical vertebral level with or without fluoroscopic guidance. A recent study showed the large anatomic variability between individuals in the size and location of Chassaignac tubercle. ${ }^{15}$ Most concerning is the breadth of the transverse process in the cephalad-caudad dimension. The average minimum breadth is only $6 \mathrm{~mm}$ (Fig. 1). The implication is that a small deviation of the needle from the anterior tubercle will significantly increase the risk of the needle entry into the vertebral artery. ${ }^{15}$ Furthermore; with the blind technique the needle may be directed to the posterior tubercle, resulting in local anesthetic spreading around the spinal nerve root.

With fluoroscopy, the needle can be accurately directed to the bony landmark, especially using the oblique approach. ${ }^{22}$ However, the anterior tubercle is only a surrogate marker because the location of the cervical sympathetic trunk is defined by the fascial plane of the prevertebral fascia, which cannot be visualized with fluoroscopy. Vascular structures (inferior thyroidal, vertebral, and carotid arteries) and soft tissues (thyroid and esophagus) are also not seen with fluoroscopy and are therefore at risk for puncture with the fluoroscopy-guided technique..$^{23}$ 


\section{Sonoanatomy}

The key structures in the ultrasound-guided injection are vessels within the carotid sheath, prevertebral fascia, longus colli muscle, anterior tubercle of the sixth cervical vertebra, and the thyroid (Fig. 2A, 2B). When performing the classic approach, the needle is inserted in the vicinity of the cervical sympathetic trunk, which occupies a space anterior and lateral to the cervical vertebral bodies and which is covered by the posterior fascia of the carotid sheath anteriorly and by the prevertebral and alar fascia posteriorly. ${ }^{24}$ Contrary to the fluoroscopy-guided method, the end point of the needle is not the contact with bone but the prevertebral fascia.23,25 This fascia lies over the vertebral bodies, their anterior transverse processes, the longus colli, capitis, and anterior scalene muscles. Ultrasound allows direct visualization of vessels and soft tissues (thyroid, esophagus, and muscle) and potentially minimizes the damage of these structures (Figs. 2A, 2B).23

Although the vertebral artery enters the foramen of the C6 transverse process in about $90 \%$ of cases, it implies that vertebral artery is "exposed" at the level of $\mathrm{C} 6$ in the remaining $10 \%$ of the population. ${ }^{26}$ This variation in anatomy can be detected by ultrasound. Injection under real-time guidance allows the visualization of spread of local anesthetic anterior or posterior to the prevertebral fascia. The absence of the spread of local anesthetic during the real-time injection raises the suspicion of intravascular injection. 

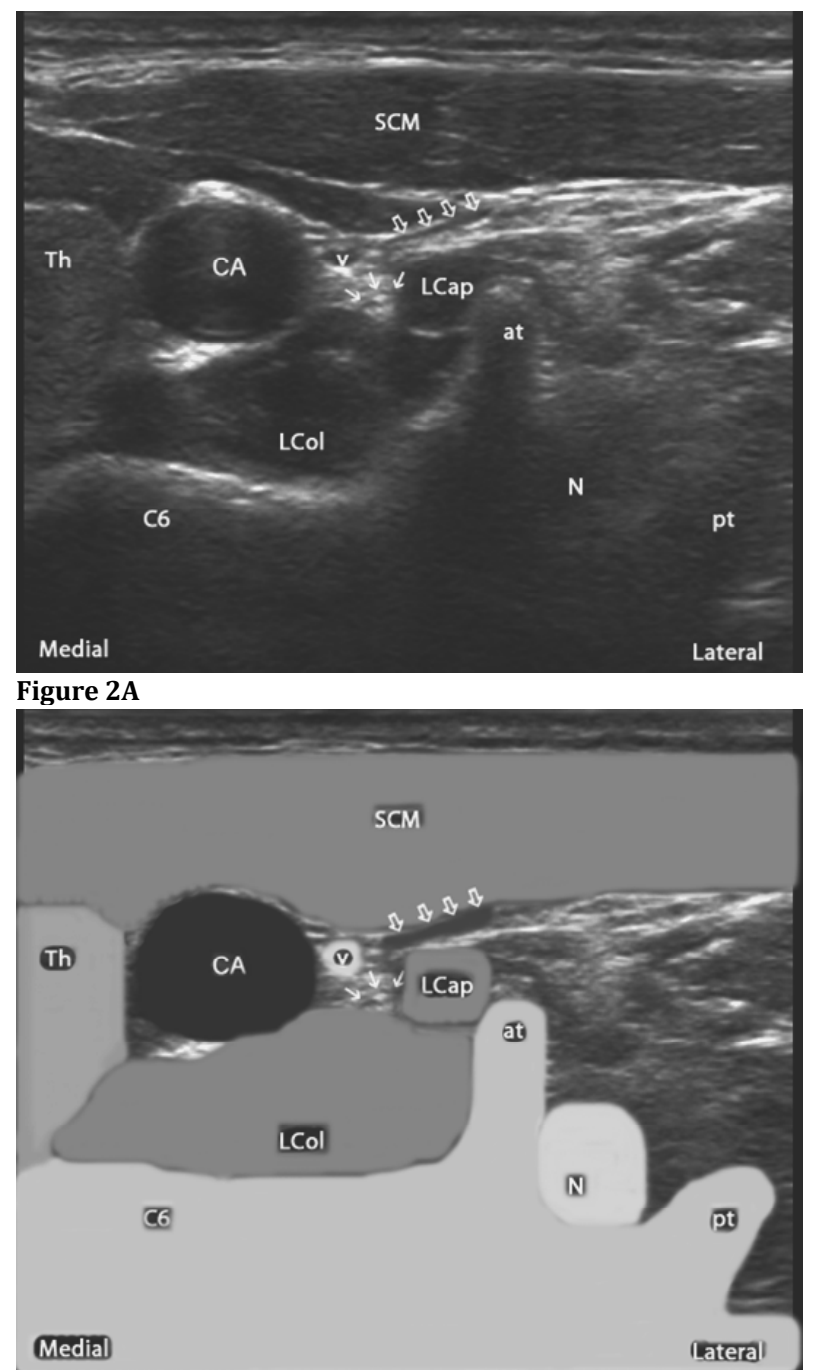

Figure 2B
Figure 2A and 2B:

Short axis sonogram at $\mathrm{C} 6$.

The transducer is moved slowly laterally and cephalad till the characteristic sharp anterior tubercle of $\mathrm{C} 6$ comes into the image (at). SCM; sternocleidomastoid muscle, Th; thyroid, V; vagus nerve posteriorly in the carotid sheet in-between the carotid artery (CA) and the compressed internal jugular vein (hollow arrows). The sympathetic chain namely the middle cervical ganglion (as indicated by the 3 small arrows) is located at the groove between the longus coli muscle (LCol) and the longus capitis muscle (LCap).

\section{Technique for Ultrasound-Guided Injection}

Ultrasound-guided approach to SGB was first reported by Kapral et al ${ }^{2}$ in 1995. In their case series, 12 patients received the classic blind SGB followed by ultrasound-guided block the next day. Three patients who had received the blind technique developed a hematoma, which did not occur with the ultrasound guided technique. The spread of the local anesthetic was observed under realtime scanning. The proximity of the local anesthetic to the recurrent laryngeal nerve and nerve root correlated well with complications such as hoarseness and 
paresthesia. In this study, $5 \mathrm{~mL}$ of local anesthetic was administered, and all patients in the ultrasound-guided group developed sympathetic block compared with 10 of 12 in the blind group. The authors did not mention specifically whether the needle was directed suprafascial or subfascial. In another study, the investigators deliberately placed the needle in the subfascial plane (26 patients) except in 7 patients because the needles were too short 25 . The change in the temperature of the ipsilateral upper arm was significant compared with that of the contralateral arm with the subfascial injection, whereas the difference in temperature changes between arms was minimal in the suprafascial group. Hoarseness was absent in the subfascial group but occurred in 4 of the 7 patients in the suprafascial group.

There are minor variations in the scanning techniques described in the literature. In general, we prefer to perform the block, with the patient in supine position (Fig. 3). A linear probe of high frequency (6-13 MHz) is placed at the level of the cricoid cartilage to obtain a transverse scan. The scan should reveal the important landmarks: the transverse process and anterior tubercle of the sixth cervical vertebra, longus colli muscle and the prevertebral fascia, carotid artery, and thyroid (Fig. 4A). A color Doppler scan will reveal if any vessel is close to the path of needle insertion (Fig. 4B). The needle insertion path should be planned to avoid puncturing important structures such as the esophagus. ${ }^{23}$ The needle is targeted to the plane between the longus colli muscle in the subfascial plane and the prevertebral fascia. In the situation when the potential needle path could cause injury to those structures, the needle can be inserted on the lateral side of the ultrasound probe (Fig. 4B). ${ }^{27}$

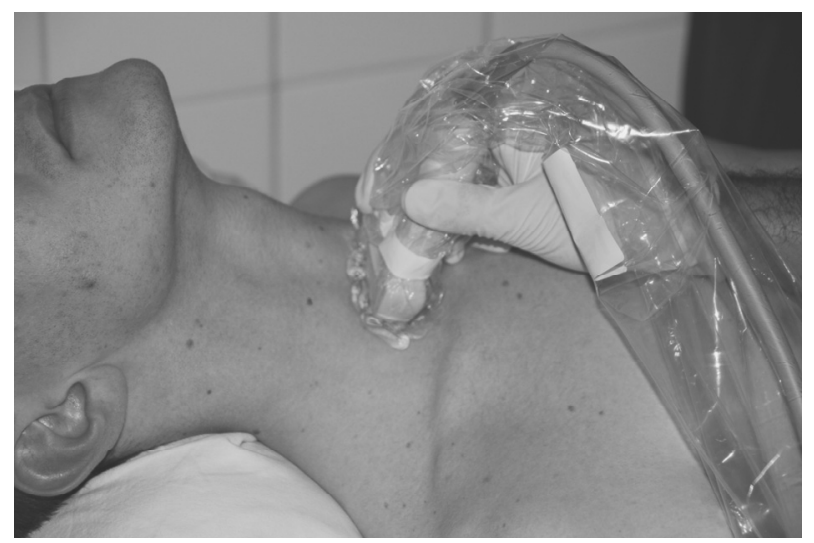

Figure 3:

Patient's position and placement of the transducer to obtain a short axis sonogram at the root of the neck. 

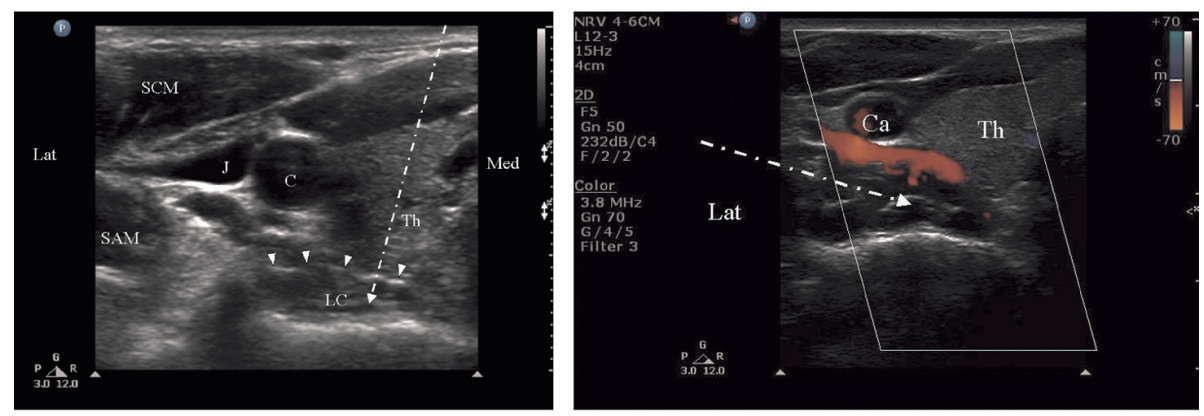

Figure 4:

Short axis sonogram at C6 (left) and with color Doppler (right). The medial (left) and lateral (right) needle paths are marked by the dotted long arrow. (C, carotid artery; J, internal jugular vein; SCM, sternocleidomastoid muscle; SAM, scalenus anterior muscle; Th, thyroid; LC, longus colli muscle; prevertebral fascia is marked by solid arrowheads).

\section{Discussion}

Ultrasound-guided SGB can improve the safety of the procedure by direct visualization of the related anatomical structures and, accordingly, the risk of vascular and soft tissue injury may be minimized.

With the fluoroscopy-guided approach, the needle is advanced until bone is reached and then withdrawn a few millimeters. Injection can occur, however, within the substance of the longus colli muscle resulting in a "myogram" and a possible block failure. This can easily be prevented using an US-guided approach as the tip of the needle is placed deep to the prevertebral fascia and superficial to the longus colli muscle (where the sympathetic chain runs) and does not contact bone (as with the fluoroscopy-guided approach).23,25

On the other hand, if injection is made anterior to the prevertebral fascia, the solution tends to spread around the carotid sheath. ${ }^{24}$ In this case, the risk of hoarseness is greater probably due to the proximity of the vagus nerve within the carotid sheath and the recurrent laryngeal nerve that lies medial to the carotid sheath and lateral to the trachea. ${ }^{24,25}$ Once again; this possible complication can be easily avoided using the US-guided approach.

We identified three major areas that show the ultrasound technique is more advantageous than the traditional landmark or fluoroscopy technique; namely the vertebral artery, the inferior thyroid artery and the esophagus.

1. The vertebral artery runs anteriorly at the $\mathrm{C} 7$ level before it enters the foramen of the C6 transverse process in about $90 \%$ of cases. It enters at C5 or higher in the remaining cases. ${ }^{26}$ It is vulnerable to injury during lower cervical sympathetic block, not only at the $\mathrm{C} 7$ level but also at C6 as well - a possibility that can be avoided by ultrasound imaging(Fig. 5) ${ }^{23}$ 
2. The inferior thyroid vessels may be a major source of a retropharyngeal hematoma because of their vulnerable and variable anatomy. ${ }^{28}$ The inferior thyroid artery originates from the thyrocervical trunk of the subclavian artery and ascends anteriorly to the vertebral artery and the longus colli muscle and then curves medially behind the carotid sheath to enter the inferior part of the thyroid lobe. It is vulnerable to injury as it lies anterior to the vertebral artery at the $\mathrm{C} 7$ level or, more commonly, when it crosses (at the C6-7 level) behind the carotid artery from lateral to medial where it terminates in the thyroid gland. This segment of the vessel is most at risk for injury during passage of the needle when using a blind technique or even when using fluoroscopic guidance due to both its variable and unpredictable anatomy and its very tortuous course. Injury can be prevented by using an ultrasound-guided technique (Fig. 5). ${ }^{28}$

3. Ultrasound imaging can also identify the esophagus, especially on the left side (Fig. 5). ${ }^{16}$ The esophagus usually appears as a outpouching behind the trachea and can be better identified by the change in shape and shadowing during swallowing and the presence of a peripheral arc-shaped echogenic line or a boundary hypoechoic zone that is suggestive of the striated structure of the digestive tract (Fig. 6) .29

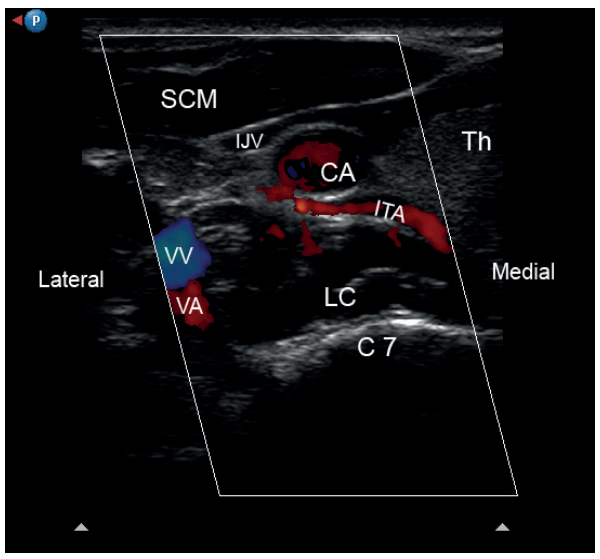

Figure 5:

Short axis sonogram at $\mathrm{C} 7$ as indicated by the "exposed" vertebral artery (VA) as it runs anterior to the transverse process of C7. The inferior thyroid artery (ITA) can be easily injured in the path of the needle. SCM, sternocleidomastoid muscle; Th, thyroid; symp Ch, sympathetic chain; LC, longus coli muscle; ITA, inferior thyroid artery; CA, carotid artery; IJV, internal jugular vein (compressed); VV, vertebral vein; $\mathrm{VA}$, vertebral artery. 


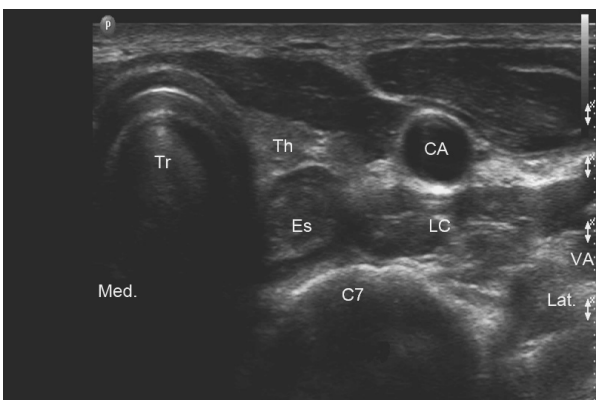

\section{Figure 6:}

Short axis sonogram at C7. Note the esophageal pouch (ES) lateral to the trachea. Tr, Trachea; Es, esophagus; Th, thyroid; CA, carotid artery; LC, longus coli muscle.

The most serious complications of stellate ganglion block include intravascular injections and retropharyngeal hematoma. The proximity of the stellate ganglion to the inferior thyroid, vertebral, or carotid arteries provides potential for either intravascular injection or vascular trauma with resulting bleeding and hematoma. ${ }^{28,30}$

Intravascular injection of even small volumes of local anesthetic may result in loss of consciousness, apnea, and seizure. ${ }^{31}$ Retropharyngeal hematoma varies in severity from mild and asymptomatic to severe and causing tracheal compression requiring emergency tracheotomy. ${ }^{32,33}$ The frequency of catastrophic retropharyngeal hematoma after stellate ganglion block has been reported to be 1 in 100,000 cases with resulting airway compromise and obstruction ${ }^{32}$. However, Kapral et al. reported a much higher incidence of asymptomatic hematoma with the blind technique. ${ }^{2}$

In summary; Ultrasound is very helpful in identifying arteries in the vicinity of the cervical sympathetic chain (i.e., thyroidal, vertebral and carotid) as well as detecting variations in vascular anatomy. Ultrasound-guided SGB can improve the safety of the procedure by direct visualization of the related anatomical structures and, accordingly, the risk of vascular and soft tissue injury may be minimized. 


\section{References}

1. Greiner L, Ulatowski L, Prohm P. Sonographically guided and intraoperative alcohol block of the celiac ganglia in conservatively uncontrollable cancer-induced epigastric pain. Ultraschall Med 1983; 4:57-59.

2. Kapral S, Krafft P, Gosch M, Fleischmann D, Weinstabl C. Ultrasound imaging for stellate ganglion block: direct visualization of puncture site and local anesthetic spread. Reg Anesth 1995; 20:323-328.

3. Vaghadia H, Jenkins LC. Use of a Doppler ultrasound stethoscope for intercostals nerve block. Can J Anesth 1988; 35:86-89.

4. Peng PWH, Tumber PS. Ultrasound-guided interventional procedures for patients with chronic pelvic painVa description of techniques and review of the literature. Pain Physician 2008; $11: 215-224$.

5. Eichenberger U, Greher M, Kirchmair L, Curatolo M, Morigg B. Ultrasound-guided blocks of the ilioinguinal and iliohypogastric nerve: accuracy of a selective new technique confirmed by anatomical dissection. Br J Anaesth 2006; 97:238-243.

6. Davros WJ. Fluoroscopy: basic science, optimal use, and patient/ operator protection. Tech Reg Anesth Pain Med 2007; 11:44-54.

7. Bouffard JA, Lee SM, Dhanju J. Ultrasonography of the shoulder. Semin Ultrasound CT MR 2000; 21:164-191.

8. Martinoli C, Bianchi S, Gandolfo N, Valle M, Simonetti S, Derchi LE. US of nerve entrapments in osteofibrous tunnels of the upper and lower limbs. Radiographics 2000; 20:S199-217.

9. Bianchi S, Martinoli C, Bianchi-Zamorani M, Valle M. Ultrasound of the joints. Eur Radiol 2002; 12:56-61.

10. Rowan KR, Kirkpatrick AW, Liu D, Forkheim KE, Mayo JR, Nicolaou S. Traumatic pneumothorax detection with thoracic US: correlation with chest radiography and CTVinitial experience. Radiology 2002; 225:210-214.

11. Maecken T, Zenz M, Grau T. Ultrasound characteristics of needles for regional anesthesia. Reg Anesth Pain Med 2007; 32:440-447.

12. Hopkins RE, Bradley M. In-vitro visualization of biopsy needles with ultrasound: a comparative study of standard and echogenic needles using an ultrasound phantom. Clin Radiol 2001; 56:499-502.

13. Stanton-Hicks MD, Burton AW, Bruehl SP, et al. An updated interdisciplinary clinical pathway for CRPS: report of an expert panel. Pain Pract 2002; 2:1-16.

14. Elias M. Cervical sympathetic and stellate ganglion blocks. Pain Physician 2000; 3:294-304.

15. Janik JE, Hoeft MA, Ajar AH, Alsofrom GF, Borrello MT, Rathmell JP. Variable osteology of the sixth cervical vertebra in relation to stellate ganglion block. Reg Anesth Pain Med 2008; 33:102108.

16. Williams PL. Gray's Anatomy. 38th ed. New York: Churchill Livingstone; 1995.

17. Fitzgerald MJT. Neuroanatomy: Basic and Clinical. 3rd ed. London: WB Saunders; 1996.

18. Tubbs RS, Loukas M, Remy AC, Shoja MM, Salter EG. The vertebral nerve revisited. Clin Anat 2007; 20:644-647.

19. Hogan QH, Erickson SJ. MR imaging of the stellate ganglion: normal appearance. Am J Roentgen 1992; 158:655-659.

20. Kiray A, Arman C, Naderi S, Güvencer M, Korman E. Surgical anatomy of the cervical sympathetic trunk. Clin Anat 2005; 18:179-185.

21. Civelek E, Kiris T, Hepgul K, Canbolat A, Ersoy G, Cansever T. Anterolateral approach to the cervical spine: major anatomical structures and landmarks. J Neurosurg Spine 2007; 7:669-678.

22. Abdi S. A new and easy technique to block the stellate ganglion. Pain Physician 2004; 7:327-331.

23. Narouze S, Vydyanathan A, Patel N. Ultrasound-guided stellate ganglion block successfully prevented esophageal puncture. Pain Physician 2007; 10:747-752.

24. Christie JM, Martinez CR. Computerized axial tomography to define the distribution of solution after stellate ganglion nerve block. J Clin Anesth 1995; 7:306-311. 
25. Shibata Y, Fujiwara Y, Komatsu T. A new approach of ultrasound-guided stellate ganglion block. Anesth Analg 2007; 105:550-551.

26. Matula C, Trattnig S, Tschabitscher M, Day JD, Koos WT. The course of the prevertebral segment of the vertebral artery: anatomy and clinical significance. Surg Neurol 1997; 48:125-131.

27. Gofeld M. Ultrasonography in pain medicine: a critical review. Pain Pract 2008; 8:226-240.

28. Narouze S. Beware of the "serpentine" inferior thyroid artery while performing stellate ganglion block. Anesth Analg 2009; 109:289-290.

29. Kwak JY, Kim E: Sonographic findings of Zenker diverticula. J Ultrasound Med 2006; 25:639-642.

30. Huntoon MA. The vertebral artery is unlikely to be the sole source of vascular complications occurring during stellate ganglion block. Pain Pract 2010; 10:25-30.

31. Mahli A, Coskun D, Akcali DT. Aetiology of convulsions due to stellate ganglion block: a review and report of two cases. Eur J Anaesthesiol 2002; 19:376-380.

32. Higa K, Hirata K, Hirota K, Nitahara K, Shono S. Retropharyngeal hematoma after stellate ganglion block: analysis of 27 patients reported in the literature. Anesthesiology 2006; 105:12381245.

33. Okuda Y, Urabe K, Kitajima T. Retropharyngeal or cervicomediastinal hematomas following stellate ganglion block. Eur J Anesthesiol 2003; 20:757-759. 


\section{Chapter 4 \\ Ultrasound-guided Cervical Nerve Root Block}

Samer Narouze, MD, MSc

Amaresh Vydyanathan, MD

Leonardo Kapural, MD, PhD

Daniel I. Sessler, MD

Nagy Mekhail, MD, PhD

Narouze S, Vydyanathan A, Kapural L, Sessler DI, Mekhail N. Ultrasound-guided

Cervical Selective Nerve Root Block: A Fluoroscopy-controlled Feasibility Study. Reg Anesth Pain Med 2009; 34:343-348. 


\begin{abstract}
Background and Objectives: Reports of intravascular injection during cervical transforaminal injections, even after confirmation by contrast fluoroscopy, have led some to question the procedure's safety. As ultrasound allows for visualization of soft tissues, nerves and vessels, thus potentially improving precision and safety, we evaluated its feasibility in cervical nerve root injections.
\end{abstract}

Methods: This is a prospective series of 10 patients who received cervical nerve root injections using ultrasound as the primary imaging tool, with fluoroscopic confirmation. Our radiologic target point was the posterior aspect of the intervertebral foramen just anterior to the superior articular process (SAP) in the oblique view, and at the midsagittal plane of the articular pillars in the anteroposterior (AP) view.

Results: The needle was exactly at the target point in 5 patients in the oblique view and in 3 patients in the AP views. The needle was within $3 \mathrm{~mm}$ in all patients in the lateral oblique view and in 8 patients in the AP view. In the remaining 2 patients the needle was within $5 \mathrm{~mm}$ from the radiologic target. In 4 patients we were able to identify vessels at the anterior aspect of the foramen, while 2 patients had critical vessels at the posterior aspect of the foramen and in one patient this artery continued medially into the foramen most likely forming or joining a segmental feeder artery. In both cases, the vessels might well have been in the pathway of a needle correctly positioned under fluoroscopic control.

Conclusion: Our case series shows the feasibility of using ultrasound imaging to guide selective cervical nerve root injections. It may facilitate identifying critical vessels at unexpected locations relative to the intervertebral foramen and avoiding injury to such vessels which is the leading cause of the reported complications from cervical nerve root injections. A randomized controlled trial to compare the effectiveness and safety of ultrasound imaging against other imaging techniques seems warranted. 


\section{Inroduction}

Cervical radicular pain manifests as pain shooting down the upper extremity caused by irritation of the cervical spinal nerves as they exit the neural foramina. The prevalence is about 1 per 1000 members of the adult population and can be disabling to affected individuals.. ${ }^{1}$ While conservative therapy, using exercises and analgesics, improves symptomatology, its success is variable. ${ }^{2,3}$ Failure of conservative therapy warrants alternatives, either surgery or cervical epidural injections.

Surgery remains the mainstay of treatment. But although studies show its efficacy in relieving symptoms over the short term, its long-term efficacy is unclear. ${ }^{4}$ Moreover, cervical spine surgery has an approximately $4 \%$ incidence of serious acute complications and requires hospitalization. ${ }^{5}$ The alternative is cervical epidural steroid injections which provide good short term symptom relief. ${ }^{6}$ The low incidence of major complications $(<1 \%$ as reported by the Bone and Joint Decade 2000-2010 Task Force on Neck Pain and its Associated Disorders) ${ }^{5}$ combined with ease of administration make them an attractive option.

The spinal nerve occupies the lower part of the foramen with the epiradicular veins occupying the upper part. The radicular arteries arising from the vertebral, ascending cervical and deep cervical arteries lie in close approximation to the spinal nerve. Traditionally, cervical transforaminal injections have been performed under fluoroscopic guidance. ${ }^{7}$ Real-time fluoroscopy with contrast injection is necessary to minimize intra-arterial injections. But even with strict guidelines, multiple instances of inadvertent intra-arterial injections with resultant spinal cord injury have been reported. ${ }^{8,9}$ For example, Wallace et al. ${ }^{10}$ reported 2 cases of vertebral artery dissection and advocated using a computerized tomography guided technique to improve the safety of the procedure. This has led some practitioners to question the use of this procedure and whether the benefits outweigh the risks. ${ }^{11,12}$

The use of ultrasound imaging to facilitate nerve blocks has increased recently. Ultrasound allows visualization of soft tissues, as well as nerves and vessels, and also permits visualization of the injectate around the nerve. ${ }^{13,14}$ Unlike fluoroscopy and computed tomography, US does not expose the patients or personnel to radiation and the image can be performed continuously while the injectate can be visualized in real time increasing thereby the precision of injection. But most importantly, ultrasound allows visualization of spinal nerves and vessels which has the potential to improve safety by decreasing the incidence of injury or injection into nearby vasculature. We therefore designed this study to examine the feasibility of performing cervical nerve root injections under real time ultrasound guidance. 


\section{Materials and Methods}

This pilot study was approved by our institutional review board and written informed consent was obtained from all patients. We enrolled ten consecutive patients with cervical radiculopathy supported by either MRI or EMG findings, each of whom failed at least six months of conservative therapy. Those patients were referred to our institute for diagnostic and/or therapeutic cervical selective nerve root block. The procedure was performed with ultrasonography as the primary imaging tool, and with fluoroscopic confirmation. Patients with severe cervical spinal stenosis or neuralgic deficits were excluded from the study.

With patients lying in the lateral decubitus position, ultrasound examinations were performed using a standard ultrasound device (Philips HD11-XL) and a high-frequency linear array transducer (3-12 MHz). Skin was prepared with povidone-iodine and strict sterile precautions were observed throughout. The transducer was applied transversely to the lateral aspect of the neck to obtain a transverse axial view. First the cervical spinal level was determined by identifying the transverse process of the seventh and sixth cervical vertebrae (C7 and C6). The seventh cervical transverse process (C7) differs from the levels above by having a rudimentary anterior tubercle and a prominent posterior tubercle ${ }^{15}$. By moving the transducer cranially, the transverse process of the sixth cervical spine can be visualized, with its characteristic sharp anterior tubercle (Fig.1A and 1B); thereafter, the consecutive cervical segments can be easily identified.

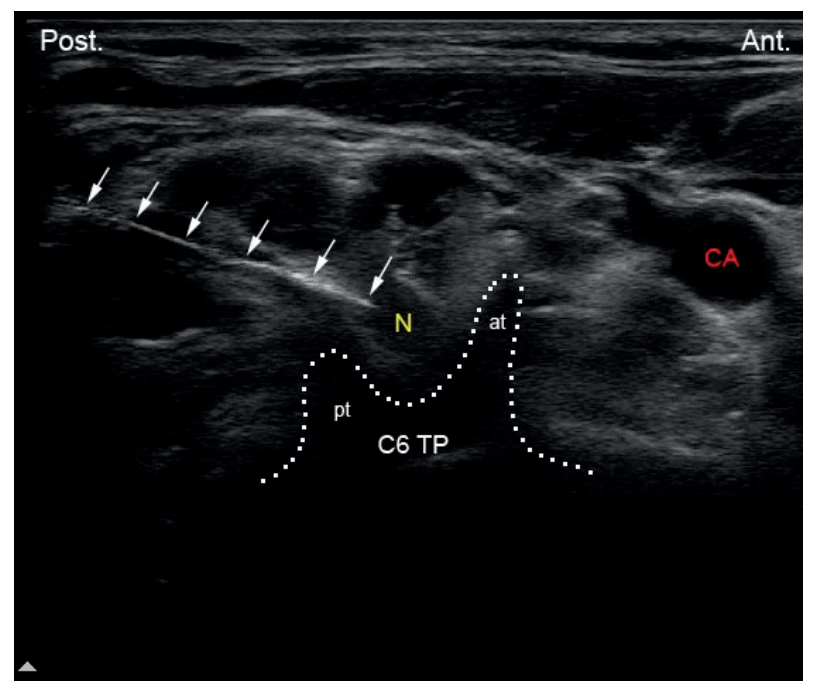

Figure 1A:

Axial transverse ultrasound image showing the sharp anterior tubercle (at) of the $\mathrm{C} 6$ transverse process (C6tp). N, nerve root; CA, carotid artery; pt, posterior tubercle. Solid arrows are pointing to the needle in place at the posterior aspect of the intervertebral foramen. 


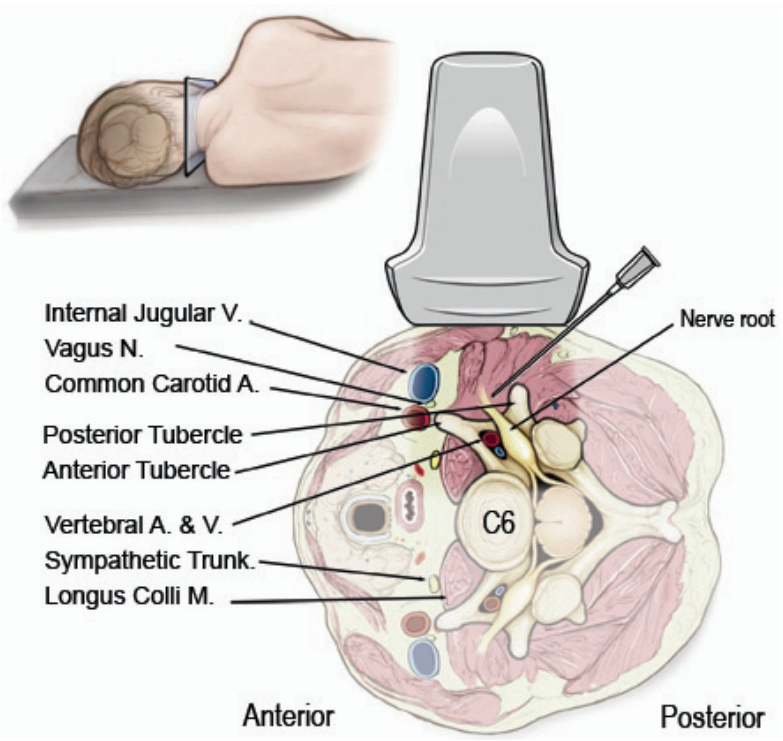

Figure 1B:

Illustration showing the relevant anatomy at C6 level and the orientation of the ultrasound transducer.

Another way to determine the cervical spinal level is by following the cervical artery which runs anteriorly at the $\mathrm{C7}$ level before it enters the foramen of C6 transverse process in about $90 \%$ of cases. However it enters at C5 or higher in the remaining cases ${ }^{16}$, and this was the case in one of our patients. If doubt remains about the spinal level and as the patient is in the lateral decubitus position, one may obtain a longitudinal midline scan by applying the transducer vertically in the midline over the cervical spinous processes and start counting from cranial to caudal ( $\mathrm{C} 1$ arch lacks a spinous process). Once the appropriate spinal level is identified the transverse axial view is obtained and a 22-gauge blunt-tip needle can be introduced just lateral to the lateral end of the transducer and advanced, from posterior to anterior, in-plane with the ultrasound beam under real-time ultrasound guidance to target the corresponding cervical nerve root (from C3-C8) at the foraminal opening between the anterior and posterior tubercles of the transverse process which can be easily identified as the "two-humped camel" sign (Fig. 2A and 2B). After placement of the needle, but before injection, needle position was verified by AP and oblique lateral fluoroscopic images. Plain radiographs were read by another physician experienced in fluoroscopy-guided nerve root blocks and the needle adjusted if necessary.

Our radiologic target point was the posterior aspect of the corresponding intervertebral foramen just anterior to the superior articular process in the oblique view, and halfway between the medial and lateral borders of the articular pillars in the AP view.

The position of the needle as placed by ultrasound was considered accurate when distance to the radiologic target point was within $5 \mathrm{~mm}$. We based this 
distance on the results of a study concerning the spread of contrast agent during cervical medial branch block ${ }^{17}$; furthermore, Eichenberger et al.18 considered this distance adequate in ultrasound-guided third occipital nerve block. Displacement of the needle from the target point was quantified after correction for the magnification effects.

After proper needle placement was confirmed, $0.5 \mathrm{ml}$ of contrast was injected under real-time fluoroscopy with digital subtraction to exclude intravascular injection. Then we injected $2 \mathrm{ml} 1 \%$ lidocaine for diagnostic blocks, or $2 \mathrm{ml}$ of a mixture of dexamethasone ( $8 \mathrm{mg}$ ) and $1 \%$ lidocaine for therapeutic blocks. All injections were performed under real-time ultrasonography. Neurological examination and sensory assessment was performed 30 minutes after the block by testing pinprick and cold sensations.

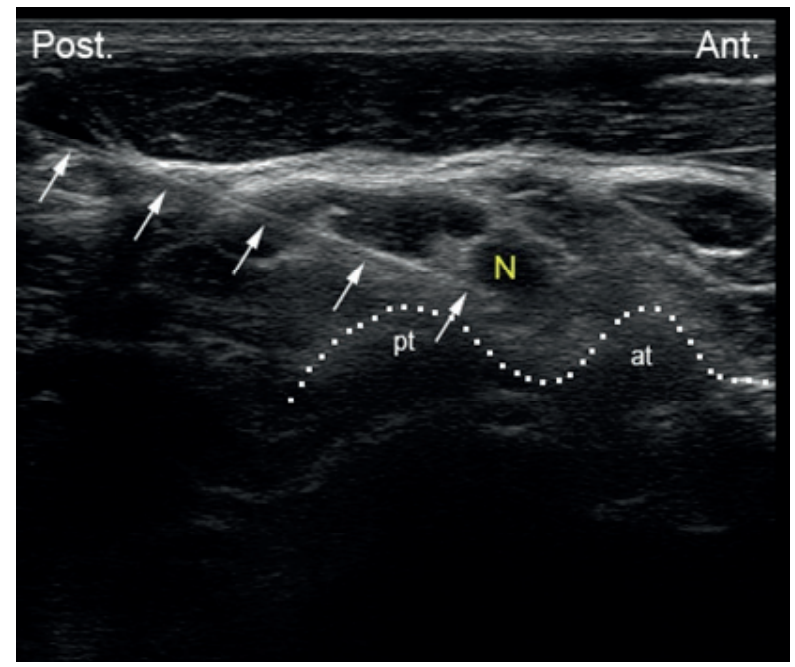

Figure 2A and 2B:

Axial transverse ultrasound images showing the anterior tubercle (at) and the posterior tubercle (pt) of the C5 transverse process as the "twohumped camel" sign. $\mathrm{N}$, nerve root; CA, carotid artery. Solid arrows are pointing to the needle in place at the posterior aspect of the intervertebral foramen.

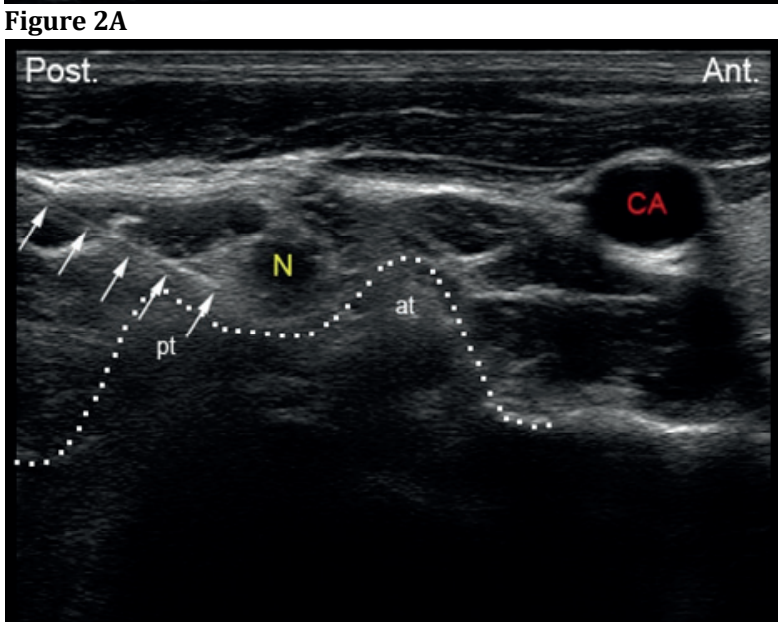

Figure 2B 


\section{Results}

10 patients ( 8 women and 2 men) were enrolled in the study with a median age of $49 \mathrm{yr}$. (range 31-54 yr.). The median body mass index (BMI) was $25 \mathrm{~kg} / \mathrm{m}^{2}$ (range $21-34 \mathrm{~kg} / \mathrm{m}^{2}$ ). In all 10 cases, we were able to identify the cervical transverse process in the transverse axial view with the anterior and posterior tubercles as hyperechoic structures, the classic "two-humped camel" sign, and the hypoechoic round or oval nerve root in-between. The cervical spinal level was correctly identified in all cases as confirmed by fluoroscopy. In one patient the vertebral artery was anterior at C6 and it entered the foramen at C5 level (Fig. 3).

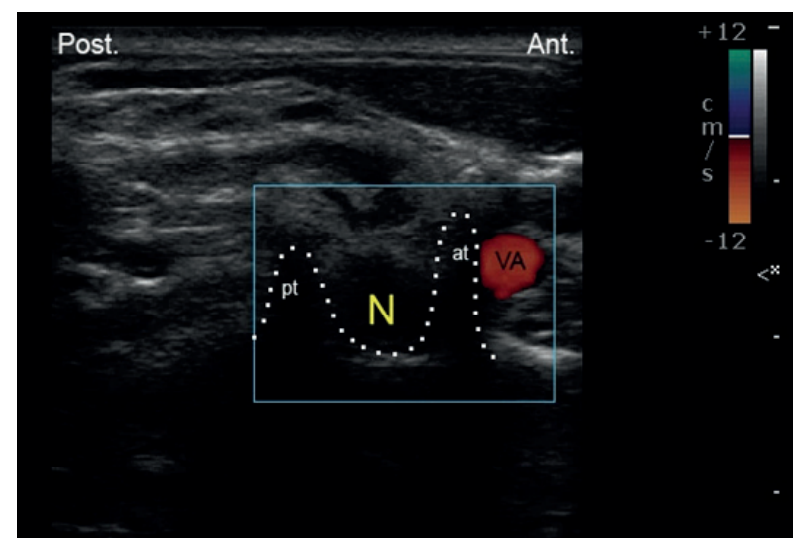

Figure 3A and 3B:

Axial transverse ultrasound images showing the sharp anterior tubercle (at) of the C6 transverse process and the vertebral artery (VA) is anterior. $\mathrm{N}$, nerve root; $\mathrm{CA}$, carotid artery; pt, posterior tubercle. Solid arrow heads are pointing to the needle in place at the posterior aspect of the intervertebral foramen.

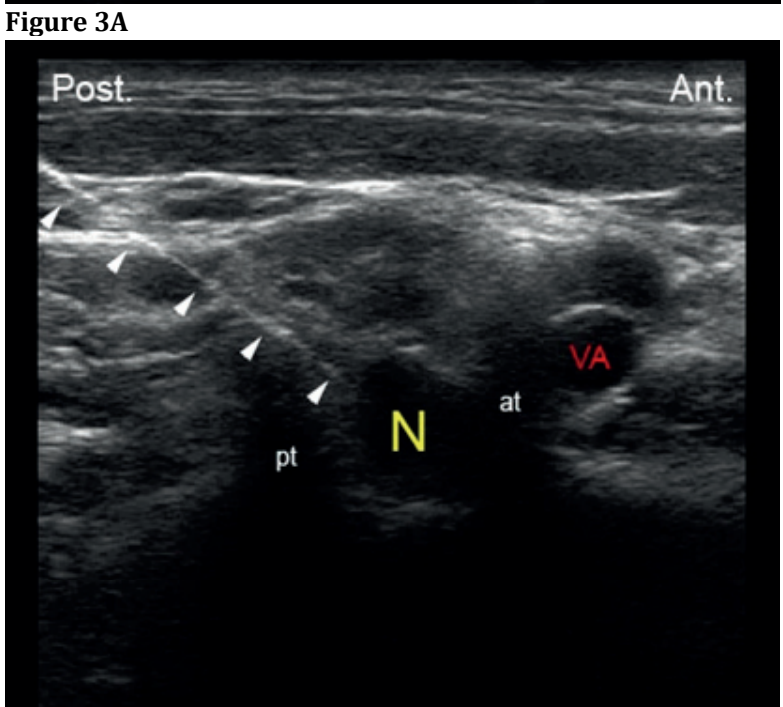

Figure 3B 
The needle was exactly at the target point in $5 / 10$ patients in the lateral oblique view and in $3 / 10$ patients in the AP view (as we tend not to advance the needle too medially into the foramen and the needle tip was lateral to the midsagittal plan of the articular pillar in the AP view). The needle was within $3 \mathrm{~mm}$ of the radiologic target in all patients in the lateral oblique view and in 8 patients in the AP view. In the other 2 patients the needle was within $5 \mathrm{~mm}$ from the radiologic target (at the external foraminal opening). In 4 patients, we were able to identify radicular arteries at the anterior aspect of the foramen (Fig. 4), while 2 patients had arterial vessels in close proximity to the posterior aspect of the foramen (at C6 and C7) and in one patient (C6) this artery (1-1.5 mm in diameter) continued medially into the foramen, most likely forming or joining a segmental feeder artery (Fig. 5A and 5B). In both cases, these vessels were in the pathway of a needle placed correctly under fluoroscopy alone and could easily have been injured. The transducer was moved slightly cephalad until those vessels disappeared as they were placed posteriorly and inferiorly relative to the intervertebral foramen, and the needle was placed safely under real-time ultrasonographic guidance to stop just at the external opening of the foramen to avoid injury to such vessels. All patients developed decreased cold and pinprick sensations along the corresponding dermatome in 30 minutes.

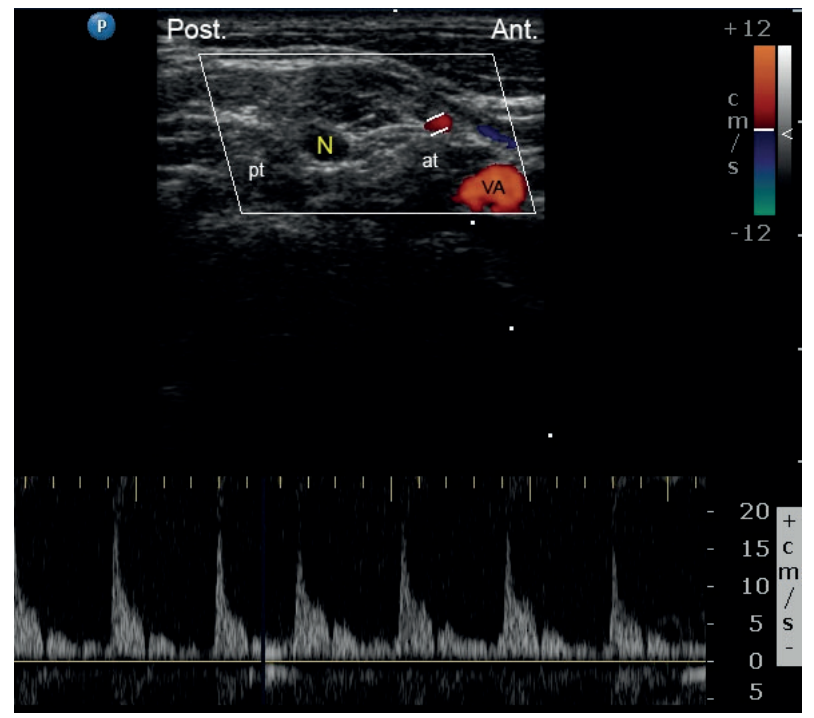

Figure 4:

Axial transverse ultrasound image with Pulsed-wave Doppler assessment showing arterial perfusion in a small vessel that is located at the anterior aspect of the intervertebral foramen. $\mathrm{N}$, nerve root; VA, vertebral artery; at, anterior tubercle; pt, posterior tubercle. 


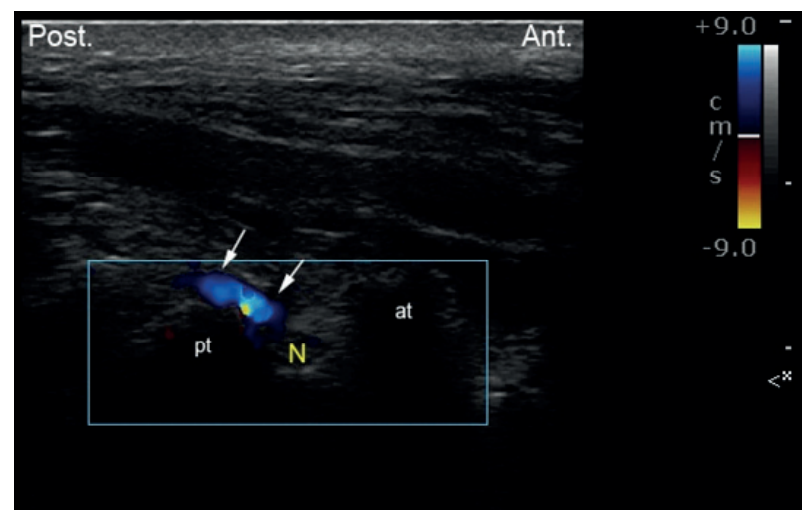

\section{Figure 5A and 5B:}

A: Axial transverse ultrasound image with Color Doppler showing a small vessel at the posterior aspect of the intravertebral foramen which continued medially into the foramen (B). at, anterior tubercle; pt, posterior tubercle.

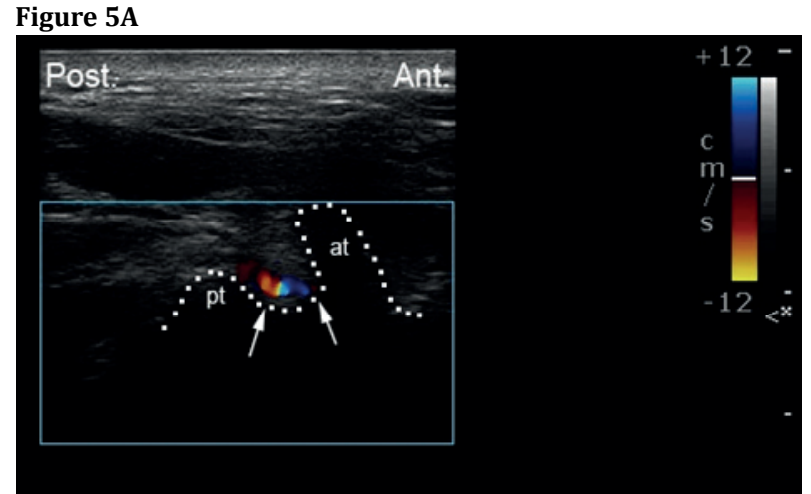

Figure 5B

\section{Discussion}

Ultrasound imaging has revolutionized the field of regional anesthesia and is rapidly becoming the technique of choice in many centers. ${ }^{19}$ The available outcome data suggest that ultrasound guidance shortens onset time, improves block success rates, and increases patient satisfaction-all without increasing block-related complications. ${ }^{20-23}$ In contrast, ultrasound guidance remains a technique in evolution for chronic pain management. Initial reports demonstrate its feasibility in performing stellate ganglion block ${ }^{24,25}$, third occipital nerve block ${ }^{18}$, cervical and lumbar facet joint injections 26,27 , lumbar medial branch block, ${ }^{28,29}$ and periradicular injections. ${ }^{30}$

The advantages of ultrasonography over fluoroscopy include lack of radiation exposure to both the patient (especially with repeated procedures) and the operator, and real-time visualization of soft tissues (nerves, muscles, vessels, etc.), visualization of needle tip advancement relevant to surrounding structures, and visualization of local anesthetic spread. The major shortcomings of ultrasonography with respect to spine injections are the bony artifacts and the limited resolution at deep levels which may prevent good visualization of small- 
gauge needles. Ultrasonography may be particularly helpful in the cervical area because a multitude of vessels and other vital structures are compacted in a limited area. ${ }^{31}$

Ma et al. ${ }^{32}$ in a survey of 1036 consecutive extraforaminal cervical blocks showed a complication rate of $1.64 \%$. But they also reported 6 patients with transient neurologic deficits and 1 patient with global amnesia. There have been reports of fatal complications in the literature as a result of vertebral artery injury. ${ }^{10,33}$ But the more commonly reported serious complication related to intravascular injections causing infarction of the spinal cord and the brain stem. 8,9,34-36 The mechanism of injury was contended to be vasospasm or the particulate nature of the steroid injectate with embolus formation after inadvertent intraarterial injection. 8,9

Furman et al..$^{37}$ showed a $19.4 \%$ incidence of inadvertent intraarterial injections during transforaminal cervical epidural steroid injections. The use of aspiration of blood was only $46 \%$ sensitive for detection and real time contrast fluoroscopy was deemed necessary to detect inadvertent intravascular injections. But Baker et al. ${ }^{9}$ showed that even real time contrast fluoroscopy may be insufficient and recommended digital subtraction angiography for detection of inadvertent intravascular injection. In our small case series we had no inadvertent intravascular injections as confirmed by digital subtraction angiography.

Current guidelines for cervical transforaminal injection technique involve introducing the needle under fluoroscopic guidance into the posterior aspect of the intervertebral foramen just anterior to the superior articular process in the oblique view to minimize the risk of injury to the vertebral artery or the nerve root.7 Despite strict adherence to these guidelines, adverse outcomes have been reported..$^{8,9}$ Complications may result from the presence of a critical feeder vessel to the anterior spinal artery in the posterior aspect of the intervertebral foramen that is in the pathway of the needle. ${ }^{38}$ Ultrasonography may be useful in such circumstances as it permits visualization of vessels. Galiano et al. ${ }^{39}$ described the use of ultrasound in performing cervical periradicular injections in cadavers. They were unable to comment on the relevant blood vessels in the vicinity of the vertebral foramen and this raised some concerns about the safety of performing the procedure with ultrasound at that time..$^{40}$ In fact, in 2 of our 10 patients, there were vessels at the posterior aspect of the foramen that could be potentially injured in the path of a correctly placed needle, if the procedure were done under fluoroscopy. These findings reconfirmed the work by Huntoon on cadavers. ${ }^{38} \mathrm{He}$ was able to show that the ascending and deep cervical arteries may contribute to the anterior spinal artery. More than $20 \%$ of the foramina dissected (21/95) had either the ascending or deep cervical artery or a large branch within $2 \mathrm{~mm}$ of the needle path for a cervical transforaminal procedure. One third of these vessels were spinal branches that entered the foramen posteriorly potentially forming a radicular or a segmental feeder vessel to the spinal cord. 
In a single cadaver dissection study, Hoeft et al. ${ }^{41}$ showed that radicular artery branches from the vertebral artery lie over the most anteromedial aspect of the foramen, while those that arise from the ascending or deep cervical arteries are of greatest clinical importance as they course medially transversing the entire extent of the foramen. It is for this reason that we avoid advancing needles deep through the foramen, instead stopping at the external foraminal opening. While ultrasonography provides more information about vascular structures than fluoroscopy, it can nonetheless be difficult to trace the vessels deep in the foramen as they course towards the spinal vessels. Thus while we were successful in monitoring the spread of the injectate around the cervical nerve, we were not able to monitor the spread of the injectate through the foramen- if any- into the epidural space (because of the bony drop out artifact of the transverse process). We therefore refer to our approach as a "cervical selective nerve root block" rather than cervical transforaminal epidural injection (Fig. 6).

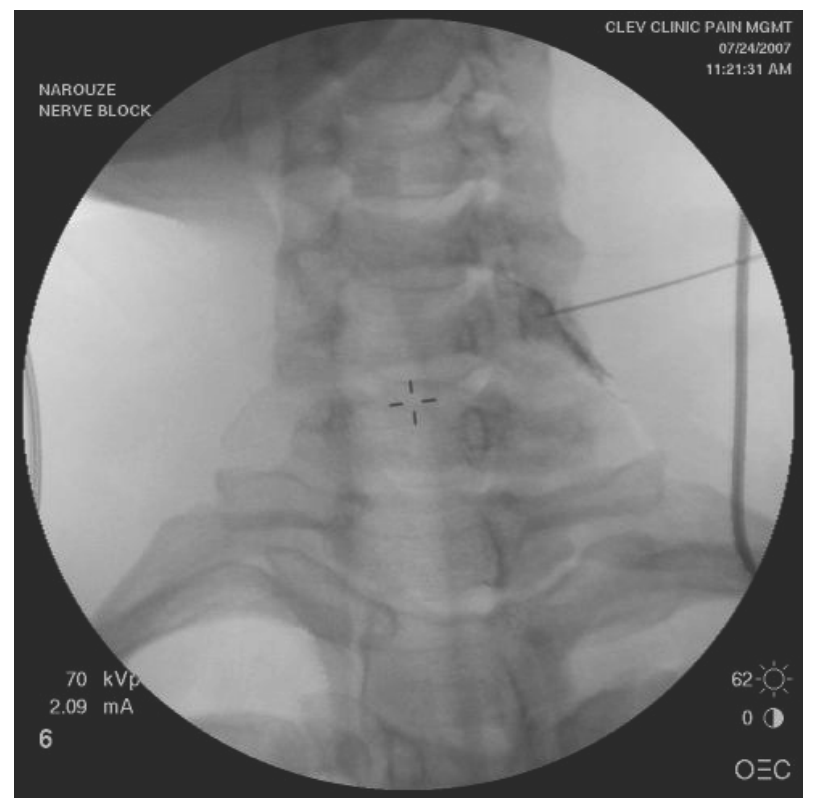

\section{Figure 6:}

AP X-ray view showing the contrast agent delineating the dorsal root ganglion and the nerve root. No spread can be seen into the epidural space.

While our case series shows the feasibility of using ultrasound imaging to guide selective cervical nerve root injections and to visualize critical vessels in the vicinity of the external cervical intervertebral foramen, use of ultrasound imaging may be difficult in certain patients and requires some experience to adequately use it for these injections. Our study is also limited in that the assessment of visualization of landmarks was made by only one of the authors of this study (SN) and may be subject to bias. We need to emphasize that, the inability to visualize critical vessels at the posterior aspect of the neuroforamen in the remaining patients doesn't necessarily mean they do not exist, may be they are 
just too small to be detected by the current ultrasound technology. While we were able to monitor the spread of the injectate in real time, ultrasonography may not reliably detect tiny intravascular injections which still can lead to neurological injury.

In summary, ultrasound imaging can be used to obtain well-defined images of the cervical neural foramina with real-time visualization of the spinal nerves and vessels and may improve the safety of the technique. It may facilitate identifying anomalous critical vessels at unexpected locations relative to the intervertebral foramen and avoiding injury to such vessels which is the leading cause of the reported complications from cervical nerve root injections. So with cervical selective nerve root block (cervical transforaminal epidural injection) there is really no safe zone, however there may be a safer tool. A randomized controlled trial to compare the effectiveness and safety of ultrasound imaging against other imaging techniques seems warranted in order to elaborate on its actual clinical utility in performing cervical nerve root injections. 


\section{References}

1. Radhakrishnan K, Litchy WJ, O'Fallon WM, Kurland LT. Epidemiology of cervical radiculopathy: A population based study of Rochester, Minnesota, 1976 through 1990. Brain 1994; 117:325335.

2. Saal JS, Saal JA, Yurth EF. Nonoperative management of herniated cervical intervertebral disc with radiculopathy. Spine 1996; 21:1877-1883.

3. Arnasson 0, Carlsson CA, Pelletieri L. Surgical and conservative treatment of cervical spondylotic radiculopathy and myelopathy. Acta Neurochir 1987; 84:48-53.

4. Fouyas IP, Statham PF, Sandercock PA. Cochrane review on the role of surgery in cervical spondylotic radiculomyelopathy. Spine 2002; 27:736-747.

5. Carragee EJ, Hurwitz EL, Cheng I, Carroll LJ, Nordin M, Guzman J, Peloso P, Holm LW, Côté P, Hogg-Johnson S, van der Velde G, Cassidy JD, Haldeman S. Treatment of neck pain: injections and surgical interventions: results of the Bone and Joint Decade 2000-2010 Task Force on Neck Pain and Its Associated Disorders. Spine 2008; 33:S153-169.

6. Abdi S, Datta S,Trescot AM, Schultz DM,Adlaka R,Atluri SL,Smith H, Manchikanti L. Epidural steroids in the management of chronic spinal pain: a systematic review. Pain Physician 2007; 10:185-212.

7. Rathmell JP, Aprill C, Bogduk N. Cervical transforaminal injection of steroids. Anesthesiology 2004; 100:1595-1600.

8. Tiso RL, Cutler T, Catania JA, Whalen K. Adverse central nervous system sequelae after selective transforaminal block: the role of corticosteroids. Spine 2004; 4:468-474.

9. Baker R, Dreyfuss P, Mercer S, Bogduk N. Cervical transforaminal injections of corticosteroids into a radicular artery: a possible mechanism for spinal cord injury. Pain 2003; 103:211-215.

10. Wallace MA, Fukui MB, Williams RL, Ku A, Baghai P. Complications of cervical selective nerve root blocks performed with fluoroscopic guidance. AJR 2007; 188:1218-1221.

11. Provenzano DA, Fanciullo G. Cervical transforaminal epidural steroid injections: should we be performing them? Reg Anesth Pain Med 2007; 32:168.

12. Scanlon GC, Moeller-Bertram T, Romanowsky SM, Wallace MS. Cervical transforaminal epidural steroid injections: more dangerous than we think? Spine 2007; 32:1249-1256.

13. Curatolo M, Eichenburger U. Ultrasound-guided blocks for the treatment of chronic pain. Tech Reg Anesth Pain Manag 2007; 11:95-102.

14. Gofeld M. Ultrasonography in pain medicine: A critical review. Pain Practice 2008; 8:226-240.

15. Martinoli C, Bianchi S, Santacroce E, Pugliese F, Graif M, Derchi LE. Brachial plexus sonography: a technique for assessing the root level. AJR 2002; 179:699-702.

16. Matula C, Trattnig S, Tschabitscher M, Day JD, Koos WT. The course of the prevertebral segment of the vertebral artery: Anatomy and clinical significance. Surg Neurol 1997; 48:125-131.

17. Barnsley L, Bogduk N. Medial branch blocks are specific for the diagnosis of cervical zygapophyseal joint pain. Reg Anesth 1993; 18:343-350.

18. Eichenberger U, Greher M, Kapral S, Marhofer P, Wiest R, Remonda L, Bogduk N, Curatolo M. Sonographic visualization and ultrasound-guided block of the third occipital nerve: prospective for a new method to diagnose C2-C3 zygapophyseal joint pain. Anesthesiology 2006; 104:303308.

19. Hopkins PM. Ultrasound guidance as a gold standard in regional anesthesia. Br J Anaesth 2007; 98:299-301.

20. Kapral S, Greher M, Huber G, Willschke H, Kettner S, Kdolsky R, Marhofer P. Ultrasonographic guidance improves the success rate of interscalene brachial plexus blockade. Reg Anesth Pain Med 2008; 33:253-258.

21. Perlas N, Brull R, Chan VWS, McCartney CJL, Nuica A, Abbas S. Ultrasound guidance improves the success of sciatic nerve block at the popliteal fossa. Reg Anesth Pain Med 2008; 33:259-265.

22. Casati A, Danelli G, Baciarello M, Corradi M, Leone S, Di Cianni S, Fanelli G. A prospective, randomized comparison between ultrasound and nerve stimulation guidance for multiple injection axillary brachial plexus block. Anesthesiology 2007; 106:992-996. 
23. Chan VW, Perlas A, McCartney J, Brull R, Xu D, Abbas S. Ultrasound guidance improves success rate of axillary brachial plexus block. Can J Anaesth 2007; 54:176-182.

24. Kapral S, Krafft P, Gosch M, Fleischmann D, Weinstabl C. Ultrasound imaging for stellate ganglion block: Direct visualization of puncture site and local anesthetic spread. Reg Anesth 1995; 20:323-328.

25. Narouze S, Vydyanathan A, Patel N. Ultrasound-guided stellate ganglion block successfully prevented esophageal puncture. Pain Physician 2007; 10:747-752.

26. Galiano K, Obwegeser AA, Bodner G, Freund MC, Gruber H, Maurer H, Schatzer R, Fiegele T, Ploner F. Ultrasound-guided facet joint injections in the middle to lower cervical spine: a CTcontrolled sonoanatomic study. Clin J Pain 2006; 22:538-543.

27. Galiano K, Obwegeser AA, Walch C, Schatzer R, Ploner F, Gruber H.Ultrasound-guided versus computed tomography-controlled facet joint injections in the lumbar spine: a prospective randomized clinical trial. Reg Anesth Pain Med 2007; 32:317-322.

28. Greher M, Kirchmair L, Enna B, Kovacs P, Gustorff B, Kapral S, Moriggl B. Ultrasound-guided lumbar facet nerve block: accuracy of a new technique confirmed by computed tomography. Anesthesiology 2004; 101:1195-1200.

29. Shim JK, Moon JC, Yoon KB, Kim WO, Yoon DM. Ultrasound-guided lumbarmedial-branch block: a clinical study with fluoroscopy control. Reg Anesth Pain Med 2006; 31:451-454.

30. Galiano K, Obwegeser AA, Bodner G, Freund M, Maurer H, Kamelger FS, Schatzer R, Ploner F. Real-time sonographic imaging for periradicular injections in the lumbar spine: a sonographic anatomic study of a new technique. J Ultrasound Med 2005; 24:33-38.

31. Narouze S. Ultrasonography in Pain Medicine: A Sneak Peak at the Future. Pain Pract 2008; 8:223-5.

32. Ma DJ, Gilula LA, Riew KD. Complications of fluoroscopically guided Extraforaminal cervical nerve blocks: An analysis of 1036 injections. JBJS 2005; 87:1025-1030

33. Rozin L, Rozin R, Koehler SA, Shakir A, Ladham S, Barmada M, Dominick J, Wecht CH. Death during transforaminal epidural steroid nerve root block (C7) due to perforation of the left vertebral artery. Am J Forensic Med Pathol 2003; 24:351-355.

34. Muro K, O'Shaughnessy B, Ganju A. Infarction of the cervical spinal cord following multilevel transforaminal epidural steroid injection: case report and review of the literature. J Spinal Cord Med 2007; 30:385-388.

35. Brouwers PJ, Kottink EJ, Simon MA, Prevo RL. A cervical anterior spinal artery syndrome after diagnostic blockade of the right C6-nerve root. Pain 2001; 91:397-399.

36. Beckman WA, Mendez RJ, Paine GF, Mazzilli MA. Cerebellar herniation after cervical transforaminal epidural injection. Reg Anesth Pain Med 2006; 31:282-285

37. Furman MB, Giovanniello MT, O'Brien EM. Incidence of intravascular penetration in transforaminal cervical epidural steroid injections. Spine 2003; 28: 21-25

38. Huntoon MA. Anatomy of the cervical intervertebral foramina: vulnerable arteries and ischemic neurologic injuries after transforaminal epidural injections. Pain 2005; 117:104-111

39. Galiano K, Obwegeser AA, Bodner G, Freund MG, Gruber H, Maurer H, Schatzer R, Ploner F. Ultrasound-guided periradicular injections in the middle to lower cervical spine: An imaging study of a new approach. Reg Anesth Pain Med 2005; 30:391-396

40. Narouze SN. Ultrasound-guided cervical periradicular injection: cautious optimism [letter]. Reg Anesth Pain Med 2006; 31:87.

41. Hoeft MA, Rathmell JP, Monsey RD, Fonda BJ. Cervical transforaminal injection and the radicular artery: Variation in anatomical location within the cervical intervertebral foramina. Reg Anesth Pain Med 2006; 31:270-274. 


\section{Chapter 5 \\ Ultrasound-guided Stellate Ganglion Block}

Samer Narouze, MD, MSc

Amaresh Vydyanathan, MD

Nilesh Patel, MD

Narouze S, Vydyanathan A, Patel N. Ultrasound-guided stellate ganglion block successfully prevented esophageal puncture. Pain Physician 2007; 10:747-752. 


\begin{abstract}
A patient with complex regional pain syndrome type I of the left upper extremity was scheduled for left stellate ganglion block with the anterior paratracheal approach under fluoroscopy. Real-time ultrasound imaging prevented inadvertent injury to the esophagus as well as the thyroid gland and vessels.

Ultrasound-guided block may improve patient safety by avoiding the soft tissue structures in the needle path that can't be readily seen by fluoroscopy. This may be particularly useful in the patient with asymptomatic pharyngoesophageal diverticulum (Zenker diverticulum).
\end{abstract}




\section{Introduction}

Stellate ganglion block is utilized in the diagnosis and management of various vascular disorders and sympathetically mediated pain in the upper extremity, , head, and neck.

Many techniques have been used to block the lower cervical sympathetic chain. The two most common techniques are at the $\mathrm{C} 6$ transverse process ${ }^{1-3}$ and the anterior paratracheal approach at $\mathrm{C} 7{ }^{4}$ with or without fluoroscopy.

This case report illustrates the clinical use of ultrasound in performing stellate ganglion blockade as it may detect and prevent many of the complications reported to be associated with its blockade.

\section{Case Report}

We report on a 25-year-old female with a history of left upper extremity complex regional pain syndrome type I (CRPS I) for the last 6 months. She was scheduled for a left stellate ganglion block. We planned to do the procedure under fluoroscopy (our routine practice) using the classic anterior paratracheal approach and to verify needle placement with ultrasound for teaching purposes. After obtaining an informed consent and applying standard ASA monitors, the patient was positioned in the supine position with the neck extended by placing a pillow under her shoulder in order to stretch the esophagus and makes it move medially under the trachea. With fluoroscopic guidance the bony target was identified at the junction of the anterolateral vertebral body with the transverse process at $\mathrm{C} 6$ level in the anteroposterior view and the skin was marked. With complete aseptic technique, a $22 \mathrm{G}$ blunt needle was used aiming towards the identified bony target under fluoroscopy guidance (Fig. 1). 




Figure 1:

AP view showing the needle in target view with the anterior paratracheal approach at C6 aiming towards the junction between the transverse process and the vertebral body at C6.

After passing through the skin and subcutaneous tissue and stabilizing the needle, a 3-12 MHz linear array probe (HD11-XL, Philips, Bothell, WA) was used to verify the position of the needle. The needle was shown to be aiming towards the thyroid tissue anteriorly and then the esophagus posteriorly. At this point the needle was withdrawn and it was reinserted obliquely and it was advanced with real-time ultrasound sonography so that the needle tip will lie anterior to the longus coli muscle (anterior to C6 transverse process) (Fig. 2,3). After negative aspiration, $1 \mathrm{ml}$ of contrast agent was injected which showed good spread without vascular escape (Fig. 4). Then $5 \mathrm{ml}$ of Bupivacaine $0.25 \%$ were injected in divided doses with real-time ultrasound imaging which showed nice spread of the local anesthetic agent at the area of the lower cervical sympathetic chain with both cephalad and caudad spread (approximately 2 segments each). 5 minutes later the patient developed left sided Horner's syndrome as well as vasodilation of the left upper extremity. The temperature at the left middle finger- measured by contact thermography- rose from $28{ }^{\circ} \mathrm{C}$ to $35^{\circ} \mathrm{C}$ (7 degrees), while it rose only 0.5 degree on the right. The patient was monitored in the recovery room for another 30 minutes. She didn't develop recurrent laryngeal nerve palsy, her pain score was dropped from 8 to 2 on a visual analog scale of $0-10$, and subsequently she was discharged home in a stable condition. 


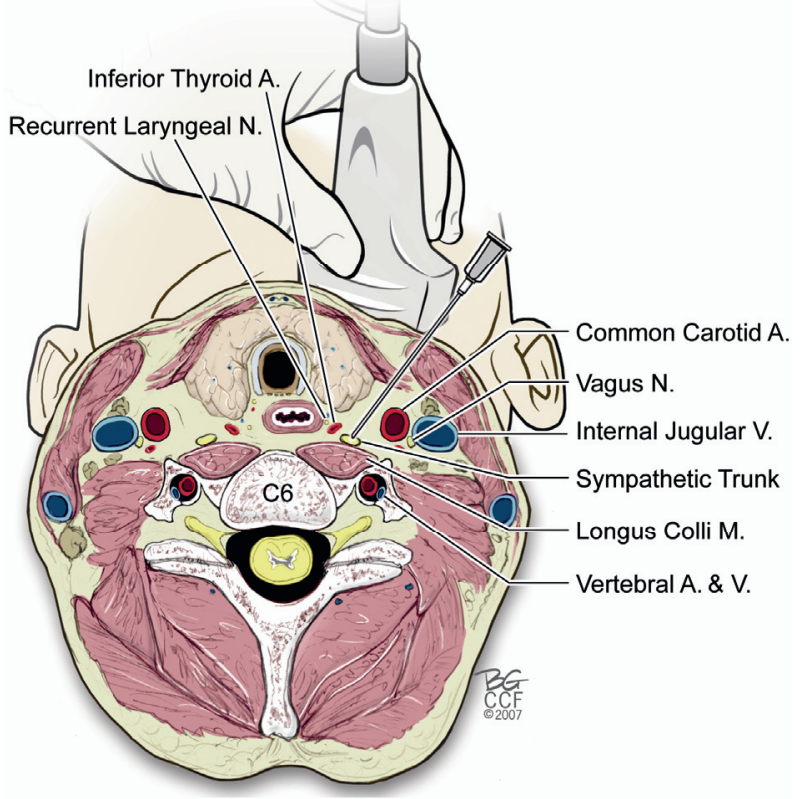

\section{Figure 2:}

Illustration showing the position of the ultrasound probe and the needle in the oblique path.

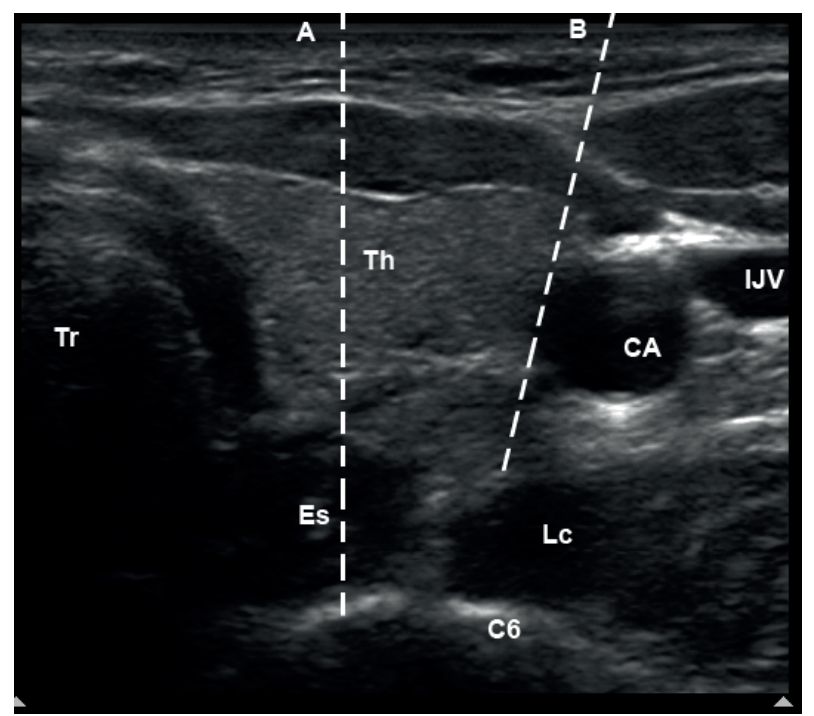

\section{Figure 3:}

Ultrasound imaging of the left stellate ganglion. A: the needle path with the anterior paratracheal approach. B: the needle path with ultrasound guidance.

Tr, Trachea; Es, esophagus; Th, thyroid; CA, carotid artery; IJV, internal jugular vein. 


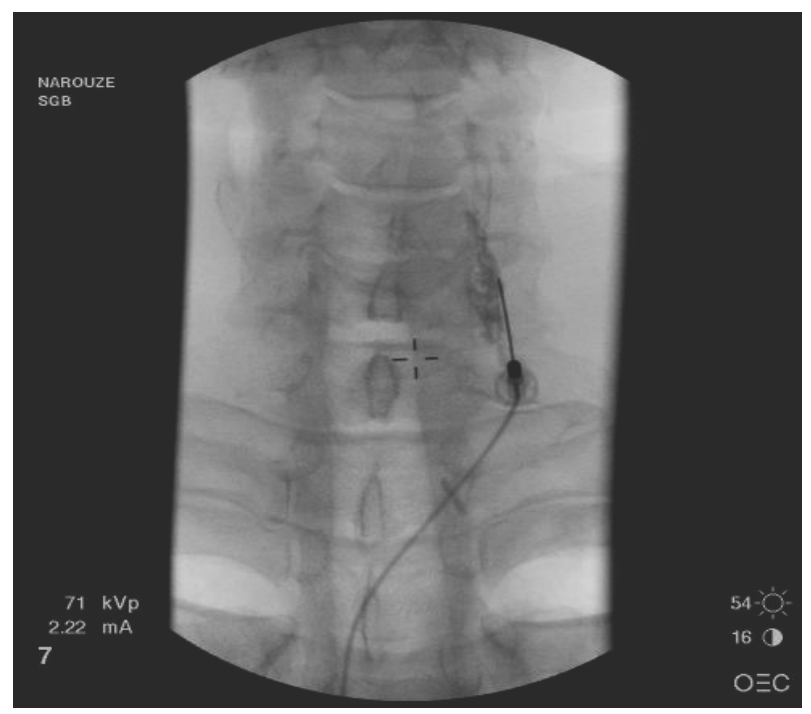

Figure 4:

AP view showing the spread of the contrast agent.

\section{Discussion}

The cervical sympathetic chain is composed of superior, middle, intermediate, and inferior cervical ganglia. In $80 \%$ of the population the inferior cervical ganglion is fused with the first thoracic ganglion, forming the stellate ganglion (cervicothoracic ganglion), which measures approximately $2.5 \mathrm{~cm}$ long, $1 \mathrm{~cm}$ wide, and $0.5 \mathrm{~cm}$ thick (anteroposterior diameter). It is usually located posteriorly in the chest in front of the neck of the first rib and may extend to the seventh cervical (C7) vertebral body. ${ }^{5-7}$ If the inferior cervical ganglion and first thoracic ganglion are not fused, the inferior cervical ganglion lies in front of the $\mathrm{C} 7$ tubercle, and the first thoracic ganglion rests over the neck of the first rib. ${ }^{5-7}$ Accordingly, by using the blind technique at $\mathrm{C} 6$ the ganglion primarily blocked is the middle cervical ganglion, and the cervicothoracic ganglion is blocked if the injectate spreads down to T1 level.

The stellate ganglion lies medial to the scalene muscles, lateral to the longus colli muscle, esophagus and trachea along with the recurrent laryngeal nerve, anterior to the transverse processes and prevertebral fascia, superior to the subclavian artery and the posterior aspect of the pleura, and posterior to the vertebral vessels at $\mathrm{C} 7$ level. 7 This explains why there may be increased risk of pneumothorax and vertebral artery injury with blockade at C7 level. 5,8

The anatomy of the stellate ganglion being in close proximity to various critical structures, results in a number of complications potentially associated with its blockade, some of which are life threatening ${ }^{9}$ Accordingly, techniques of blockade have evolved and varied from the use of the standard blind tech- 
nique to the use of computerized tomography (CT) ${ }^{10}$, magnetic resonance imaging (MRI) 7,11 and radionuclide tracers. ${ }^{12}$

However these techniques may not be practical in clinical practice as they are time consuming, cost ineffective, and involve radiation exposure.

Fluoroscopy has been suggested as a safer and more effective way to perform SGB than the traditional blind approach. ${ }^{13,14}$ Abdi et al. ${ }^{14}$ described an oblique fluoroscopic approach targeting the junction between the uncinate process and the vertebral body at the $\mathrm{C} 7$ level.

Inadvertent placement of the needle into the vertebral artery, thyroid, neural tissues, or esophagus can occur with the fluoroscopic approach. Fluoroscopy is a reliable method for identifying bony structures; however the adjacent anatomical structures can't be identified. On the contrary ultrasound can identify the vertebral vessels, thyroid gland and vessels, longus colli muscle, nerve roots, and the esophagus and accordingly can prevent inadvertent placement of the needle into these structures as might happen with either the classical blind technique or the more widely used fluoroscopic technique. ${ }^{15}$

Kapral et al. ${ }^{16}$ first described ultrasound imaging (US) for stellate ganglion block. They showed that the blind technique resulted in hematoma formation in 3 out of 12 patients (asymptomatic), with no hematoma occurring during US technique. They attributed this to injury to the thyroid gland or the vertebral artery.

The frequency of retropharyngeal hematoma after SGB was reported to be 1 in 100,000 cases with resulting airway compromise and obstruction. ${ }^{9}$ However Kapral et al. ${ }^{16}$ reported a much higher incidence of asymptomatic hematoma with the blind technique.

The vertebral artery runs anteriorly to the stellate ganglion at the $\mathrm{C7}$ level before it enters the foramen of C6 transverse process in about $90 \%$ of cases. However it enters at $\mathrm{C} 5$ or higher in the remaining cases. ${ }^{17}$ This makes it vulnerable to injury during lower cervical sympathetic block, not only at the C7 level but at $\mathrm{C} 6$ as well, a possibility that can be easily avoided by ultrasound imaging. Also the inferior thyroid vessels runs ventrally at the C6 and C7 level, these together with the thyroid gland itself were reported to be a source of retropharyngeal hematoma with SGB. ${ }^{9}$ With the blind technique and even with fluoroscopic guidance the thyroid gland and vessels can be easily injured in the path of the needle, and again this can be prevented with ultrasound (Fig. 5). 


\section{Anterior Paratracheal Approach Path}

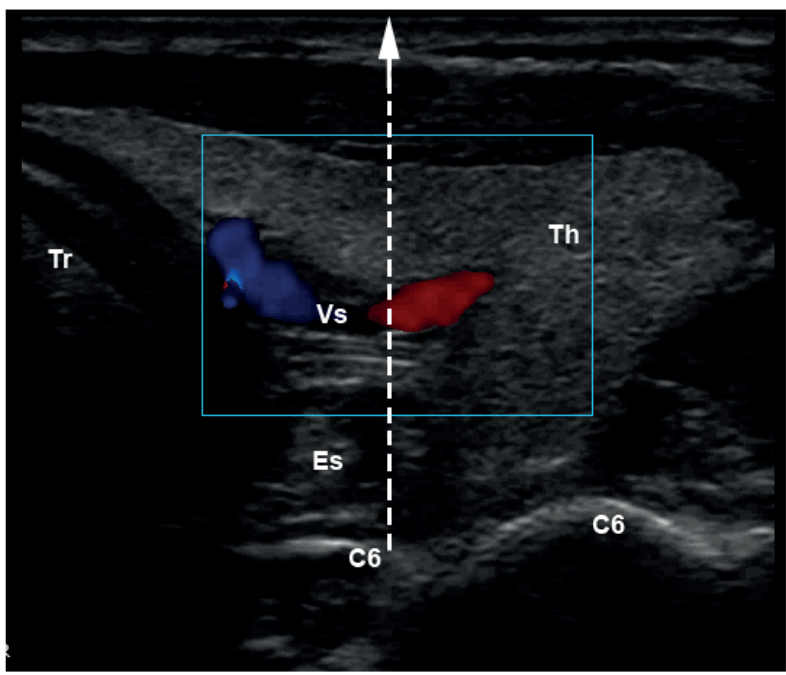

\section{Figure 5:}

Ultrasound imaging showing that with the anterior paratracheal approach the needle may inadvertently injure the thyroid vessels with the potential for hematoma formation. Tr, Trachea; Es, esophagus; Th, thyroid; Vs, thyroid vessels.

Ultrasound imaging can easily identify the esophagus especially on the left, and our case showed that this is a very important tool as it avoided esophageal penetration and prevented the potential development of mediastinal infection and/or mediastinal emphysema. The procedure was repeated safely as the esophagus was visualized and avoided (which is unique to ultrasound compared to fluoroscopy, unless it is performed after a barium swallow study). It showed that the esophagus has an outpouching that clearly occupies the area that would have been traversed by the needle using the classical anterior paratracheal approach.

The esophagus can be identified by the change in shape and shadowing during swallowing and the presence of a peripheral arc-shaped echogenic line or a boundary hypoechoic zone, which is suggestive of the striatal structure of the digestive tract. 18,19

This may be even more impotent in patients with pharyngoesophageal diverticulum (Zenker diverticulum) as they are usually asymptomatic and detected incidentally by neck sonography. ${ }^{18,19}$ Hardy and Wells ${ }^{20}$ showed that cervicothoracic sympathetic block was only achieved by using $20 \mathrm{ml}$ local anesthetic. However placing the needle by ultrasound closer to the target will minimize the amount of local anesthetic and hence improving the patient's safety as Wulf et al. ${ }^{21}$ reported toxic plasma levels in 30\% of patients undergoing SGB using $10 \mathrm{ml}$ Bupivacaine 0.5\%.

Another common side effect of SGB is recurrent laryngeal nerve (RLN) block, which is the main reason behind the common practice of avoiding bilateral SGB. Hardy and Wells ${ }^{20}$ reported an incidence of $10 \%$ with $10 \mathrm{ml}$ local anesthetic LA solution and up to $80 \%$ with $20 \mathrm{ml}$ solution. Kapral et al. ${ }^{16}$ reported RLN palsy in only one patient $(\mathrm{N}=12)$ where the US showed the spread of the LA 
between the carotid sheath, thyroid gland, and the esophagus (the anatomic site of the RLN). Ultrasound may predict and/or avoid such complication by repositioning the needle and monitoring the spread of the LA, and if the spread of the LA is away from the site of the RLN, then bilateral SGB may be performed safely.

Ultrasound-guided SGB may improve the safety of the procedure by direct visualization of the related anatomical structures and accordingly the risk of thyroid gland and vessels, vertebral artery, or esophagus injury may be minimized. Also ultrasound guidance will allow direct monitoring of the spread of the LA and hence complications like RLN palsy, intrathecal, epidural, or intravascular spread may be minimized as well. 


\section{References}

1. Bryce-Smith R: Stellate ganglion block. Anaesthesia 1952; 7:154-156.

2. Davies RM: Stellate ganglion block, a new approach. Anaesthesia 1952; 7:151-153.

3. Carron H, Litwiller R: Stellate ganglion block. Anesth Analg 1975; 54:567-570.

4. Moore DC, Bridenbaugh LD Jr: The anterior approach to the stellate ganglion. JAMA 1956; 160:158-162.

5. Raj PP: Stellate ganglion block. In Waldman and Wenner (eds). Interventional Pain Management. Philadelphia, Saunders, 1996.

6. Ellis H, Feldman S: Anatomy for Anesthetists, 3rd ed. Blackwell Scientific Publications, Oxford, 1979, pp 256-262.

7. Hogan Q, Erickson SJ: Magnetic resonance imaging of the stellate ganglion: Normal appearance. Am J Roentgenol 1992; 158:655-659.

8. Matsumoto S: Thermographic assessments of the sympathetic blockade by stellate ganglion: Comparison between C7-SGB and C6-SGB in patients. Masui 1991; 40:562-569.

9. Higa K, Hirata K, Hirota K, Nitahara K, Shono S: Retropharyngeal hematoma after stellate ganglion block. Anesthesiology 2006; 105: 1238-1245.

10. Hogan QH, Erickson SJ, Abram SE: Computerized tomography (CT) guided stellate ganglion blockade. Anesthesiology 1992; 77:596-599.

11. Slapppendel F, Thijssen H, Crul BJ, Merx JL: The stellate ganglion in magnetic resonance imaging, a quantification of anatomic variability. Anesthesiology 1995; 83:424-426.

12. Elias M: Cervical sympathetic and stellate ganglion blocks. Pain Physician 2000; 3:294-304.

13. Abdi S, Zhou Y, Patel N, Saini B, Nelson J: A new and easy technique to block the stellate ganglion. Pain Physician 2004; 7: 327-331.

14. Baumann JM, Middaugh RE, Cawthon MA, Hartshorne MF, Menk EJ, baysinger C: Radionuclideanesthetic flow study: A new technique for the study of regional anesthesia. J Nucl Med 1986:27: 1487-1489.

15. Curatolo M, Eichenberger U: Ultrasound-guided blocks for the treatment of chronic pain. Tech Reg Anesth Pain Manage 2007; 11:95-102.

16. Kapral S, Krafft P, Gosch M, Fleischmann D, Weinstabl C: Ultrasound imaging for stellate ganglion block: Direct visualization of puncture site and local anesthetic spread. Reg Anesth 1995; 20:323-328.

17. Matula C, Trattnig S, Tschabitscher M, Day JD, Koos WT: The course of the prevertebral segment of the vertebral artery: Anatomy and clinical significance. Surg Neurol 1997; 48:125-131.

18. Kim J, Kim YJ, Kim EK, Park CS: Incidentally found pharyngoesophageal diverticulum on ultanosonography. Yonsei Med J 2002; 43:271-273

19. Kwak JY, Kim E: Sonographic findings of Zenker diverticula. J Ultrasound Med 2006; 25:639-642.

20. Hardy PAJ, Wells JCD: Extent of sympathetic blockade after stellate ganglion block with bupivacaine. Pain 1989; 36:193-196.

21. Wulf H, Maier C, Schele H, Wabbel W: Plasma concentration of bupivacaine after stellate ganglion blockade. Anesth Analg 1991: 72:546-548. 


\section{Chapter 6 \\ Atlanto-axial Joint Injection for \\ Cervicogenic Headache}

Samer N Narouze, MD MSc

Jose Casanova, MD, PhD

Nagy Mekhail, MD, PhD

Narouze S, Casanova J, Mekhail N. The longitudinal effectiveness of lateral atlantoaxial intra-articular steroid injection in the management of cervicogenic headache. Pain Medicine 2007; 8:184-188. 


\begin{abstract}
Objective: The most accepted mechanism of Cervicogenic headache is referred pain from cervical structures innervated by the upper three cervical spinal nerves. The lateral atlantoaxial joint is not an uncommon cause of cervicogenic headache.

In this retrospective study, we examined the effect of lateral atlantoaxial intraarticular steroid injection in managing 32 patients with cervicogenic headache who have a clinical picture suggestive of atlantoaxial joint pain.
\end{abstract}

Design and Setting: The data were collected retrospectively by reviewing the patients' medical records and pain questionnaires.

Patients and Interventions: 115 patients with cervicogenic headache who were referred to our institute were identified. Of those patients, 32 had a clinical picture suggestive of atlantoaxial joint pain and subsequently underwent a diagnostic/therapeutic intra-articular block.

Results: $15 / 32$ patients $(46.8 \%)$ had a post-procedure pain score of 0 (95\% CI= 17.5 - 72.1\%). 26/32 patients (81.2\%) had a decrease in their post-procedure pain score of $50 \%$ or more $(95 \% \mathrm{CI}=62.4-97.6 \%)$. The mean pre-procedure pain score was 6.8 and post-procedure was 2.2 (Bonferroni adjusted $\mathrm{p}<0.001$ ). At 1 month and 3 months, the mean pain scores were 1.9 and 3.6 respectively $(\mathrm{p}<0.001$ and $\mathrm{p}<0.01$ respectively). However at 6 months, the mean pain score was 3.7 and this was not statistically significant $(p=0.2)$.

Conclusions: Lateral atlantoaxial intra-articular corticosteroid injections may provide short-term analgesia for patients with pain originating form the lateral atlantoaxial joint. 


\section{Introduction}

The most accepted mechanism of cervicogenic headache is referred pain from cervical structures innervated by the upper three cervical spinal nerves. ${ }^{1}$

The lateral atlanto-axial joint, which is innervated by the $\mathrm{C} 2$ ventral ramus, is not an uncommon cause of cervicogenic headache. It may account for $16 \%$ of patients with occipital headache. ${ }^{1}$ In human volunteers, distending the lateral atlanto-axial joint with contrast agent produces occipital pain and injection of local anesthetic into the joint relieves the headache.1,2

Clinical presentations suggestive of pain originating from the lateral atlantoaxial joint include: occipital or suboccipital pain, focal tenderness over the suboccipital area or over the transverse process of $\mathrm{C} 1$, restricted painful rotation of $\mathrm{C} 1$ on $\mathrm{C} 2$, and pain provocation by passive rotation of $\mathrm{C}$.

Clinical signs indicate that the lateral atlantoaxial joint may be a potential pain generator, but are not specific enough to conclusively establish the diagnosis. ${ }^{3}$ At best; these clinical signs have a positive predictive value of only $60 \% .{ }^{1} \mathrm{~A}$ diagnostic block with intra-articular injection of local anesthetic helps to confirm the presumptive diagnosis.

The lateral atlantoaxial joint has been previously suggested as a potential source of occipital headache.1, 2 However, to our knowledge, no published studies have examined the efficacy of lateral atlantoaxial intra-articular steroids for cervicogenic headaches.

\section{Methods}

After obtaining our institution research review board's approval, the data were collected retrospectively by reviewing the patients' medical records and pain questionnaires. In the period from January 2003 to June 2004, 115 patients with occipital headache were referred to our institute.

These patients were evaluated by a neurologist and headache specialist (JC). Of those patients, 32 had a clinical picture suggestive of atlanto-axial joint pain and subsequently underwent a diagnostic/therapeutic intra-articular block by one investigator (SN).

Those patients had intractable headaches, failed multiple pharmacological management (nonsteroidal antiinflammatory drugs, muscle relaxants, antiseizures, tricyclic antidepressants, opioids, etc.)

The blocks were performed using the classic intra-articular posterior approach under fluoroscopic guidance. The periarticular approach to the atlantoaxial joint may lack specificity, as local anesthetic may be deposited in the vicinity of the $\mathrm{C} 2$ spinal nerve root as it crosses the posterior middle aspect of 
the joint. Intra-articular block is more target -specific as it can selectively anesthetize the joint space.

Patients are placed in the prone position with standard monitors in place and a pillow under their chest to allow for slight neck flexion. The fluoroscopy $\mathrm{C}$ arm is brought to the head of the table in an anteroposterior direction. Under fluoroscopic guidance the $\mathrm{C}$ arm is rotated in the sagittal plane till the lateral atlantoaxial joint is better visualized with its biconcave appearance. Using a marking pen, the needle insertion site is marked on the skin overlying the lateral part of the atlantoaxial joint. The skin is prepped and draped in the usual sterile fashion and a skin wheel is raised with local anesthetic at the insertion site. Then a 24G 3-1/2 inches blunt needle (to minimize vascular entry) is advanced in anterior and medial direction towards the posterolateral aspect of the inferior margin of the inferior articular process of the atlas. This will avoid contact with the $\mathrm{C} 2$ nerve root and dorsal ganglion, which crosses the posterior aspect of the middle of the joint. After touching the bone to safely establish the correct depth, the needle is withdrawn slightly, directed towards the posterolateral aspect of the lateral atlantoaxial joint, and advanced for only few millimeters and usually a distinctive pop is felt signaling entering the joint cavity. At this point, a lateral view is obtained, which shows the tip of the needle in the middle of the joint anterior to the posterior margin of the joint. Careful attention should be paid to avoid the vertebral artery that lies lateral to the lateral atlantoaxial joint as it courses through the $\mathrm{C} 1$ and $\mathrm{C} 2$ foramina. After careful negative aspiration for blood or cerebrospinal fluid $0.2 \mathrm{ml}$ of water-soluble non-ionic contrast agent (Omnipaque 240) is injected to verify intra-articular placement of the tip of the needle.

Injection of the contrast agent is done under direct real-time fluoroscopy to check for inadvertent intraarterial injection which is manifest by rapid clearance of the contrast agent (the use of digital subtraction fluoroscopy adds to the accuracy of detecting intravascular access as negative aspiration is not reliable). Anteroposterior and a lateral view are obtained to insure that the contrast agent remained confined to the joint cavity without escape to the surrounding structures specially the epidural space or posteriorly to the $\mathrm{C} 2$ ganglion which will adversely affects the specificity of the block. The anteroposterior view usually demonstrates the bilateral concavity of the joint with the contrast material inside the joint space, and sometimes it shows that the lateral atlantoaxial joint space may communicate with that of the median atlantoaxial joint space. After careful negative aspiration, $1.0 \mathrm{ml}$ of a mixture of bupivacaine $0.5 \%$ and $10 \mathrm{mg}$ of triamcinolone is injected. This may trigger the patient's usual occipital headache. ${ }^{4,5}$ A positive response to the block was reported if there was complete relief of the patient's headache after the block at least for the duration of the local anesthetic.

The data collected included: demographic variables; onset and duration of the headache; clinical picture of the headache; pain score on a visual analogue 
scale pre-block and post-block; pain score on subsequent visits at 1,3,6 months; changes in the headache pattern, and any changes in the medications used.

\section{Results}

32 patients with clinical picture suggestive of atlantoaxial pain underwent lateral atlantoaxial intraarticular local anesthetic and steroid injection. There was no significant difference in the demographics between responders and nonresponders. There were no significant adverse events encountered in these patients other than transient mild ataxia in 4 patients.

$81.2 \%(26 / 32)$ had a decrease in their post-procedure pain score of $50 \%$ or more $(95 \% \mathrm{CI}=62.4-97.6 \%) .46 .8 \%(15 / 32)$ of the patients had complete relief of their headache with a post-procedure pain score of $0(95 \% \mathrm{CI}=17.5$ $72.1 \%$ ) and this is considered a positive response to the diagnostic block.

$40.6 \%$ (13/32) experienced exacerbation of their occipital headache during the injection. Of those 13 patients, 10 patients (77\%) had a positive response to the block.

The pre-procedure pain score was $6.8 \pm 0.5$ (mean $\pm \mathrm{SE}$ ). The pain score immediately following the procedure was $2.2 \pm 0.5(\mathrm{p}<0.001)$. The pain score at 1,3 , and 6 months post-procedure were $1.9 \pm 0.5(\mathrm{p}<0.001), 3.6 \pm 0.7(\mathrm{p}<$ $0.008)$ and $3.7 \pm 1.1(p=0.208)$ respectively. The $p$-values are Bonferroni adjusted $\mathrm{p}$-values from multiple paired t-tests compared with pre-procedure pain score.

The percentage of patients who had $>50 \%$ relief at 2 weeks, 1 month, and 3 months were $56.3 \%, 37.5 \%$ and $25 \%$ respectively. At the 9 month follow up visit, $16.6 \%$ (5/32) completely stopped their narcotic medications with marked improvement of their functional activity level (there were few other patients who continued to be on narcotics for other chronic pain conditions). Three patients had sustained complete headache resolution for the 9 month study period.

The estimated prevalence of lateral atlantoaxial joint pain in our patient population is about $13 \%$ (15/115 patients). However this may be an underestimation as not all the patients with cervicogenic headaches underwent the diagnostic block.

\section{Discussion}

The most accepted mechanism of cervicogenic headache is referred pain from cervical structures innervated by the upper three cervical spinal nerves. Thus the differential diagnosis of cervicogenic headache is: atlanto-occipital joint, 
median and lateral atlanto-axial joints, C2-3 intervertebral disc, C2-3 zygapophyseal joint, third occipital nerve, upper posterior neck and paravertebral muscles, the trapezius and the sternocleidomastoid muscles, spinal and posterior cranial fossa dura mater, cervical spinal nerves and roots and the vertebral artery. ${ }^{3}$

The spinal nucleus of the trigeminal nerve extends caudally to the outer lamina of the dorsal horn of the upper three to four cervical spinal segments. This is known as the trigeminocervical nucleus, which receives afferents from the trigeminal nerve as well as the upper three cervical spinal nerves.

Convergence between these afferents accounts for the cervical-trigeminal pain referral. Therefore, pain originating from cervical structures supplied by the upper cervical spinal nerves could be perceived in areas innervated by the trigeminal nerves such as the orbit and the fronto-temporo-parietal region.

Cervicogenic headache is defined as unilateral headache that is provoked by neck movement or pressure over tender points in the neck with associated reduced range of movement of the cervical spine. The headache occurs in nonclustering episodes and is usually nonthrobbing in nature, originating from the neck and spreading over the oculofrontotemporal regions. ${ }^{6-8}$

These clinical criteria are not enough to make a definite diagnosis of cervicogenic headache, as it is sometimes difficult to differentiate clinically between cervicogenic headache, migraine, and specially tension-type headache. ${ }^{9-11} \mathrm{Re}-$ sponse to diagnostic blockade of the nerve supply of these cervical structures or intraarticular injection of local anesthetic into the culprit joint is now considered the major criterion in the diagnosis of cervicogenic headache. ${ }^{12}$

The C2-3 zygapophyseal joint and the greater occipital nerve were extensively studied as a source of cervicogenic and occipital headache. ${ }^{13-17}$ However there are sparse reports about the lateral atlantoaxial joint.1,2

The criteria for diagnosis of atlanto-axial joint pain are: occipital or suboccipital pain, focal tenderness over the suboccipital area or over the transverse process of $\mathrm{C} 1$, restricted painful rotation of $\mathrm{C} 1$ on $\mathrm{C} 2$, and pain provocation by passive rotation of $\mathrm{C} 1$.

The major criterion in the diagnosis is the positive response to the intraarticular injection of local anesthetic. The pathology of lateral atlantoaxial joint pain is usually osteoarthritis or post-traumatic in nature. ${ }^{18,19}$ However the presence of osteoarthritic changes in imaging studies doesn't mean that the joint is necessarily painful, also the absence of abnormal findings doesn't preclude the joint from being painful. ${ }^{1}$ That is why we don't routinely order pre-block imaging study of the joints.

There is no conservative treatment for lateral atlanto-axial joint pain. However our data showed that intra-articular steroids might be effective in shortterm relief of pain originating from the lateral atlanto-axial joint. Long-lasting pain relief may require arthrodesis of the lateral atlanto-axial joint.20,21 
Currently there are insufficient data regarding long-term outcome after percutaneous radiofrequency lesioning of the lateral atlantoaxial joint. Further research of this technique may be warranted. 


\section{References}

1. Aprill C, Axinn MJ, Bogduk N. Occipital headaches stemming from the lateral atlanto-axial (C1-2) joint. Cephalalgia 2002; 22:15-22.

2. Busch E, Wilson PR. Atlanto-occipital and atlanto-axial injections in the treatment of headache and neck pain. Reg Anesth 1989; 14 (S2): 45.

3. Bogduk N. The neck and headache. Neurol Clin 2004; 22:151-171.

4. Dreyfuss P, Michaelson M, Fletcher D. Altanto-occipital and lateral atlanto-axial joint pain pattern. Spine 1994; 19:1125-1131.

5. Racz GB, Sanel H, Diede JH. Altanto-occipital and lateral atlanto-axial injections in the treatment of headache and neck pain. In Waldman S, Winnie A (eds): Interventional pain management. Philadelphia, WB Saunders, 1996, pp 220-222.

6. Sjaastad O, Saunte C, Hovdahl H. et al. Cervicogenic headache. A hypothesis. Cephalalgia 1983; 3:249-256.

7. Fredriksen TA, Hovdal H, Sjaastad O. Cervicogenic headache: clinical manifestation. Cephalalgia 1987; 7:147-160.

8. Sjaastad 0. Fredriksen TA, Pfaffenrath V. Cervicogenic headache: diagnostic criteria. Headache 1990; 30:725-726.

9. Leone M, D'Amico D, Moschiano F, et al. Possible identification of cervicogenic headache among patients with migraine: an analysis of 374 headaches. Headache 1995; 35:461-464.

10. Leone M, D'Amico D, Grazzi L, et al. Cervicogenic headache: a critical review of the current diagnostic criteria. Pain 1998; 781-5.

11. Suijlekom JA, de Vet HCW, van den Berg SGM, Weber WEJ. Interobserver reliability of diagnostic criteria for cervicogenic headache. Cephalgia 1999; 19:817-823.

12. Sjaastad 0. Fredriksen TA, Pfaffenrath V. Cervicogenic headache: diagnostic criteria. Headache 1998; 38:442-445.

13. Inan $\mathrm{N}$, Ceyhan $\mathrm{A}$, Inan $\mathrm{L}$, et al. $\mathrm{C} 2 / \mathrm{C} 3$ nerve blocks and greater occipital nerve block in cervicogenic headache treatment. Funct Neurol 2001; 16:239-243.

14. Bovim G, Berg R, Dale LG. Cervicogenic headache: anesthetic blockade of cervical nerves (C2-C5) and facet joints (C2/C3). Pain 1992; 49:315-320.

15. Traver-Jones R. Osteoarthritis of the paravertebral joints of the second and third cervical vertebrae as a cause of occipital headache. South Afr Med J 1964; 30: 392-394.

16. Bogduk N, Marshland A. On the concept of third occipital headache. J Neurol Neurosurg Psychiat 1986; 49:775-780.

17. Lord S, Barnsley L, Wallis B, Bogduk N. Third occipital headache: a prevalence study. J Neurol Neurosurg Psychiat 1994; 57:1187-1190.

18. Ehni G, Benner B. occipital neuralgia and the C1-2 arthrosis syndrome. J Neurosurg 1984; 61:961-965.

19. Schonstorm N, Twomey L, Taylor J. The lateral atlanto-axial joints and their synovial folds: an in vitro study of soft tissue injury and fractures. J Trauma 1993; 35:886-892.

20. Joseph B, Kumar B. Gallie's fusion for atlantoaxial arthrosis with occipital neuralgia. Spine 1994; 19:454-455.

21. Ghanayem AJ, Leventhal M, Bohlman HH. Osteoarthrosis of the atlantoaxial joints- long term follow up after treatment with arthrodesis. J Bone Joint Surg Am 1996; 78: 1300-1307. 


\section{Chapter 7 \\ Ultrasound-guided Atlanto-axial Joint Injection}

Samer Narouze, MD, MSc

Narouze S.Ultrasound-guided atlanto-axial joint injection. In: Narouze SN, ed. Atlas of Ultrasound-Guided Procedures in Interventional Pain Management. 1st ed. New York, NY: Springer; 2011:353-357.

Narouze S. Ultrasound-guided Atlanto-axial joint injection for the treatment of cervicogenic headache(Abstract). Pain Med 2009; 10:222. 
CHAPTER 7 


\section{Introduction}

The atlanto-axial joint accounts for up to $16 \%$ of patients with occipital headache. In human volunteers, distending the lateral atlanto-axial joint with contrast agent produces occipital pain and injection of local anesthetic into the joint relieves the headache. ${ }^{1,2}$

The clinical presentation of atlanto-axial joint pain is not specific and therefore cannot be used alone to establish the diagnosis. The only means of establishing a definite diagnosis is a diagnostic block with intra-articular injection of local anesthetic. ${ }^{1}$

As we demonstrated in the previous chapter intra-articular steroids are effective in short-term relief of pain originating from the lateral atlanto-axial joint. $^{3}$ The major complication and limitation of the fluoroscopy guided approach is the inability to identify and hence avoid vertebral artery injury. Here we are describing a new ultrasound guided approach that will add more safety to the procedure.

\section{Anatomy of the Atlanto-axial joint (AAJ)}

Atlanto-axial and atlanto-occipital joint intra-articular injections have the potential for serious complications; so it is imperative to be familiar with the anatomy of those joints in relation to the surrounding vascular and neural structures. The vertebral artery lies lateral to the atlanto-axial joint as it courses through the C2 and $\mathrm{C} 1$ foramina. Then it curves medially to go through the foramen magnum crossing the medial posterior aspect of the atlanto-occipital joint.

The C2 dorsal root ganglion and nerve root with its surrounding dural sleeve cross the posterior aspect of the middle of the joint. Therefore, during atlanto-axial joint injection, the needle should be directed toward the posterolateral aspect of the joint. This will avoid injury to the $\mathrm{C} 2$ nerve root medially or the vertebral artery laterally. On the other hand, the atlanto-occipital joint should be accessed from the most superior posterior lateral aspect to avoid the vertebral artery medially. Meticulous attention should be paid to avoid intravascular injection as the anatomy may be variable. Inadvertent puncture of the C2 dural sleeve with CSF leak or high spinal spread of the local anesthetic may occur with atlanto-axial joint injection if the needle is directed only few millimeters medially. 4

Ultrasound allows visualization of soft tissues, nerves, and vessels (abnormal anatomy), which has the potential to improve the safety of atlanto-axial and atlanto-occipital joint injections by decreasing the incidence or by avoiding injury of nearby structures. ${ }^{5}$ 


\section{Ultrasound-guided atlanto-axial joint (AAJ) injection technique}

The procedure is performed with the patient in the prone position, using a highfrequency ultrasound transducer (low-frequency transducer may be used depending on body habitus). A transverse short-axis view is obtained by applying the transducer in the midline over the occiput and then scanning caudally to identify C1-2 level. C1 lacks a spinous process and the first bifid spinous process encountered is $\mathrm{C} 2$.

Then the transducer is moved laterally till the $\mathrm{C} 2$ nerve root and dorsal root ganglion (DRG) is seen, more laterally the C1-2 joint (AA joint) appears in the image between the C2 DRG medially and the vertebral artery laterally (Fig. 1-3). The transducer is adjusted so that the AA joint is in the middle of the picture and a 22-gauge blunt-tip needle is advanced usually out-of-plane under real-time ultrasound guidance to target the AA joint just medial to the vertebral artery (Fig. 4). The transducer is then shifted to obtain a longitudinal scan at the C1-2 joint and the needle tip may need to be adjusted slightly to enter the joint cavity under vision. ${ }^{6}$

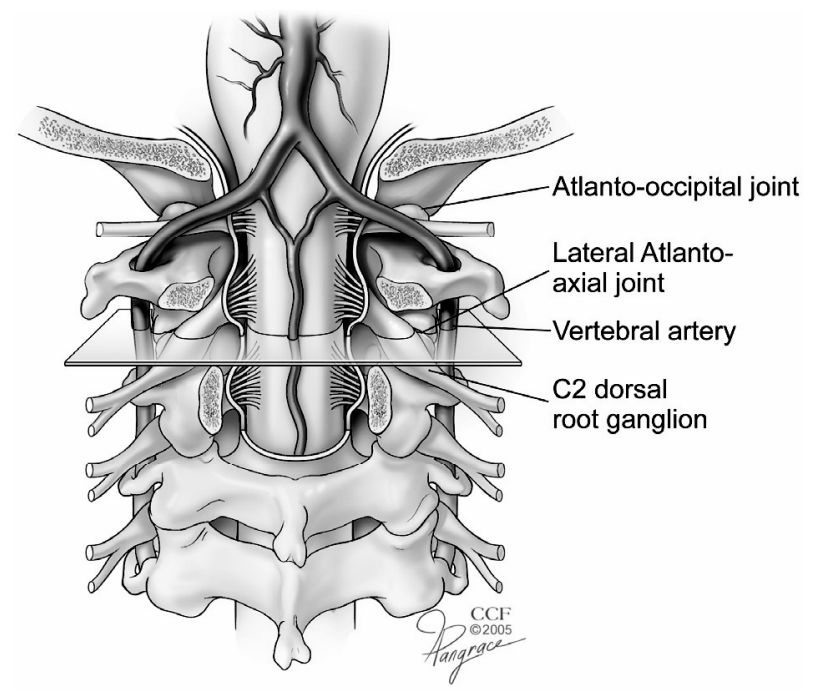

Figure 1:

Illustration showing the ultrasound transducer in the transverse plane over the atlantoaxial joint to obtain a shortaxis view. 


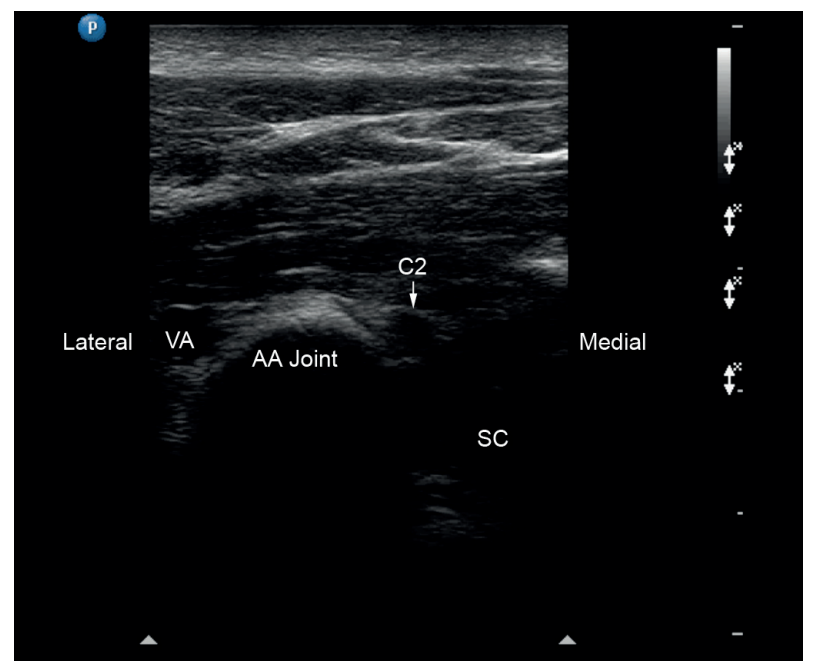

\section{Figure 2:}

Short-axis sonogram at the level of AA joint. VA, vertebral artery; C2, C2 nerve root and dorsal root ganglion; AA joint, atlanto-axial joint; SC, spinal cord.

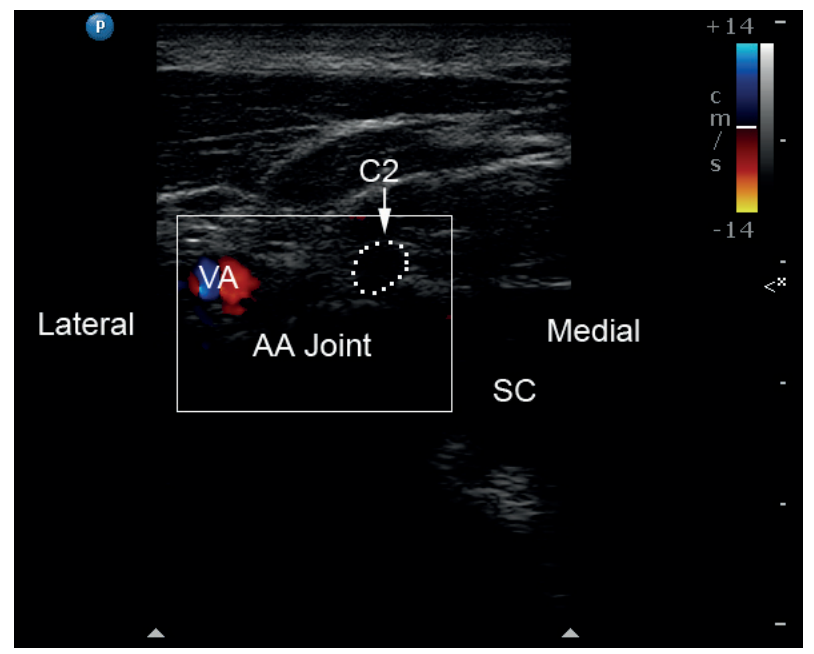

\section{Figure 3:}

Short-axis sonogram with Doppler to show the vertebral artery (VA) just lateral to the atlanto-axial joint (AA joint) C2, C2 nerve root and dorsal root ganglion; SC. spinal cord. 


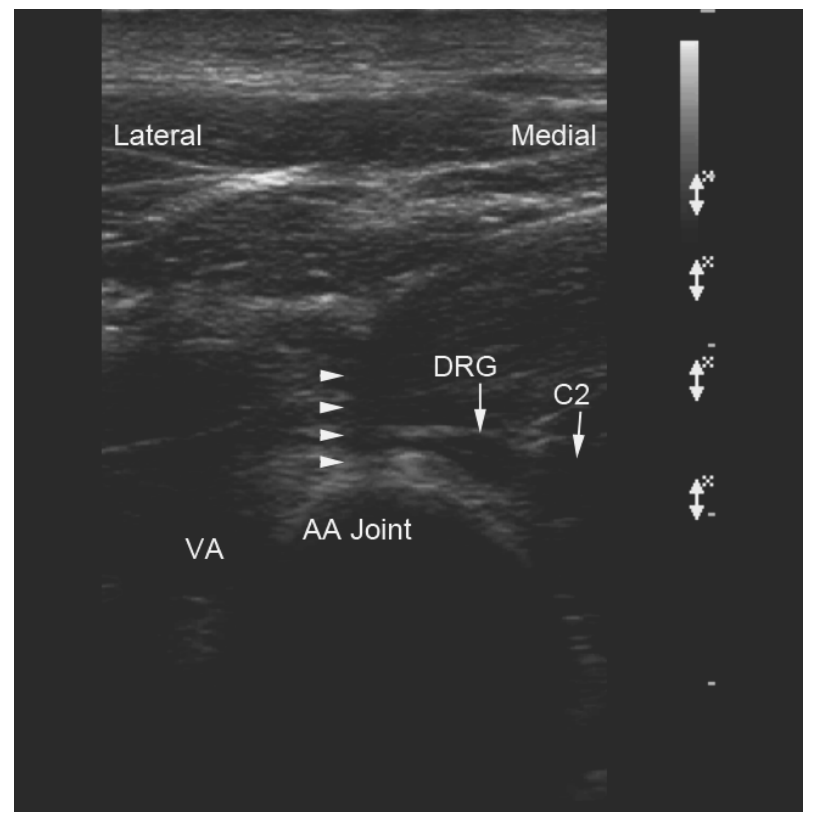

\section{Figure 4:}

Short-axis sonogram showing the needle (out of plane) inside the atlanto-axial joint (arrowheads). VA, vertebral artery; C2, C2 nerve root; DRG, C2 dorsal root ganglion; AA joint, atlanto-axial joint.

Alternatively, a longitudinal midline scan can be obtained by applying the transducer vertically in the midline over the occiput and cervical spinous processes and C1-2 level is identified as above. Then the transducer is moved laterally till the C1-2 joint (AA joint) appears in the image, slightly laterally one can identify the vertebral artery. The needle is introduced just caudal to the transducer and advanced in-plane under real-time ultrasound guidance to target the AA joint just medial to the vertebral artery

The author prefers the short-axis view (although, it is out of plan approach) as in the same image one can see the needle advancement - with real time ultrasonography - into the joint between the C2 DRG medially and the vertebral artery laterally.

\section{Conclusion}

Ultrasound allows direct visualization of soft tissue structures and may play an important role in performing such high risk procedures as atlanto-axial joint injections. It may improve the safety of atlanto-axial joint injections by avoiding injury of nearby structures (vertebral artery and C2 dorsal root ganglion). Further prospective studies are needed to confirm the safety and reproducibility of the described technique. 


\section{References}

1. Aprill C, Axinn MJ, Bogduk N. Occipital headaches stemming from the lateral atlanto-axial (C1-2) joint. Cephalalgia 2002; 22:15-22.

2. Busch E, Wilson PR. Atlanto-occipital and atlanto-axial injections in the treatment of headache and neck pain. Reg Anesth 1989; 14(S2):45.

3. Narouze SN, Casanova J, Mekhail N. The longitudinal effectiveness of lateral atlanto-axial intraarticular steroid injection in the management of cervicogenic headache. Pain Med 2007; 8:184188.

4. Narouze S. Complications of head and neck procedures. Tech Reg Anesth Pain Manag 2007; 11:171-177.

5. Narouze S. Ultrasonography in pain medicine: future directions. Tech Reg Anesth Pain Manag 2009; 13:198-202.

6. Narouze S. Ultrasound-guided lateral atlanto-axial joint injection for the treatment of cervicogenic headache (abstract). Pain Med 2009; 10:222. 



\title{
Chapter 8 \\ USPM Education and Training Recommendations
}

\author{
Samer Narouze, MD, MSc \\ David Provenzano, MD \\ Philip Peng, MBBS, FRCPC \\ Urs Eichenberger, MD \\ Sang Chul Lee, MD, PhD \\ Bernhard Morrigl, MD
}

Narouzs S, Provenzano D, Peng P, Eichenberger U, Lee SC, Morrigl B. The American Society of Regional Anesthesia and Pain Medicine, the European Society of Regional Anesthesia and Pain Therapy, and the Asian Australasian Federation of Pain Societies Joint Committee Recommendations for Education and Training in Ultrasound-Guided Interventional Pain Procedures. Accepted for publication pending revision. Reg Anesth Pain Med 2012. 
CHAPTER 8 


\section{Introduction}

Ultrasonography in pain medicine (USPM) is a rapidly growing medical field in interventional pain management. In the last few years, there has been substantial growth in the interest in USPM as evidenced by the remarkable increase in the publication of literature on ultrasound guided injections and by the growing number of workshops offered at large national and international meetings. ${ }^{1-5}$ Traditionally, axial, non-axial, and musculoskeletal interventional pain procedures have been performed with either landmark or fluoroscopy and computed tomography (CT) image guided techniques. Both of these methods have limitations.

Landmark based techniques do not allow for confirmation of the appropriate placement of the needle and subsequent injectate around a targeted structure. Also, critical structures (e.g. blood vessels and pleura) cannot be visualized as one advances the needle. Many of the landmark based techniques are associated with high failure rates which may stem from the variable anatomical courses of the targeted structures from the chosen landmarks. ${ }^{4,6,7}$ Traditional visualization techniques for interventional pain procedures have included fluoroscopy and computed tomography (CT), both of which are associated with ionizing radiation. Radiation exposure to both patients and healthcare providers from diagnostic and interventional procedures is receiving greater attention from the medical community. Since the 1980s the per capita dose of radiation for medical imaging has increased by factor of 6.8 The FDA has received reports of interventional pain physicians developing radiation skin injuries from performing pain procedures. ${ }^{9}$ Furthermore, the long-term adverse effects and biological consequences of cumulative exposure to low dose radiation remain unclear. Soft tissues cannot be directly visualized with fluoroscopy. With fluoroscopic guided procedures, the initial extrapolation of the position of soft tissues (i.e. muscles, blood vessels, and nerves) is based on their anatomic relationship to the viewed bony structures.

Increased utilization of ultrasound for interventional pain procedures has originated from specific advantages including the ability to: 1) visualize soft tissues including muscle layers, nerves, and blood vessels; 2 ) visualize real-time needle advancement; and 3) reduce radiation exposure to both the patient and healthcare provider. ${ }^{1,2}$ Ultrasound allows the practitioner to choose a needle trajectory which may limit the risk of intravascular injection and to use smaller volumes of injectate which may limit spread to non-targeted nearby structures. Other advantages with ultrasound include reduced equipment costs and improved portability in comparison to fluoroscopy, CT scan, and magnetic resonance imaging machines. ${ }^{1,2}$

In order to select clinical scenarios where USPM is warranted and safe, pain physicians performing USPM need to understand the current limitations of ultrasound for specific procedures. Limitations to current ultrasound technology 
include narrow image windows, limited resolution with increasing depth, and acoustic shadow artifact.10,11 Acoustic shadow artifact results in the inability to view structures deep to the bony elements. This artifact results from the large attenuation coefficient associated with bone which causes the tissue below to appear less echogenic. Additionally patient factors such as degenerative changes and body habitus may negatively affect image quality. ${ }^{12}$ In order to visualize deep structures, a low frequency curved array probe is used which provides the ability for deeper penetration but sacrifices image resolution. Because the ultrasound beam width is narrow, visualizing the needle tip requires a significant degree of technical skill that is operator dependent.

The visual limitations associated with ultrasound are most obvious in the interlaminar epidural and intrathecal blocks. ${ }^{1,13}$ For these neuraxial procedures ultrasound does not offer the same quality of visual information for detection of intravascular injections that can be obtained with the use of real-time fluoroscopy and digital subtraction technology.1,2 When performing neuraxial blocks ultrasonography does not allow for visualization of the spread of injectate or the recognition of vascular uptake. ${ }^{1}$ Therefore, at this point in time, the use of ultrasound cannot be recommended as the sole visualization technique for these procedures in chronic pain medicine..$^{1,2}$ In some cases it may be viewed as an adjunct (e.g. pre-intervention scan) to assist fluoroscopically guided procedures. ${ }^{14}$

In 1999, recognizing the rapid growth in the clinical use of ultrasound, the AMA drafted resolution 802 stating that "the AMA affirms that ultrasound imaging is within the scope of practice of appropriately trained physicians." 15 In an effort to safely advance the progression of ultrasound in clinical medicine, the resolution recommended that medical fields utilizing ultrasound develop specialty specific guidelines. Furthermore, the AMA recommends that hospitals grant ultrasound privileges based on the scope of practice defined in each specialties' guidelines. Multiple examples exist for ultrasound specialty specific guidelines. For example, in 2001The American College of Emergency Physicians approved comprehensive guidelines for the use of ultrasound in emergency medicine. ${ }^{16}$ These guidelines were later updated in 2008. ${ }^{17}$ Recently, the recommendations for scope of practice for the use of ultrasound in regional anesthesia have been developed. ${ }^{18}$ MSK guidelines and course training recommendations have been published. ${ }^{19,20}$ To date no specialty specific guidelines exist for USPM.

Due to the rapid growth in the utilization, research and advancement of USPM, it is important to define the current scope of practice for USPM. The following document represents an international collaborative effort. Assigned pain physicians from the Special Interest Group on Ultrasonography in Pain Medicine from both the American Society of Regional Anesthesia and Pain Medicine, the European Society of Regional Anesthesia and Pain Therapy, and the Australasian Federation of Pain Societies developed the following recommendations to define 
the scope of best practice for USPM, the teaching curriculum, and the algorithms for the implementation of USPM into clinical practice. Committee members were selected based on clinical and research expertise in both the technical and educational components of USPM. Members included practitioners from both academic and private practice. An open forum was held at the 2011 ASRA Pain Medicine Meeting to acquire input on the draft recommendations. For the recommended technique for each specific procedure in USPM, all relevant current research was evaluated and reviewed. The document should be viewed as an extension to the previously published recommendations for the education and training in ultrasound guided regional anesthesia. ${ }^{18}$ Specifically, the objectives of the guidelines are listed below.

1. Describe the core tasks, competencies and skills required when performing an US-guided pain procedure.

2. Define and develop a process for the proper education and training in USPM for established practitioners, residents, and fellows.

3. Highlight and outline the current recommended ultrasound technique for key interventional procedures in USPM.

4. Develop a quality improvement process that encourages and advances the integration of USPM into clinical practice.

The target audience for these guidelines is all clinicians performing USPM. The recommendations will provide a framework for educators, practicing pain physicians, and trainees interested in learning and implementing USPM. Although the below recommendations received unanimous agreement from ASRA/ESRA/Asian Australasian federation of Pain Societies and committee members, it is important to recognize that evidence based medicine is currently lacking for certain areas in USPM. ${ }^{2}$ Therefore, some of the suggestions and recommendations in this document represent the opinions and clinical experience of the committee members. As the field of USPM matures and expands these recommendations will need to be periodically reviewed and updated when appropriate based on new clinical experience and research knowledge. As our knowledge level increases, some of the material presented here may be discovered to be inaccurate.

\section{Indications and Scope of Practice}

Ultrasonography in pain medicine is used to facilitate the performance of various pain procedures as it allows for visualization of real-time needle advancement, and soft tissue structures as well as bony surfaces without radiation exposure. Noninvasively, ultrasonography can identify individual typical and atypical anatomy and structural pathologies. ${ }^{21,22}$ Furthermore, ultrasonography provides 
the unique opportunity to perform dynamic examination of the target in contradistinction to fluoroscopy, CT, or MRI.

Ultrasound-guided pain procedures are performed by pain physicians and the committee members identified the following tasks to be helpful in performing an ultrasound-guided pain block. These tasks are not necessarily sequential and may not be appropriate for all block scenarios.

1. Maintain an aseptic technique, including probe sterility, throughout the procedure (Appendix 1).

2. Perform a systematic scan that allows for the confirmation of normal anatomy and recognition of structural pathologies and anatomic variations.

3. Visualize key landmark structures including nerves, blood vessels, pleura, muscles, tendons, fascia, and bone. Use the Doppler functions to identify vascular structures.

4. Identify the target on short-axis imaging (preferred) or long-axis imaging (if applicable).

5. Plan for a safe needle approach that avoids unnecessary tissue trauma or injury to other surrounding structures.

6. Follow the tip of the needle under real-time visualization as it advances toward the target.

7. Consider injecting an initial small volume of a test solution. If the solution is not visualized during injection, presume that the needle tip is either intravascular or out of the imaging plane.

8. Monitor the spread of the injectate under real-time visualization and make necessary needle adjustments if an undesired pattern of injectate spread is visualized. The visualization of the injectate should be monitored throughout the injection to avoid intravascular injection and to limit its spread to non-targeted adjacent structures.

9. When performing musculoskeletal procedures avoid intratendinous corticosteroid injections and needle damage to articular cartilage.

10. Maintain traditional safety guidelines including the presence of standard monitoring and resuscitation equipment.

11. When applicable, consider a secondary confirmation technique, such as fluoroscopy.

12. Maintain appropriate ultrasound ergonomics.

13. Maintain appropriate documentation and image storage with an archival system (Appendix 2).

\section{Contraindications}

There are no known absolute contraindications to the use of ultrasound. With respect to safety, the Food and Drug Administration (FDA) has stated, "Even 
though there are no known risks, ultrasound energy heats the tissues and may have other biologic effects. It can also produce small pockets of gas in body fluids or tissues (cavitation). The long-term effects of tissue heating and cavitation are not known." ${ }^{33}$ Doppler modes may result in higher exposure levels. The pain physician should limit and minimize the use of ultrasound to only the time necessary to perform each procedure. ${ }^{24}$

\section{Procedures}

Ultrasound had a wide variety of applications in interventional pain medicine (peripheral, spinal or axial, and musculoskeletal (MSK) applications, (Table 1).

Table 1: Common USPM Applications and Anatomical Targets

\begin{tabular}{lll}
\hline Peripheral structure & Axial structure & MSK applications \\
\hline Greater occipital nerve & Cervical-Nerve root & Large joints injection \\
Stellate ganglion block & Cervical-Third occipital nerve (TON) & Intermediate joint \\
Intercostal nerves & Cervical -facet periarticular & Small joints \\
$\begin{array}{l}\text { Suprascapular nerve } \\
\text { Iliohypogastric/ilioinguinal } \\
\text { nerve/TAP block }\end{array}$ & Cervical-medial branch & Joint aspiration \\
Lateral femoral cutaneous nerve & Thoracic paravertebral block & Ligaments \\
$\begin{array}{l}\text { Celiac plexus block } \\
\text { Inguinal Canal block }\end{array}$ & Lumbar-medial branch & Peri-tendonous injections \\
Pudendal nerve & SIJ-periarticular & Intramuscular/TPI/Botox \\
Other UE/LE peripheral nerves & Interlaminar epidural** & Bursa injection \\
\hline
\end{tabular}

SIJ: sacroiliac joint; TPI: trigger point injection; TAP: transversus abdominis plane

** refer to the limitations section

The Joint Committee recognizes that there are different levels of difficulty for the various pain procedures (Table 2A, 2B). Characteristics that tend to increase the level of difficulty include:

(1) Deep blocks resulting in the degradation of both the ultrasound and needle image,

(2) Blocks that have the potential for serious complications (e.g. unintentional intravascular injection, pneumothorax),

(3) Blocks that involve small nerves that are difficult to image,

(4) Patient-related factors such as obesity, degenerative, and arthritic changes. 
Table 2A: Scoring Criteria for the Level of Block Difficulty

For each block, the total score based on the following 4 criteria:

Ease of visualization of target structures 1-easy; 2-intermediate; 3-difficult

Ease of visualization of identifying structures 1-easy; 2-intermediate; 3-difficult

Technical performance of block

1-easy; 2 -intermediate; 3 -difficult

Risk of complication from associated structures

1-low; 2 -intermediate; 3-high

Table 2B: Assigned Level of Difficulty for Specific Ultrasound-Guided Pain Interventions

\begin{tabular}{|c|c|}
\hline \multicolumn{2}{|c|}{ Peripheral structures } \\
\hline Level I* & GON (nuchal level), SSN, II/IH, peripheral nerves/neuroma \\
\hline Level II* & GON (C2 level), SGB, ICN, LFCN, Inguinal canal block, pudendal \\
\hline Level III* & $\mathrm{CPB}$ \\
\hline \multicolumn{2}{|c|}{ Axial Structures } \\
\hline Level I & SIJ-periarticular, Caudal, Sacral foramen \\
\hline Level II & $\begin{array}{l}\text { C-nerve root, C-facet periarticular, Thoracic paravertebral, L-medial branch, L- } \\
\text { facet periarticular, Interlaminar epidural }\end{array}$ \\
\hline Level III & C-TON, C- medial branch \\
\hline \multicolumn{2}{|l|}{ MSK } \\
\hline Level I & $\begin{array}{l}\text { Joints injection and aspiration, Bursa, ligaments, Intramuscular, and periten- } \\
\text { denous injections }\end{array}$ \\
\hline Level II & Fenestration and lavage \\
\hline Level III & N/A \\
\hline
\end{tabular}

*The level of difficulty was appraised based on 4 criteria (List in Table 2A above). The summation of the scores from these 4 criteria result in the summary score: Level I (Basic) is 4 to 6; Level II (Intermediate) is 7 to 9; and Level III (Advanced) is 10-12.

\section{Proficiency}

Various skills are required to ensure an appropriately conducted ultrasoundguided pain procedure. These skills can be divided into five major categories: (1) understanding ultrasound system operations, (2) image optimization, (3) image interpretation based on profound knowledge of sonoanatomy, (4) visualization of needle approaching the target, (5) monitoring the spread of the injectate. For each one of these categories, the Joint Committee recognizes a defined skill set. These skill sets are explained in Table 3. 
Table 3: Required Skills for Ultrasound Guided Pain Medicine Procedure Proficiency Adapted with modifications from the reference 18 .

\begin{tabular}{|c|c|c|c|}
\hline $\begin{array}{l}\text { Ultrasound System } \\
\text { Operations }\end{array}$ & Image Optimization & $\begin{array}{l}\text { Identification and } \\
\text { Interpretation of Image }\end{array}$ & Procedural Technique \\
\hline Frequency & Probe selection & $\begin{array}{l}\text { Define relevant anatomical } \\
\text { structures }\end{array}$ & $\begin{array}{l}\text { Standardization of image } \\
\text { orientations }\end{array}$ \\
\hline Depth \& focus settings & $\begin{array}{l}\text { Transducer } \\
\text { pressure }\end{array}$ & $\begin{array}{l}\text { Recognition of anatomical } \\
\text { variations and structural } \\
\text { pathologies }\end{array}$ & Probe sterility \\
\hline $\begin{array}{l}\text { Gain \& time gain } \\
\text { compensation settings }\end{array}$ & $\begin{array}{l}\text { "PART" probe } \\
\text { placement* }\end{array}$ & $\begin{array}{l}\text { Recognition of vascular } \\
\text { structures }\end{array}$ & Appropriate ergonomics \\
\hline B-mode & Dynamic imaging & $\begin{array}{l}\text { Recognition of anatomic } \\
\text { artifacts }\end{array}$ & In plane needle insertion \\
\hline $\begin{array}{l}\text { Tissue harmonic } \\
\text { imaging }\end{array}$ & Needle selection & $\begin{array}{l}\text { Recognition of acoustic } \\
\text { artifact }\end{array}$ & $\begin{array}{l}\text { Out of plane needle } \\
\text { insertion }\end{array}$ \\
\hline Color Doppler & & $\begin{array}{l}\text { Selection of safe needle } \\
\text { trajectory }\end{array}$ & Needle tip identification \\
\hline Power Doppler & & & Hydrolocalization \\
\hline $\begin{array}{l}\text { Image acquisition \& } \\
\text { storage }\end{array}$ & & & $\begin{array}{l}\text { Monitoring injectate } \\
\text { spread }\end{array}$ \\
\hline
\end{tabular}

*PART $=$ pressure, alignment, rotation and tilting

\section{Training}

Two pathways have been developed for USPM training. The first pathway, the practice-based pathway, has been designed to assist current practicing pain specialists with formal pain training that require additional education to become proficient and adequately educated in USPM. The second pathway, the fellowship-based pathway, has been developed to structure ultrasound education for graduate medical training and to develop criteria for fulfilling pain medicine training requirements. Both pathways will include didactics, practical hands-on training, competency assessment, and performance improvement. After completion of the appropriate pathways, steps must be taken to maintain clinical competency (cognitive and technical skills) through continuing medical education and sustained performance of US examinations and procedures. The committee has not provided specific recommendations for a minimum number of procedures for each technique that are required to achieve the appropriate level of competency. The minimum number of required procedures will depend on the complexity of the procedure and the individual's level of education and expertise. 


\section{Practice Pathway Recommendations}

The Joint Committee recognizes the existence of different practice patterns (i.e., private vs academic), varying institutional processes for adopting new technology and techniques, and individual styles of learning. As such, several options are available for the established practitioner to begin to acquire the skill sets associated with USPM.

1. Participation in an accredited Continuous Medical Education (CME) event in which the skill sets listed under the proficiency section are covered. It is recommended that these educational events include both didactic and hands-on experience, with duration of at least 16 hours. Additional educational resources are available including Web-based training, video, lectures, textbooks, and simulator-based programs. These materials can help supplement the information learned during the CME activity.

2. Practice ultrasound scanning techniques and learn sonoanatomy by imaging oneself and colleagues.

3. Practice needle insertion techniques using simulators, phantoms, and cadavers.

4. Whenever possible, spend time with experienced individuals observing and learning techniques of USPM.

5. The Joint Committee recommends that the novice's initial clinical experience be mentored and supported by an individual experienced in USPM.

During the initial exposure to USPM, the Committee recommends that a procedure log be maintained with documentation of procedure success and complications including intravascular injection, nerve injury, infection, and pneumothorax.

The Joint Committee recommends that individuals who engage in USPM have significant exposure to continuing education. Many formats for continuing education exist such as departmental conferences, review courses, self-study, preceptorships, hands-on training courses, and other CME established formats. The CME attendance should be in accordance with specialty and local guidelines. In addition, following initial exposure to USPM, continual use of ultrasound skills is recommended to maintain proficiency and personal comfort level with performing USPM.

\section{Fellowship-Based Pathway Recommendation}

A fellowship-based pathway should be the primary mode for pain medicine fellows to attain competency in USPM during Accreditation Council for Graduate Medical Education (ACGME) accredited or equivalent programs. The training 
program should incorporate the 6 core competencies as defined by the ACGME (Appendix 3).

The didactic component should consist of the fellow completing a defined USPM curriculum that addresses the following 4 major categories: (1) understanding system operations, (2) image optimization, (3) image interpretation based on profound knowledge of sonoanatomy, and (4) visualization of needle insertion and injection as described under the Proficiency section. Pain medicine fellowship program directors should have flexibility to present the curriculum over the duration of the fellowship period. Additionally, ultrasound training may further occur through coordination with the ultrasound-guided regional anesthesia service. The recommended curriculum is provided in Appendix 4.

The Joint Committee recommends that each fellow perform enough ultrasound-guided blocks to satisfy the attainment of the aforementioned core competencies and skill sets. The Joint Committee also recommends that each fellow have exposure to varying types of pain procedures including axial, peripheral, and MSK applications. Each fellow should keep a database log of his or her procedures. Fellows are encouraged to record and store static images and video clips of the critical aspects of each procedure. The fellow should periodically review static images and video with appropriate supervision to confirm proper scanning and needle insertion techniques. Performance steps for the most common ultrasound-guided pain procedures are provided in Appendix 5.

\section{Quality Improvement}

Continuous quality improvement (CQI) is integral to the safe and appropriate use of USPM. CQI evaluates multiple parameters including knowledge of relevant anatomy, ultrasound equipment, and procedural technique. In addition the process implemented should be able to identify procedural technical competency and appropriate image interpretation. The evaluation should also include a competency assessment which monitors the performance of procedures in a safe and efficient manner. The process should provide constructive and timely feedback to both practicing physicians and trainees. Complication rates should also be tracked and monitored. Processes for the quality assurance in the USPM program may include reviews of still images and videos from a procedural database and/or direct supervision of procedures. Specific individuals at each institution may be appointed to oversee the quality assurance/improvement program. A method to ensure continuous professional development should also be in place.

Ultrasound equipment should be periodically inspected per the manufacturer's recommendations by each institution's biomedical engineering department to ensure the machines are in appropriate working condition. Institutional 
and national standards need to be followed for the cleaning and disinfection of the US equipment (Appendix 1).

\section{Credentialing and Privileging}

Specific recommendations have not been provided for the credentialing or privileging of individual practitioners to perform USPM. The process of credentialing and authorizing clinical privileges will depend on individual institution and department policies. The training requirements provided in this document serve as a foundation for the appropriate education of clinicians performing USPM. In order to promote the safe and effective practice of USPM, the Joint Committee does recommend that the preceding training guidelines for the practice-based and the fellowship-based pathways be met prior to granting hospital-based privileges.

\section{Ultrasound Research for Interventional Pain Procedures}

Currently, a majority of the research on ultrasound for interventional pain medicine consists of a small case series, observational, feasibility, and technical studies. ${ }^{2,3}$ Randomized control trials do exist for lumbar facet intraarticular injections and some musculoskeletal applications. ${ }^{2,25}$ Future larger scale studies are needed on the safety and efficacy of ultrasound-guided techniques in chronic pain management with direct correct comparison to landmark based and fluoroscopy guided techniques. Attention should also be directed in study design to humanistic (e.g. associated procedural pain) and economic outcomes.

\section{Limitations and Challenges of Ultrasound for USPM}

Despite various advantages, ultrasound imaging has several limitations. The technique and the image are quite operator dependent. Patient characteristics such as obesity and degenerative changes may also negatively limit the quality of the ultrasound image. The practitioner requires experience to obtain a good image and direct the needle safely to the target structure. Furthermore, the quality of the image in certain areas is poor. This is particularly true in the visualization of axial or spine structures where an acoustic shadow artifact is produced by bone, which has a high attenuation coefficient. Also visualization of deep structures is also suboptimal because a low-frequency probe is commonly used in these situations, and the resolution is inferior to that provided by a high- 
frequency probe. Another limitation is the visualization of a thin needle or a needle inserted at a steep angle.

The inability to detect intravascular injection and the spread of the injectate significantly limits the utilization of ultrasound for neuraxial procedures (interlaminar epidural and intrathecal blocks). Although US-assisted neuraxial block may be more advantageous than the traditional blind surface-landmark approach that is used in regional and obstetric anesthesia, at this time the sole use of ultrasound for these blocks for interventional chronic pain management cannot be recommended. ${ }^{1}$ Significant and devastating complications have occurred with transforaminal epidural steroid injections including death, brain, and spinal cord injuries. In certain areas such as the cervical spine, ultrasound guidance may have the ability to increase the safety of periradicular injections due to its ability to detect vascular structures, although future efficacy and safety studies are needed. In addition critical vessels that are small in the region of the cervical spine may still not be identified by current ultrasound technology. ${ }^{14}$ These procedures should only be performed by highly trained individuals with a detailed understanding and appreciation of the risk/benefit profile of the procedure for each respective patient. Real-time fluoroscopy with radiographic contrast and digital subtraction and contrast fluoroscopy still remain the current standard of practice to detect intravascular injection with neuraxial blocks.

\section{Conclusions}

Ultrasound guidance for chronic pain procedures is rapidly evolving. The goal of Joint Committee's recommendations is to promote the safe and the efficacious utilization of ultrasound for pain medicine procedures. The Joint Committee's recommendations and training guidelines provide a structure for attaining and maintaining proper levels of competency, proficiency, and quality improvement for USPM. The use of ultrasound for the performance of peripheral nerve blocks, axial blocks, and MSK is within the scope of practice of an appropriately trained pain physician. 


\section{APPENDIX 1: \\ Techniques for Probe Handling and Sterility}

When performing ultrasound-guided interventional pain procedures aseptic technique should be followed. Both ultrasound coupling gel and transducers can be sources of nosocomial infection. ${ }^{26,27}$ Below are the listed steps for maintaining ultrasound probe sterility.

1. Prior to performing ultrasound scanning confirm that the ultrasound equipment was cleaned and disinfected according to the specific institutional policy. The level of disinfection required depends on the procedure being performed and the tissue that will be contacted by the probe.

2. The Food and Drug Administration (FDA) and CDC (Centers for Disease Control and Prevention) provides further guidance on probe sterility and chemical sterilants/high level disinfectants. ${ }^{28,29}$

3. A sterile ultrasound sheath or sterile adhesive transparent dressing should be utilized..$^{30}$ The anatomical location and the need to cover the transducer cord will dictate which type of dressing is appropriate. For example, for single shot blocks involving peripheral structures an adhesive sterile transparent dressing may be used in place of the sterile sheath. Make sure that all portions of the cord that will come into contact with the procedural field are contained within a sterile sheath.

4. An ultrasound coupling agent should be placed between the transducer and the inside of the sterile sheath ensuring that there is good contact and no air bubbles. For the adhesive dressing it is not necessary to place gel between the transducer surface and the dressing.

5. Sterile ultrasound coupling agent is applied between the skin and the covered transducer.

6. At the end of the procedure the sterile cover is properly disposed.

7. The probe is then cleaned and disinfected according to the hospital policy.

\section{APPENDIX 2: Documentation}

The following steps are recommended for appropriate documentation.

1. Create a separate procedure note that is stored in the medical record. The written report should identify the individual who performed the procedure, reason for the procedure, description of relevant procedural anatomy and pathology, and explanation of the procedure.

2. Image documentation and storage should occur through a hard copy or electronic archival system. Minimum image documentation recommenda- 
tions include visualization and labeling of appropriate anatomical structures including the target structure, needle localization, and injectate spread (when applicable). Recorded videos should be encouraged when feasible.

For further information on documentation requirements for appropriate reimbursement refer to specific policies dictated by regulatory and payer entities.

\section{APPENDIX 3: \\ Core competencies for fellowship training in USPM}

The following list overlaps with the skills defined in the proficiency section of the Practice Pathway:

\section{Patient care}

- Perform gentle ultrasound examinations, providing appropriate sedation if indicated.

- Demonstrate proper patient selection.

- Use appropriate monitoring during USPM.

- Demonstrate proper target localization techniques.

- Perform effective and safe procedures.

\section{Ultrasound knowledge}

- Understand the general principles of ultrasound physics.

- Understand benefits and limitations of USPM techniques.

- Understand differences between in-plane vs out-of-plane techniques and their respective advantages and disadvantages.

- Understand key artifacts and pitfall errors associated with USPM.

- Develop a profound knowledge of sonoanatomy of the spine, paraspinal structures, peripheral nerves, muscles, tendons, and joints.

- Appreciate common non-neural pathological states that are diagnosed by ultrasound.

- Establish familiarity with the major scientific literature related to USPM.

- Learn techniques for USPM (refer to list of applications in Table 1).

- Understand the applications and interpretation of color and power Doppler.

- Understand equipment specifications.

- Infection control and equipment cleaning.

Interpersonal/communication skills

- Communicate sensitively and effectively with patients and their families regarding ultrasound findings.

- Explain any complexities of USPM in terms that the patient can understand.

- Demonstrate team leadership/management skills for the management of an effective pain medicine services.

\section{Professionalism}

- Be open to constructive criticism regarding ultrasound skills. 


\section{System-based practice}

- Recognize costs associated with various imaging modalities; e.g. fluoroscopy, ultrasound, CT scan, and MRI.

- Collaborate with other members of the health care team to ensure quality patient care.

- Use evidence-based, cost-effective strategies in caring for all patients.

\section{Practice-based learning and improvement}

- Identify and acknowledge gaps in personal knowledge and skills in the care of patients presenting for USPM.

- Use textbook and online and computer-based resources to broaden knowledge base regarding USPM techniques.

- Perform electronic searches of the medical literature to identify articles that address the medical issues surrounding USPM.

- Understand and critically evaluate USPM outcome studies.

- Attend the department's required teaching conferences.

- Develop time management skills to perform the required tasks in a reasonable amount of time with satisfactory quality.

\section{APPENDIX 4:}

\section{Recommended ultrasound curriculum: Equipment Specifications:}

- Minimal ultrasound machine specifications include a machine with a linear transducer with high frequency, curved transducer with low frequency, color Doppler technology, and image storage/transfer capabilities.

\section{Curriculum Content: Scanning Techniques}

- The role of ultrasound physics pertinent to USPM; understand terminology (e.g., piezoelectric effect, frequency, resolution, attenuation, echogenicity, color Doppler, power Doppler).

- The role of instrumentation in image acquisition (e.g., image mode, gain, time gain compensation, transducer types).

- Equipment requirements: types of transducers (linear, curved and phased array for different indications and scanning at different depths), footprint length, and frequency (range, 2-18 $\mathrm{MHz}$ ).

- Ultrasound acoustic artifacts and imaging artifacts (pitfalls). These include reverberation artifacts, acoustic enhancement, acoustic shadowing, gainrelated artifacts, resolution-related artifacts, mistaking tendon or muscle for nerve, anisotropic behavior of tissues (especially nerves and tendons).

- Techniques to perform effective ultrasound examinations; appreciate the Joint Committee recommended PART maneuvers for generating optimal imaging: Pressure, Alignment, Rotation, and Tilt (APPENDIX 5). 
- The role of maintaining appropriate ultrasound ergonomics in order to improve technical proficiency and reduce work-related musculoskeletal strain disorders.

\section{Curriculum Content: USPM Procedures}

- Define patient selection, indications and contraindications.

- Practice procedural technique on available organic and inorganic simulators.

- Define relevant anatomy in each region including the ability to identify muscle, tendon, bone, nerve, vessels, and pleura.

- Define needle insertion technique (in-plane vs out-of-plane).

- Understand potential difficulties and pitfalls.

- Describe ultrasound appearance of common anatomical variations seen during musculoskeletal, axial, and non-axial pain procedures.

- Recognize correct and incorrect injectate spread.

\section{APPENDIX 5:}

\section{Recommended techniques for common US-guided pain procedures:} General Recommendations

1. Maintain aseptic technique throughout.

2. Find landmark structures e.g. bone, muscle, vessels.

3. Find nerve or target on short-axis imaging (transverse scan) or long axis imaging (if applicable).

4. Place machine focus on target structures.

5. Adjust depth, gain, time gain compensation, and frequency as necessary.

6. Initiate the PART maneuvers to optimize image quality.

a. Pressure: varying degrees of transducer pressure on skin.

b. Alignment: sliding movement of the transducer to define the lengthwise course of the nerve.

c. Rotation: the transducer is turned in either a clockwise or counter clockwise direction to optimize the image.

d. Tilting: the transducer is tilted in both directions to maximize the angle of incidence of the ultrasound beam with the target nerve to optimize the image.

7. Scan anticipated needle trajectory with the Doppler function on to identify any unsuspected vascularity in the path of the needle.

\section{Recommended technique for ultrasound-guided cervical spine injections Identifying the correct cervical spine level:}

Lower cervical spine procedures:

The sixth cervical (C6) transverse process is easily identified in the short axis view with its characteristic sharp anterior tubercle. This is well differentiated 
from C7 transverse process which has only one prominent posterior tubercle. Subsequently, the consecutive cervical spinal level is identified by moving the transducer cranially.

This approach is applicable for patients in either the supine or lateral decubitus position.

Upper cervical spine procedures:

Long axis view: The transducer is applied over the midline to obtain a long axis view of the spine. The occiput, C1 (no or rudimentary spinous process), and C2 (first bifid spinous process) can be easily identified.

Short axis view: The transducer is applied over the occipital area to obtain a short axis view. First the occipital bone is identified and by moving the transducer slowly caudally the arch of $\mathrm{C} 1$ (atlas) can be easily spotted and subsequently the first bifid spinous process belongs to C2. This approach is applicable for patients in either the prone or lateral decubitus position.

\section{Recommended technique for ultrasound-guided cervical medial branch blocks}

1. Place the patient in a lateral position with the painful side upwards and a pillow under the head to have the cervical spine as straight as possible.

2. Utilize a high-frequency linear array probe (to better visualize the nerves).

3. Follow a systematic approach and identify key anatomical structures to identify each zygapophyseal joint from C2-3 to C6-7.

4. Identify the correct spinal level as above. Alternatively, the lateral aspect of the neck is scanned in a transverse axis view in the region of the mastoid process and, by moving the transducer caudally, the most superficial situated bony landmark of the upper cervical spine, i.e., the transverse process of $\mathrm{C} 1$, is visualized.

5. A few millimeter more caudally, the vertebral artery can be located and followed until it enters the transverse foramen of $\mathrm{C} 2$, where the $\mathrm{C} 2-\mathrm{C} 3 \mathrm{zy}-$ gapophyseal joint can be located posterior.

6. Here the transducer is turned approximately $90^{\circ}$ until the typical longitudinal axis view of the cervical zygapophyseal joint region appears, and each level can be determined by simply counting the "hills" (joints) and "grooves" (articular pillars).

7. Reaching the level $\mathrm{C} 7$, the transducer is rotated back to a transverse position (approximately $90^{\circ}$ ) to visualize the transverse process of C7 missing an anterior tubercle. This serves as a control of correct level determination.

8. Return to the longitudinal axis view identifying the appropriate procedural level.

9. Place probe that targeted articulation is in the middle of the probe. Identify the medial branch in the groove above the targeted articulation and the medial branch in the groove caudal of the targeted articulation. (Exception: TON - single nerve innervating C2-C3 - crosses over the articulation). 
10. Utilize an out-of-plane needle advancement technique from anterior to posterior to the target zone under real-time visualization.

11. Place the needle tip just beside the nerve and contact bone.

12. Inject the desired injectate under real-time sonography.

\section{Recommended technique for ultrasound-guided cervical intra-articular facet injections}

1. Place the patient in a prone position (for unilateral or bilateral injections) or a lateral position (for unilateral injection).

2. Utilize a low frequency curvelinear array probe (for better orientation, counting the cervical level and to facilitate multiple injections in the same view).

3. Identify the correct cervical spinal level as above.

4. The transducer is applied over the midline to obtain a long axis view (sagittal scan) of the spine. The occiput, C1 (no or rudimentary spinous process), C2 (first bifid spinous process), and subsequent levels can be easily identified. Then the scanning continues laterally (parasagittal scan) to identify the lamina and then more laterally, the facet column appears in the image as the characteristic "saw sign".

5. The inferior articular process of the level above and the superior articular process of the level below appear as a hyperechoic signals and the joint space appears as anechoic gap in-between.

6. Introduce the needle just caudal to the inferior end of the transducer and advance it in-plane in the long axis view into the joint space under real-time sonography.

7. Inject the desired injectate under real-time sonography.

\section{Recommended technique for ultrasound-guided greater occipital nerve (GON) block}

1. Place the patient in the prone or sitting position with head flexed in a neutral position.

2. Utilize a high frequency linear probe (better nerve visualization). Low frequency curvilinear probe may be more suitable for better orientation, thus advisable for training; nerve visibility decreased).

3. Start with transverse transducer position (short axis view) over the occipital bone (with external protuberance in center of image); slowly move caudad till curved and smooth surface of posterior arch of atlas is seen (with acoustic shadow); move further downwards to identify bifid spinous process of C2 (left and right tubercles); move transducer laterally to appropriate side, orientate slightly oblique with lateral end of the trasducer more cephalad to identify the key landmark (the thick and hypoechoic obliquus capitis inferior muscle). Deep to medial half of this muscle, the lamina of C2 has to be seen (acoustic shadow). 
4. The GON appears as an oval hypoechoic structure approx. $2-3 \mathrm{~cm}$ lateral to C2 spinous process, between the obliquus capitis inferior muscle (deep layer) and the semispinalis capitis muscle (superficial layer).

5. If the probe is moved more laterally, the transverse process of atlas and the vertebral artery can be identified The latter is seen medial to the bone shadow of transverse process of the atlas and deep to (in front of) the lateral end of obliquus capitis inferior muscle.

6. As vessels may mimic GON (especially parts of suboccipital venous plexus), use power Doppler and reduce probe pressure prior to needle advancement.

7. The needle can be advanced either in-plane (preferably from lateral to medial) or out-of-plane (may use hydro dissection).

8. Inject the desired injectate under real-time sonography.

\section{Recommended technique for ultrasound-guided cervical sympathetic (stellate ganglion) block}

1. Place the patient in the supine position with neck extended and slightly tilted to the other side.

2. Utilize a high frequency linear array probe.

3. Start scanning by obtaining a short axis view at the root of the neck with the medial end of the transducer at the midline. Identify the relevant anatomical landmarks (trachea, esophagus, thyroid gland, carotid sheath, longus colli muscle, and prevertebral fascia).

4. Continue scanning laterally to keep the carotid sheath in the middle of the screen.

5. Continue scanning cephalic till the characteristic $\mathrm{C} 6$ transverse process (anterior tubercle) is identified, differentiating C6 from C7 level.

6. The vertebral artery should be identified.

7. The target (sympathetic chain) should be just anterior to the longus colli muscle.

8. Scan anticipated needle trajectory with color Doppler to identify any vessels in the path of the needle (e.g. inferior thyroid artery or ascending cervical artery branches).

9. The needle should be advanced under real-time sonography (either out of plane or in-plane) at either C6 or C7 level depending on the findings in step 8.

10. The spread of the test dose and injectate should be monitored under realtime sonography to rule out intravascular injection.

11. Optimal injectate spread should be deep to the deep layer of the prevertebral fascia and superficial to the fascia investing the longus colli muscle.

12. The spread of the injectate along the anterior surface of the longus colli muscle can be visualized in the long-axis view as well. 


\section{Recommended technique for ultrasound-guided suprascapular nerve block in the suprascapular fossa}

1. Place the patient in either the prone or sitting position.

2. Palpate the scapular spine, coracoid process, and acromion landmarks.

3. Utilize a high frequency linear array probe. Low frequency curved array probe may be needed depending on body habitus.

4. Place the ultrasound probe in a coronal plane over the suprascapular fossa.

5. The ultrasound view should isolate the area of the floor of the scapular spine between the suprascapular notch and spinoglenoid notch.

6. Identify the supraspinatus muscle, trapezius muscle, and floor of the scapular spine.

7. Adjust the ultrasound probe in a cephalo-caudad direction to visualize the suprascapular nerve and artery.

8. Insert the needle from the medial aspect of the probe in a medial to lateral direction under real-time sonography (either out of plane or in-plane) targeting the area of suprascapular nerve, while avoiding the suprascapular artery, on the scapular spine between the suprascapular notch and spinoglenoid notch.

9. Inject the desired injectate under real-time sonography.

\section{Recommended technique for ultrasound-guided intercostal nerve block}

1. Place the patient in the prone or lateral position.

2. Utilize a high-frequency linear array probe.

3. Orient the transducer for a short axis (parasagittal) view identifying two consecutive ribs.

4. Identify the $12^{\text {th }}$ rib and move the transducer cephalad to identify the appropriate space for the targeted intercostal nerve. The intercostal nerve is usually difficult to visualize.

5. Place the probe at the angle of the rib which is approximately 6 to $7 \mathrm{~cm}$ lateral to the spinous processes.

6. At the appropriate level identify the pleura, ribs, and intercostal muscles (external, internal, and innermost muscles). The innermost intercostal muscle is often poorly defined.

7. Prior to needle insertion employ the Doppler function to identify any vascular structures.

8. Utilize an in- or out-of-plane technique and advance a 22 or 25-gauge needle from the superior margin of the caudad rib to the level of the internal intercostal muscle and approximately 2-3 $\mathrm{mm}$ proximal to the pleura midway between the ribs. The location of the neurovascular bundle is typically between the internal intercostal and innermost intercostal muscles. The intercostal nerve is usually difficult to visualize.

9. Once needle tip placement is confirmed by hydrolocalization, then inject desired therapeutic agent. 
10. Following the procedure check for the absence of a pneumothorax by identifying normal lung sliding and comet tail artifacts.

\section{Recommended technique for ultrasound-guided lumbar spine injections: Identifying the correct lumbar spine level:}

\section{Long axis view (sagittal scan):}

The transducer is applied longitudinally over the midline to obtain a long axis view of the spine. The dorsal surface of the sacrum appears as a solid continuous hyperechoic line and more cranially the spinous process of L5 appears in the image. Subsequently by scanning more cranially, the higher lumbar spine levels can be identified.

Short axis view:

The transducer is applied transversely to obtain a short axis view of the spine. The S1 level has only a median crest and more cranially the first sharp spinous process belongs to L5 level.

\section{Ultrasound-guided lumbar medial branch blocks}

1. Place the patient in the prone position with a pillow under their abdomen to reduce lumbar lordosis.

2. Utilize a low-frequency curvilinear array probe.

3. Follow a systematic approach and identify key anatomical structures in the five basic lumbar spine ultrasonography views: 1) parasagittal transverse process, 2) parasagittal articular process, 3) parasagittal oblique, 4) transverse spinous process, and 5) transverse interlaminar.

4. Obtain a longitudinal axis paravertebral view (parasagittal oblique view).

5. Identify the sacrum, and then label each respective lumbar level.

6. Move the probe laterally from the midline in order to view the following structures: spinous processes, articular processes, and transverse processes.

7. Scan cephalad in the short axis view (transverse) starting at the level of the S1 median crest to verify the labeled structures in the long axis view.

8. Correlate the spinous process markings from both the short axis and long axis views.

9. Return to the longitudinal axis view and identify the appropriate procedural level.

10. Rotate the probe $90^{\circ}$ to obtain the short axis view of the treatment level and visualize the spinous process, or intraspinous ligament, superior articular process and the transverse process.

11. The target zone is the cranial junction of the transverse process and the base of the superior articular process. Often this is at the level of the interlaminar space.

12. Utilize an in-plane needle advancement technique to the target zone under real-time sonography. 
13. Once bony contact occurs, rotate the transducer to the long axis view to confirm needle placement at the cranial edge of the transverse process.

14. Inject the desired injectate under real-time sonography.

\section{Recommended technique for ultrasound-guided lumbar intra-articular facet injections}

1. Perform steps 1 through 10 described above for the lumbar medial branch block.

2. Adjust the ultrasound probe in order to visualize the junction (posterior entrance of the joint) between the superior and inferior articular processes.

3. Advance the needle in the short axis view into the joint space under realtime sonography.

4. Inject the desired injectate under real-time sonography.

\section{Recommended technique for ultrasound-guided sacroiliac joint injection}

1. Place the patient in the prone position with a pillow under the abdomen.

2. Utilize a low-frequency curvelinear array probe.

3. Scan with probe in a transverse position to obtain a short axis image.

4. Identify key landmarks for primary orientation including the posterior superior iliac spine, median sacral crest, posterior sacral foramen one, and posterior sacral foramen two, and sacral hiatus.

5. For identification of the inferior target zone of the joint, scan cephalad from the sacral hiatus and identify the inferior intersection between the lateral edge of the sacrum and the medial border of the ilium.

6. For confirmation of the appropriate inferior target zone, scan caudad from the level of the posterior superior iliac spine identifying the dorsal surfaces of the sacrum and ilium. Identify the first and second posterior sacral foramina. The inferior target zone is the hypoechoic cleft between the sacrum and ilium located laterally to the second posterior sacral foramen.

7. Direct a needle with an in-plane technique from the medial end of the transducer to the hypoechoic cleft representing the inferior portion of the sacroiliac joint.

8. Limitations exist with the ultrasound-guided technique including the inability to obtain a radiographic contrast arthrogram and to detect an intravascular injection. 


\section{References}

1. Narouze S, Peng PWH. Ultrasound-guided interventional procedures in pain medicine: a review of anatomy, sonoanatomy, and procedures. Part II: axial structures. Reg Anesth Pain Med 2010; 35:386-396.

2. Narouze SN. Ultrasound-guided interventional procedures in pain management: Evidence-based medicine. Reg Anesth Pain Med 2010; 35:S55-58.

3. Neal JM, Brull R, Chan VW, Grant SA, Horn JL, Liu SS, McCartney CJ, Narouze SN, Perlas A, Salinas FV, Sites BD, Tsui BC. The ASRA evidence-based medicine assessment of ultrasound-guided regional anesthesia and pain medicine: Executive summary. Reg Anesth Pain Med 2010; 35:S1-9.

4. Peng PW, Narouze S. Ultrasound-guided interventional procedures in pain medicine: a review of anatomy, sonoanatomy, and procedures: part I: nonaxial structures. Reg Anesth Pain Med 2009; 34:458-474.

5. Gofeld M. Ultrasonography in pain medicine: a critical review. Pain Pract 2008; 8:226-240.

6. Eichenberger U, Greher M, Kirchmair L, Curatolo M, Moriggl B. Ultrasound-guided blocks of the ilioinguinal and iliohypogastric nerve: accuracy of a selective new technique confirmed by anatomical dissection. Br J Anaesth 2006; 97:238-243.

7. Ng I, Vaghadia H, Choi PT, Helmy N. Ultrasound imaging accurately identifies the lateral femoral cutaneous nerve. Anesth Analg 2008; 107:1070-1074.

8. Fazel R, Krumholz HM, Wang Y, Ross JS, Chen J, Ting HH, Shah ND, Nasir K, Einstein AJ, Nallamothu BK. Exposure to low-dose ionizing radiation from medical imaging procedures. $\mathrm{N}$ Engl J Med 2009; 361:849-857.

9. Valentin J. Avoidance of radiation injuries from medical interventional procedures. Ann ICRP 2000; 30:7-67.

10. Sites BD, Brull R, Chan VW, Spence BC, Gallagher J, Beach ML, Sites VR, Hartman GS. Artifacts and pitfall errors associated with ultrasound-guided regional anesthesia. Part I: understanding the basic principles of ultrasound physics and machine operations. Reg Anesth Pain Med 2007; 32:412-418.

11. Sites BD, Brull R, Chan VW, Spence BC, Gallagher J, Beach ML, Sites VR, Abbas S, Hartman GS. Artifacts and pitfall errors associated with ultrasound-guided regional anesthesia. Part II: a pictorial approach to understanding and avoidance. Reg Anesth Pain Med 2007; 32:419-433.

12. Rauch S, Kasuya Y, Turan A, Neamtu A, Vinayakan A, Sessler DI. Ultrasound-guided lumbar medial branch block in obese patients: a fluoroscopically confirmed clinical feasibility study. Reg Anesth Pain Med 2009; 34:340-342.

13. Chin KJ, Karmakar MK, Peng P: Ultrasonography of the adult thoracic and lumbar spine for central neuraxial blockade. Anesthesiology 2011; 114:1459-85.

14. Narouze SN, Vydyanathan A, Kapural L, Sessler DI, Mekhail N. Ultrasound-guided cervical selective nerve root block: a fluoroscopy-controlled feasibility study. Reg Anesth Pain Med 2009; 34:343-348.

15. American Medical Association House of Delegates. Privileging for ultrasound imaging. Resolution 802, December 1999; reaffirmed; Sub. Res 108, June 2000. H-230.960. Available at: http://www.ama.assn.org. Accessed December 2, 2012.

16. American College of Emergency Physicians (ACEP) emergency ultrasound guidelines-2001. Ann Emerg Med 2001; 38:470-481.

17. American College of Emergency Physicians: Emergency ultrasound guidelines. Ann Emerg Med 2009; 53:550-570.

18. Sites BD, Chan VW, Neal JM, Weller R, Grau T, Koscielniak-Nielsen ZJ, Ivani G. American Society of Regional Anesthesia and Pain Medicine, European Society Of Regional Anaesthesia and Pain Therapy Joint Committee: The American Society of Regional Anesthesia and Pain Medicine and the European Society Of Regional Anaesthesia and Pain Therapy Joint Committee recommendations for education and training in ultrasound-guided regional anesthesia. Reg Anesth Pain Med 2009; 34:40-46. 
19. Finnoff J, Lavallee ME, Smith J. Musculoskeletal ultrasound education for sports medicine fellows: a suggested/potential curriculum by the American Medical Society for Sports Medicine. $\mathrm{Br}$ J Sports Med 2010; 44:1144-1148.

20. Pineda C, Reginato AM, Flores V, Aliste M, Alva M, Aragon-Lainez RA, Gonzalez AB, Bouffard JA, Caballero-Uribe CV, Chavez-Lopez M, Chavez-Perez NN, Collado P, Diaz-Coto JF, Duarte M, Filippucci E, Galarza-Maldonado C, Garcia-Kutzbach A, Godoy FJ, Gonzalez-Sevillano E, Da Silveira IG, Gutierrez M, Hernandez-Diaz C, Hernandez J, Lamuno-Encorrada M, Marcos JC, Marin-Arriaga N, Mendonca JA, Michaud J, Moya C, Munoz-Louis R, Neubarth F, Quintero M, Reyes B, Ruta S, Rodriguez-Henriquez PJ, Solano C, Ventura-Rios L, Moller I, Naredo E, Pan-American League of Associations for Rheumatology (PANLAR) Ultrasound Study Group: Pan-American League of Associations for Rheumatology (PANLAR) recommendations and guidelines for musculoskeletal ultrasound training in the Americas for rheumatologists. J Clin Rheumatol 2010; 16:113-118.

21. Sites BD, Macfarlane AJ, Sites VR, Naraghi AM, Chan VW, Antonakakis JG, Singh M, Brull R. Clinical sonopathology for the regional anesthesiologist: part 1: vascular and neural. Reg Anesth Pain Med 2010; 35:272-280.

22. Sites BD, Macfarlane AJ, Sites VR, Naraghi AM, Chan VW, Antonakakis JG, Singh M, Brull R. Clinical sonopathology for the regional anesthesiologist: part 2: bone, viscera, subcutaneous tissue, and foreign bodies. Reg Anesth Pain Med 2010; 35:281-289.

23. US Food and Drug Administration. Department of Health and Human Services. FDA Radiological Health Program. Available at: http://www.fda.gov/RadiationEmittingProducts/RadiationEmittingProductsandProcedures/MedicalImaging/ucm115357.htm\#rb. Accessed December 2, 2011.

24. Shankar H, Pagel PS. Potential adverse ultrasound-related biological effects: a critical review. Anesthesiology 2011; 115:1109-1124.

25. Sibbitt WL, Jr, Peisajovich A, Michael AA, Park KS, Sibbitt RR, Band PA, Bankhurst AD. Does sonographic needle guidance affect the clinical outcome of intraarticular injections? J Rheumatol 2009; 36:1892-1902.

26. Muradali D, Gold WL, Phillips A, Wilson S. Can ultrasound probes and coupling gel be a source of nosocomial infection in patients undergoing sonography? An in vivo and in vitro study. AJR Am J Roentgenol 1995; 164:1521-1524.

27. Hutchinson J, Runge W, Mulvey M, Norris G, Yetman M, Valkova N, Villemur R, Lepine F: Burkholderia cepacia infections associated with intrinsically contaminated ultrasound gel: the role of microbial degradation of parabens. Infect Control Hosp Epidemiol 2004; 25:291-296.

28. Rutala WA, Weber DJ and Healthcare Infection Control Practices Advisory Committee (HICPA): Centers for Disease Control and Prevention Guideline for Disinfection and Sterilization in Healthcare Facilities, 2008. Available at: http://www.cdc.gov/hicpac/pdf/guidelines/Disinfection_Nov_2008.pdf. Accessed December 2, 2011.

29. Centers for Devices and Radiological Health: Centers for Devices and Radiological Health Guidance for Industry and FDA Staff: Information for Manufacturers Seeking Marketing Clearance of Diagnostic Ultrasound Systems and Transducers, September 9, 2008. Available at: www.fda.gov/downloads/MedicalDevices/DeviceRegulationandGuidance/GuidanceDocuments /UCM070911.pdfcdc. Accessed December 2, 2011.

30. Abdullah BJ, Mohd Yusof MY, Khoo BH. Physical methods of reducing the transmission of nosocomial infections via ultrasound and probe. Clin Radiol 1998; 53:212-214. 



\section{Chapter 9 Summary}

Samer Narouze, MD, MSc

Narouze S. Ultrasound-guided Cervical Spine Injections: Ultrasound "prevents" while contrast fluoroscopy "detects" intra-vascular injections. Reg Anesth Pain Med 2012; 37:127-130. 
Subsequent to the paradigm shift established by ultrasound in the field of regional anesthesia, we now started to see a new wave of reports advocating the use of ultrasonography to guide pain blocks. This new wave started in 20042005 with the description of ultrasound guided techniques for lumbar and cervical facet nerve blocks and intra-articular injections. This was succeeded by a renewed interest in ultrasound-guided stellate ganglion block with the goal to decrease potential complications. Since then, there has been a rapidly growing interest in the application of ultrasonography in pain medicine as evident by the plethora of published reports.

Since the main avail of ultrasonography, besides no radiation exposure, is direct visualization of soft tissue structures, it lends it particularly beneficial in cervical spine injections with the multitude of vessels and other vital soft tissue structures compacted in a small area that make it vulnerable to injury with fluoroscopy guided injections. In this thesis we demonstrated that this is especially true with cervical nerve root injections, stellate ganglion block, and atlanto-axial joint injections. Ultrasound is an excellent tool in "visualizing" and hence "avoiding" vascular injury during cervical spine procedures, while contrast fluoroscopy can only "detect" that the tip of the needle is intravascular (after the fact). One should be mindful that fluoroscopy may not detect that the needle has already traversed a vessel on its way to the target, while ultrasound can avoid this.

The purpose of this thesis is to review the sonoanatomy of the neck and cervical spine and to demonstrate the feasibility and reliability of using the ultrasound to guide different cervical spine injections for the treatment of various cervical pain syndromes. Chapter I is an overview of the advantages and limitations of ultrasound in spine injections. The chapter sheds the light on the potential applications of ultrasound in the field of interventional pain management with special attention to the neck and cervical spine. The rational for considering ultrasound for stellate ganglion block, cervical transforaminal and atlantoaxial joint injections is offered with the references to support such rational. Five questions were offered to be addressed in the following chapters.

The sonoanatomy of the cervical spine is reviewed in details in chapter II as well as the literature review in regards to ultrasound-guided cervical procedures. The techniques for performing cervical nerve root injection, cervical facet medial branch block as well as cervical facet intra-articular injections were discussed. The techniques were supported by various illustrations and sonograms to explain the sonoanatomy relevant to each procedure. Apart from cervical spine sonoanatomy, the thesis offers a detailed description of the anatomy and sonoanatomy of the soft tissue structures in the anterior neck in relation to cervical sympathetic chain block in chapter III. We showed that the esophagus, vertebral artery, inferior thyroid artery and other arteries can be located along the needle path of fluoroscopy-guided stellate ganglion block. These findings are really alarming and will raise few eye brows. 
Currently the guidelines for cervical transforaminal injection technique involve introducing the needle under fluoroscopic guidance into the posterior aspect of the intervertebral foramen just anterior to the superior articular process in the oblique view to minimize the risk of injury to the vertebral artery or the nerve root. Despite strict adherence to these guidelines adverse outcomes have been reported. A potential shortcoming to these current guidelines would be the presence of a critical feeder vessel to the anterior spinal artery in the posterior aspect of the intervertebral foramen that could be injured in the pathway of the needle. Here the ultrasonography may come to play; as it allows for visualization of soft tissues, nerves and vessels and also facilitates visualization of the injectate around the nerve thus it may be advantageous to fluoroscopy. Chapter IV covers ultrasound-guided cervical nerve root injections. This is a prospective observational study evaluating the feasibility of ultrasound in identifying the correct cervical level and accurate placement of the needle compared to fluoroscopy.

The radiologic target point was the posterior aspect of the intervertebral foramen just anterior to the superior articular process in the oblique view, and at the midsagittal plane of the articular pillars in the anteroposterior view. The needles placed with ultrasound were within $5 \mathrm{~mm}$ from the radiologic target in all patients as confirmed by fluoroscopy. Vessels at the anterior aspect of the foramen were identified in 4 patients by color Doppler, while 2 patients had critical vessels at the posterior aspect of the foramen. In these 2 cases such vessels could have been injured in the pathway of a correctly placed needle under fluoroscopy alone. So with cervical selective nerve root block (cervical transforaminal epidural injection) there is really no safe zone, however there may be a safer tool, the ultrasound. In another case scenario, we demonstrated in chapter $\mathbf{V}$ that ultrasound-guided needle placement for stellate ganglion block prevented esophageal penetration in clinical practice especially with left sided injections.

The lateral atlanto-axial joint (AAJ) is a common cause of cervicogenic headache and it may account for up to $16 \%$ of patients with occipital headache. Chapter VI discusses a retrospective review of 115 patients with cervicogenic headache, of which 32 had a clinical picture suggestive of atlanto-axial joint pain and underwent AAJ injection with local anesthetic and steroids. The data showed a statistically significant pain relief at 1 and 3 month follow up but not at the 6 month follow up visit. AAJ injections can be associated with serious complications mainly because of its close proximity to the vertebral artery and the C2 dorsal root ganglion. This led some pain physician to abandon AAJ injections as fluoroscopy can't directly identify the vertebral artery. On the other hand ultrasound can easily identify both the $\mathrm{C} 2$ dorsal root ganglion and the vertebral artery as it courses lateral to the AAJ from C2 to C1 foramina and this is demonstrated in chapter VII. Ultrasound guidance can increase the safety of this much needed procedure in selected patients with cervicogenic headache. 
All the previous examples increased the enthusiasm of pain physicians to learn more about ultrasound-guided injections in pain management. As we witness an expansion in the number of pain physicians who perform pain procedures with ultrasound guidance, it is high time for pain medicine societies to consider establishing recommendations for education and training and to encourage clinical outcome studies. Due to the lack of specialty specific guidelines for ultrasonography in interventional pain management, an international collaborative effort consisting of members of the Special Interest Group on Ultrasonography in Pain Medicine from the American Society of Regional Anesthesia and Pain Medicine, the European Society of Regional Anesthesia and Pain Therapy, and the Asian Australasian Federation of Pain Societies developed recommendations for education and training in ultrasound-guided interventional pain procedures that is presented in chapter VIII. The purpose of the recommendations is to define the required skills for performing ultrasound-guided pain procedures, the process for appropriate education and training, and the quality improvement process.

In conclusion; ultrasound provides direct visualization of various soft tissues, real-time needle advancement and avoids exposing the healthcare provider and the patient to the risks of radiation. The machine itself is more affordable and transferrable than a fluoroscopy or CT scan. These factors make ultrasonography an attractive adjunct to other imaging modalities in interventional pain management especially in the cervical spine area. 


\section{Chapter 10 \\ Samenvatting}

Samer Narouze, MD, MSc

Narouze S. Ultrasound-guided Cervical Spine Injections: Ultrasound "prevents" while contrast fluoroscopy "detects" intra-vascular injections. Reg Anesth Pain Med 2012 (in press) 
Ultrasound echografie in de regionale anesthesie heeft het laatste decennium een explosieve groei gekend. Ultrasonografie wordt nu ook toegepast bij chronische pijnbestrijding. Sinds 2004-2005 worden ultrasound-geleide technieken gebruikt voor lumbale en cervicale facet denervatie en intra-articulaire injecties, gevolgd door een vernieuwde interesse in ultrasound-geleide blokkade van het ganglion stellatum, met als doel de incidentie van potentiële complicaties te verminderen. Sindsdien groeit de interesse in de toepassing van ultrasonografie in pijnbestrijding, wat tot uiting komt in een plethora aan publicaties.

Ultrasonografie heeft duidelijk zijn nut bewezen - gezien blootstelling aan bestraling vermeden wordt en zachte weefsels direct gevisualiseerd kunnen worden - bij injecties ter hoogte van de cervicale wervelkolom, waar in een compacte omgeving vele bloedvaten en andere vitale structuren gemakkelijker beschadigd worden bij gebruik van fluoroscopie-geleide injecties. In dit proefschrift hebben wij aangetoond dat dit specifiek het geval is voor cervicale wortelbehandelingen, ganglion stellatum blokkades en injecties in de atlanto-axiale gewrichten. Ultrasound is een uitstekend instrument bij het "visualiseren" en bijgevolg het "vermijden" van vasculaire schade gedurende ingrepen aan de cervicale wervelkolom, terwijl fluoroscopie enkel de tip van de naald kan "detecteren" eenmaal deze in het bloedvat is terecht gekomen (postfactum). Men moet begrijpen dat tijdens fluoroscopie niet gedetecteerd wordt dat een naald al in een bloedvat is terechtgekomen, terwijl ultrasound dit kan vermijden.

Het doel van dit proefschrift is om de sonoanatomie van de nek en de cervicale wervelkolom te beschrijven in een reviewartikel en om de haalbaarheid en betrouwbaarheid van het gebruik van ultrasound aan te tonen, als geleide bij verschillende injectietechnieken ter hoogte van de cervicale wervelkolom bij de behandeling van meerdere cervicale pijnsyndromen.

Hoofdstuk I geeft in een overzichtsartikel de voordelen en de beperkingen van ultrasound-geleide injecties ter hoogte van de wervelkolom. Het hoofdstuk belicht de potentiële toepassingen van ultrasound in het gebied van interventie pijnbehandelingen met een speciale aandacht voor de nek en cervicale wervelkolom. De ratio achter het gebruik van ultrasound voor het ganglion stellatumblok, cervicale transforaminale en atlantoaxiale gewrichtsinjecties wordt belicht, gesteund door de literatuur. Een vijftal vragen wordt beantwoord in de volgende hoofdstukken.

De sonoanatomie van de cervicale wervelkolom is beschreven in een overzichtsartikel in hoofdstuk II, met tevens verwijzingen naar de literatuur gerelateerd aan ultrasound-geleide cervicale procedures. De technieken om injecties te verrichten ter hoogte van de cervicale zenuwwortels, facetten en gewrichten worden bediscussieerd. De technieken worden ondersteund door verschillende illustraties en sonografieën om de relevante sonoanatomie toe te lichten. Behalve de cervicale sonoanatomie, geeft dit proefschrift eveneens een gedetailleerde beschrijving van de anatomie en de sonoanatomie van de zachte weefsels in de voorste halsregio in relatie met een blokkade van de cervicale 
sympathicusketen in hoofdstuk III. We konden aantonen dat de slokdarm, arteria vertebralis, arteria thyroidea inferior en andere slagaders zich op het pad bevinden van een fluoroscopisch-geleid ganglion stellatum blok. Dit zijn alarmerende bevindingen waarbij menigeen zijn wenkbrauwen zal fronsen.

Op dit ogenblik bevelen de richtlijnen voor de toepassing van transforaminale injectietechnieken het gebruik van naalden onder fluoroscopische geleiding aan in het posterieure gebied van het foramen intervertebrale, anterior van de processus articularis superior in de schuine opname om beschadiging van de arteria vertebralis of de zenuwwortel te minimalizeren. Ondanks het strikt toepassen van deze richtlijnen, werden negatieve resultaten gerapporteerd. Een potentiële tekortkoming van deze richtlijnen is de aanwezigheid van een kritisch bloedvat van de arteria spinalis anterior in het posterieure deel van het foramen intervertebrale, dat beschadigd kan worden tijdens de introductie van de naald. Hier kan ook de sonoanatomie een rol spelen daar het toelaat zachte weefsels, zenuwen en bloedvaten te visualiseren, evenals de visualisatie van de injectievloeistof rond de zenuw, waardoor deze techniek waardevoller is dan de fluoroscopie. Hoofdstuk IV behandelt ultrasound-geleide injecties ter hoogte van de cervicale zenuwwortels. Een prospectief observationele studie evalueert de toepassing van ultrasound met fluoroscopie in het identificeren van de juiste cervicale wervel en accurate plaatsing van de naald. Het radiologische einddoel is het posterior deel van het foramen intervertebrale anterior van de processus articularis superior in de schuine opname, en in het midsagitaal vlak van de gewrichtspijlers in de anterioposterior opname. De naalden geplaatst met ultrasound bevonden zich binnen $5 \mathrm{~mm}$ van het radiologische doel in alle patiënten, zoals aangetoond door fluoroscopie. Met behulp van de kleuren Doppler technieken werden bij vier patiënten bloedvaten aangetoond ter hoogte van het voorste deel van het foramen, terwijl twee patiënten kritische vaten vertoonden ter hoogte van het posterieure deel van het foramen. In deze twee patiënten zouden de vaten beschadigd kunnen worden tijdens het traject van een correct geplaatste naald indien enkel fluoroscopie wordt toegepast. Er is werkelijk geen enkele veilige zone bij het zetten van een selectief cervicale zenuwblokkade (cervicale transforaminale epidurale injectie). Er bestaat echter wel een veiliger techniek, namelijk de ultrasound. In een ander scenario, zoals beschreven in hoofdstuk $\mathbf{V}$, wordt aangetoond dat het plaatsen van een ultrasound-geleide naald voor een ganglion stellatum blok, in de klinische praktijk voorkomt dat de slokdarm wordt aangeprikt, in het bijzonder bij linkszijdige injecties.

Het laterale atlanto-axiale gewricht (AAJ) is een gebruikelijke oorzaak van cervicogene hoofdpijn en is verantwoordelijk voor $16 \%$ van de patiënten met occipitale hoofdpijn. Hoofdstuk VI bediscussieert een retrospectief onderzoek bij 115 patiënten met cervicogene hoofdpijn, waarvan 32 een klinisch beeld vertonen, suggestief voor atlanto-axiale gewrichtspijn, die behandeld wordt met lokaal anesthetica en steroiden. De data tonen een statistische signi- 
ficante verbetering van de pijn aan op 1 en 3 maanden follow-up, maar niet op 6 maanden. AAJ injecties kunnen geassocieerd worden met ernstige complicaties, die voornamelijk berusten op hun nabijheid van de arteria vertebralis en het C2 dorsaal wortel ganglion. Dit heeft er toe geleid dat sommige pijnbestrijders AAJ injecties hebben verlaten, daar fluoroscopie geen directe identificatie toelaat van de arteria vertebralis. Anderzijds laat ultrasound gemakkelijk toe om zowel het $\mathrm{C} 2$ dorsaal wortel ganglion als de arteria vertebralis te identificeren daar hun beloop lateraal is van het AAJ van de foramina C2 tot C2 (hoofdstuk VII). Ultrasound-geleide technieken verhogen de veiligheid van deze vaak voorkomende behandeling in geselecteerde patiënten met cervicogene hoofdpijn.

Alle aangehaalde voorbeelden verhogen het enthousiasme van pijnbestrijders om meer kennis op te doen van ultrasound-geleide injectie technieken in chronische pijnbestrijding. Daar we getuige zijn van een grote groei in het aantal pijnbestrijders die ultrasound toepassen, is het de hoogste tijd voor de wetenschappelijke secties pijnbestrijding om aanbevelingen te doen in verband met opleiding en training en om het verrichten van klinische studies aan te moedigen. Ten gevolge van het gebrek aan specifieke richtlijnen voor ultrasonografie in interventionele pijnbestrijding, is er een internationale samenwerking opgericht, bestaande uit leden van een "Special Interest Group" voor ultrasonografie in pijnbestrijding, door de American Society of Regional Anesthesia and Pain Medicine, de European Society of Regional Anaesthesia and Pain Therapy, en de Asian Australasian Federation of Pain Societies, die aanbevelingen hebben opgesteld voor opleiding en training in procedures voor ultrasound-geleide interventie pijnbestrijding (hoofdstuk VIII). Het doel van deze aanbevelingen is om de vereiste vaardigheden te definiëren van ultrasound-geleide pijnbestrijdingsingrepen, het juiste opleidings- en trainingsproces en het kwaliteitsverbeteringsproces.

Samenvattend kan gesteld worden dat ultrasound een directe visualisatie van diverse zachte weefsels toelaat, met real-time visualisatie van het inbrengen van een naald, waarbij de patiënt en de pijnbestrijder zelf geen bestraling ondervinden tijdens de ingreep. Het toestel zelf is meer betaalbaar en verplaatsbaar dan een fluoroscopie of CT scan toestel. Deze factoren maken ultrasonografie een aanlokkelijk instrument boven andere toestellen in interventionele pijnbestrijding, speciaal in het gebied van de cervicale wervelkolom. 
Chapter 11

Acknowledgements 
I would like to acknowledge and extend my heartfelt gratitude to Prof. Dr. Maarten van Kleef and Prof. Dr. André van Zundert for giving me the opportunity to carry out this project. Words are inadequate in offering my thanks to them for their continued help, support, encouragement, and inspiration. Special thank you to Dr. Micha Sommer for his help and guidance throughout the whole process.

I take immense pleasure in thanking Prof. Dr. Klaus Galliano and Prof. Dr. Hannes Gruber as they are the first to introduce me to ultrasound guided spine injections in 2005 when I visited their institute in Innsbruck, Austria.

Words are inadequate in offering my thanks to all my research colleagues for their help and cooperation in carrying out the research projects behind this thesis. Special thanks to all my American, Canadian, European, Asian and Australian friends and colleagues who helped me-relentlessly-over the last couple of years to come up with the USPM recommendations for education and training that will help shaping the future of USPM.

Needless to mention the great impact and support of my partners and the whole staff at Summa Western Reserve Hospital.

I would also like to thank Ms. Hermina Gielen and Ms. Sandra Reijnders in Dr. van Kleef's office for their invaluable administrative assistance in this project.

Finally, yet importantly, I would like to express my heartfelt thanks to my beloved parents for their blessings, my wife and family for their help and wishes for the successful completion of this thesis. 
Chapter 12

Curriculum Vitae and List of Publications 


\section{Curriculum Vitae}

Samer Narouze was born in Cairo, Egypt in 1966. He obtained his medical degree in 1989 at Ain Shams University in Cairo. Subsequently, he finished Anesthesiology residency training and obtained a Master's degree in Anesthesiology and Intensive care in 1993 at Ain Shams University in Cairo where he was appointed as Assistant Professor of Anesthesiology from 1993-1997. He then moved to the USA in 1997. He finished Anesthesiology residency training at Cleveland Clinic in Cleveland, $\mathrm{OH}$ in 2000 followed by Pain Management Fellowship also at Cleveland Clinic in 2001. He helped restructuring the multidisciplinary pain medicine fellowship program at Cleveland Clinic and was appointed as the Program Director for the Pain Medicine Fellowship in 2006-2010. He served as an Assistant Professor then Associate Professor in 2010 at the Lerner College of Medicine of Case Western Reserve University in Cleveland, $\mathrm{OH}$ before moving to Akron, $\mathrm{OH}$.

He is currently the Chairman of the Center for Pain Medicine at Summa Western Reserve Hospital in Akron, OH. He is a Clinical Professor of Anesthesiology and Pain Medicine at Ohio University College of Osteopathic Medicine (OUCOM). He is also a Clinical Professor of Neurological Surgery at Ohio State University (OSU) in Columbus, $\mathrm{OH}$ and an Associate Professor of Surgery at Northeast Ohio College of Medicine (NEOMED). He is board certified in interventional pain management, pain medicine, headache medicine/neurology, as well as anesthesiology. His specialty interests focus on ultrasound-guided techniques, interventional headache medicine, and neuromodulation.

He received the "Master Educator Award" in 2010 from Cleveland Clinic for his work in education and structuring the multidisciplinary pain medicine fellowship program. He also held the "2008 Innovator award" from the Cleveland Clinic for his innovations in ultrasound and neuromodulation. He was selected as the America's Top Pain Medicine Physicians in 2007 by the Consumers' Research Council of America. He is an active member of several national and international anesthesiology, headache, and pain medicine societies. He served as Chair of the special interest group on interventional management of head and face pain for the American Headache Society (AHS), 2006-2007. He also leads the special interest group on Ultrasonography in Pain Medicine (USPM) for the American Society of Regional Anesthesia and Pain Medicine (ASRA).

He edited and co-edited 4 books in pain management and headache field and contributed more than 100 medical articles, book chapters and abstracts. 


\section{Publications}

1. Narouze S. Ultrasound-guided Cervical Spine Injections: Ultrasound "prevents" while contrast fluoroscopy "detects" intra-vascular injections. Reg Anesth Pain Med 2012; 37:127-130.

2. Samer Narouze, David Provenzano, Philip Peng, Urs Eichenberger, Sang Chul Lee, Bernhard Morrigl. The American Society of Regional Anesthesia and Pain Medicine, the European Society of Regional Anesthesia and Pain Therapy, and the Asian Australasian Federation of Pain Societies Joint Committee Recommendations for Education and Training in UltrasoundGuided Interventional Pain Procedures. Reg Anesth Pain Med 2012 (submitted).

3. Lerman IR, Souzdalnitski D, Narouze S. A Low Cost, Durable, Combined Ultrasound and Flouroscopic Phantom for Cervical Transforaminal Injections. Reg Anesth Pain Med 2012 (in press).

4. Hakim SM, Narouze S, Shaker NN, Mahran MA. Risk Factors for New-Onset Persistent Low Back Pain Following Non-Obstetric Surgery Performed with Epidural Anesthesia. Reg Anesth Pain Med 2012 Jan 26 [Epub ahead of print].

5. Narouze S, Peng P. Ultrasound-guided Interventional Procedures in Pain Medicine: A Review of Anatomy, Sonoanaotmy and Procedures. Part II: Axial structures. Reg Anesth Pain Med 2010; 35:386-96.

6. Veizi IE, Hayek SM, Narouze SN, Mekhail N. Combination of intrathecal opioids with bupivacaine attenuates opioid dose escalation in chronic noncancer pain patients. Pain Med 2011; 12:1481-9.

7. Oluigbo CO, Makonnen G, Narouze S, Rezai AR. Sphenopalatine ganglion interventions: technical aspects and application. Prog Neurol Surg 2011; 24:171-9.

8. Hayek SM, Veizi IE, Narouze SN, Mekhail N. Age-dependent Intrathecal Opioid Escalation in Chronic Noncancer Pain Patients. Pain Med 2011; 12:1179-89.

9. Narouze S, Peng P. Ultrasound-guided Interventional Procedures in Pain Medicine: A Review of Anatomy, Sonoanaotmy and Procedures. Part II: Axial structures. Reg Anesth Pain Med 2010; 35:386-96. 
10. Blumenfeld A, Ashkenazi A, Grosberg B, Napchan U, Narouze S, Nett B, DePalma T, Rosenthal B, Tepper S, Lipton RB. Patterns of use of peripheral nerve blocks and trigger point injections among headache practitioners in the USA: Results of the American Headache Society Interventional Procedure Survey (AHS-IPS). Headache 2010; 50:937-42.

11. Ashkenazi A, Blumenfeld A, Napchan U, Narouze S, Grosberg B, Nett R, Depalma T, Rosenthal B, Tepper S, Lipton RB. Peripheral Nerve Blocks and Trigger Point Injections in Headache Management - A Systematic Review and Suggestions for Future Research. Headache 2010; 50:943-52.

12. Narouze S. Ultrasound-guided Interventional Procedures in Pain Management: Evidence Based Medicine. Reg Anesth Pain Med 2010; 35(S2):S55-8.

13. Neal JM, Brull R, Chan VW, Grant SA, Horn JL, Liu SS, McCartney CJ, Narouze SN, Perlas A, Salinas FV, Sites BD, Tsui BC. The ASRA evidence-based medicine assessment of ultrasound-guided regional anesthesia and pain medicine: Executive summary. Reg Anesth Pain Med 2010; 35(S2):S1-9.

14. Lin CS, Cheng JK, Hsu YW, Chen CC, Lao HC, Huang CJ, Cheng PH, Narouze S. . Ultrasound-guided Ganglion Impar Block: A Technical Report. Pain Med. 2010;11:390-4.

15. Suijlekom H, van Zundert J, Narouze S, van Kleef M, Mekhail N. Evidencebased Interventional Pain Medicine according to clinical diagnoses.6. Cervicogenic headache. Pain Practice 2010; 10:124-30.

16. Ansarinia M, Rezai A, Tepper SJ, Steiner CP, Stump J, Stanton-Hicks M, Machado A, Narouze S Electrical Stimulation of Sphenopalatine Ganglion (SPG) for Acute Treatment of Cluster Headaches. Headache 2010; 50:116474.

17. Narouze SN. Role of sphenopalatine ganglion neuroablation in the management of cluster headache. Curr Pain Headache Rep 2010;14:160-3.

18. Peng $\mathrm{P}$, Narouze S. Ultrasound-guided Interventional Procedures in Pain Medicine: A Review of Anatomy, Sonoanaotmy and Procedures. Part I: Nonaxial structures. Reg Anesth Pain Med 2009; 34:458-74.

19. Narouze, S. Sonoanatomy of the cervical spinal nerve roots: implications for brachial plexus block. Reg Anesth Pain Med 2009; 34:616-17.

20. Mekhail NA, Cheng J, Narouze S, Kapural L, Mekhail MN, Deer T. Clinical Applications of Neurostimulation: Forty Years Later. Pain Practice 2010; 10:103-12. 
21. Narouze S, Kapural L, Casanova J, Mekhail N. Sphenopalatine Ganglion Radiofrequency Ablation for the Management of Chronic Cluster Headache. Headache 2009; 49: 571-577.

22. Narouze S, Vydyanathan A, Kapural L, Sessler DI, Mekhail N. Ultrasoundguided Cervical Selective Nerve Root Block: A Fluoroscopy-controlled Feasibility Study. Reg Anesth Pain Med 2009; 34:343-348.

23. Narouze S, Govil H, Guirguis M, Mekhail N. Continuous Cervical Epidural Analgesia for Rehabilitation after Shoulder Surgery: A Retrospective Study. Pain Physician 2009; 12:189-94.

24. Tepper SJ, Rezai A, Narouze S, Steiner C, Mohajer P, Ansarinia M. Acute treatment of intractable migraine with sphenopalatine ganglion electrical stimulation Headache 2009; 49:983-9.

25. van Kleef M, Lataster A, Narouze S, Mekhail N, Geurts JW, van Zundert J. Evidence-based interventional pain medicine according to clinical diagnoses. 2. Cluster headache. Pain Pract 2009; 9:435-42.

26. Narouze S. Ultrasonography in pain medicine: Introduction (editorial). Tech Reg Anesth Pain Manage 2009; 13:1-2.

27. Narouze S. Ultrasonography in pain medicine: Future directions. Tech Reg Anesth Pain Manage 2009; 13; 198-202.

28. Narouze S, Vydyanathan A. Ultrasound-guided cervical transforaminal injection and selective nerve root block Tech Reg Anesth Pain Manage 2009; 13:137-141.

29. Vydyanathan A, Narouze S. Ultrasound-guided caudal and sacroiliac joint injections . Tech Reg Anesth Pain Manage 2009; 13:157-160.

30. Narouze S, Vydyanathan A. Ultrasound-guided cervical facet intra-articular injection. Tech Reg Anesth Pain Manage 2009; 13:133-136.

31. Cheng PH, Narouze S. Ultrasound-guided shoulder joint injections. Tech Reg Anesth Pain Manage 2009; 13:184-190.

32. Cheng PH, Narouze S. Ultrasound-guided injections of the knee and hip joints . Tech Reg Anesth Pain Manage 2009; 13:191-197.

33. Soliman LM, Narouze S. Ultrasound-guided transversus abdominus plan block for the management of abdominal pain: An alternative to differential epidural block. Tech Reg Anesth Pain Manage 2009; 13:117-120. 
34. Siegenthaler A, Narouze S, Eichenberger U. Ultrasound-guided third occipital nerve and cervical medial branch nerve blocks . Tech Reg Anesth Pain Manage 2009; 13:128-132.

35. van Kleef M, van Genderen WE, Narouze S, Nurmikko TJ, van Zundert J, Geurts JW, Mekhail N. Trigeminal neuralgia. Pain Pract 2009; 9:252-9.

36. Hayek SM, Jasper J, Deer TR, Narouze S. Occipital neurostimulation-induced muscle spasms: implications for lead placement. Pain Physician 2009; 12:867-76.

37. Narouze S. Beware of the "serpentine" inferior thyroid artery while performing stellate ganglion block. Anesth Analg 2009; 109:289-90.

38. Kapural L, Cata JP, Narouze S. Successful treatment of lumbar discogenic pain using intradiscal biacuplasty in previously discectomized disc. Pain Pract 2009; 9:130-4.

39. Narouze S, Zakari A, Vydyanathan A Ultrasound-guided placement of a permanent percutaneous femoral nerve stimulator leads for the treatment of intractable traumatic femoral neuropathy. Pain Physician 2009; 12:3058.

40. Narouze S. Ultrasonography in pain medicine: a sneak peak at the future (editorial). Pain Pract 2008; 8:223-5.

41. Kapural L, Nageeb F, kapural M, Cata J, Narouze S, Mekhail N. Cooled radiofrequency system for the treatment of chronic pain from sacroiliitis: The first case series. Pain Pract 2008; 8:348-354.

42. Narouze S, Vydyanathan A, Patel N. Ultrasound-guided stellate ganglion block successfully prevented esophageal puncture. Pain Physician 2007; 10:747-752.

43. Narouze S. Supraorbital nerve electrical stimulation for the treatment of intractable chronic cluster headache. Headache 2007; 47:1100-2.

44. Narouze S. Complications of head and neck procedures. Techniques in Regional Anesthesia and Pain Management 2007; 11:171-177.

45. Narouze S, Casanova J, Mekhail N. The longitudinal effectiveness of lateral atlantoaxial intra-articular steroid injection in the management of cervicogenic headache. Pain Medicine 2007; 8:184-188.

46. Kapural L, Narouze S, Mekhail N. Spinal cord stimulation is an effective treatment for chronic intractable pelvic visceral pain. Pain Medicine 2006; 7:440-3. 
47. Narouze SN, Casanova J, Farag E, Tetzlaf J. Inadvertent dural puncture during attempted thoracic epidural catheter placement complicated by cerebral and spinal subdural hematoma. J Clin Anesth 2006; 18:132-4.

48. Narouze $\mathrm{S}$. Is it time to perform all thoracic epidural placements under fluoroscopy? Anesth Analg 2006; 102:1585.

49. Narouze S. Epidural steroid injections after epidurography may prevent otherwise devastating complications. Anesth Analg 2006; 102:1585.

50. Narouze S. Ultrasound-guided cervical periradicular injection: Cautious optimism (letter). Reg Anesth Pain Med 2006; 31:88.

51. Tetzlaff JE, Ayad S, Narouze S. Cautious optimism on reducing spinal headache with spinal catheters: Reply. Reg Anesth Pain Med 2004; 29:299-301.

52. Ayad S, Narouze S, Tetzlaff JE. Possible asymptomatic cerebrospinal fluid leak following successful labour epidural catheter placement. Can J Anaesth 2004; 51: 518-519.

53. Narouze S, Basali A, Mandel M, Tetzlaff JE. Horner's Syndrome and Trigeminal Nerve Palsy after Lumbar Epidural Analgesia for Labor and Delivery. J Clin Anesth 2002; 14: 532-534.

54. Ayad S, Demian Y, Narouze S, and Tetzlaff J. Subarachnoid catheter placements after wet- tap for analgesia in labor. Influence on the risk of headache in obstetric patients. Reg Anesth Pain Med 2003; 28:512-515.

55. Narouze S, Yonan S, and Malak 0 . Inferior epigastric artery erosion: A rare complication of intrathecal drug delivery system. Reg Anesth Pain Med 2003; 28:589-590.

56. Farag E, Argalious M, Narouze S, DeBoer G, Tome J. The anesthetic management of ventricular septal defect (VSD) repair in a child with mitochondrial cytopathy. Can J Anesth 2002; 49:958-962.

\section{Abstracts and Case Reports:}

1. S Narouze, R Saad,, H Nagem, L Kapural. Occipital Nerve Stimulation with Self-anchoring Leads for the Management of Refractory Chronic migraine Headache. International Headache Congress, Berlin 2011.

2. Stephen Silberstein, David Dodick, Joel Saper, Billy Huh, Ken Reed, Samer Narouze, Donald Bacon, Alon Mogilner, James Banks, Roger Cady, Stuart Black, Konstantin Slavin, Jerome Goldstein, Herbert Markley, Tim Deer, 
Robert Levy, Nagy Mekhail. Occipital Nerve Stimulation for the Management of Chronic Migraine Headaches. International Headache Congress, Berlin 2011.

3. B. Bouche, S. Narouze, E. Eisenberg, M.K. Karmakar, M. Meignier, V. Dixneuf, J. Lemarie Ultrasound-Assisted lumbar épidural percutaneous Spinal Cord Stimulation (SCS): case report. 30th Annual ESRA Congress, Dresden 2011.

4. B. Bouche, E. Eisenberg, S. Narouze, M.K. Karmakar, M. Meignier, J. Lemarie Facilitation of diagnostic and percutaneous trial lead placement with ultrasound guidance for peripheral nerve stimulation suprascapular neuralgia. 30th Annual ESRA Congress, Dresden 2011.

5. B. Bouche, E. Eisenberg, S. Narouze, M.K. Karmakar, M. Meignier, J. Lemarie. Facilitation of diagnostic and percutaneous trial lead placement with ultrasound guidance for peripheral nerve stimulation on lateral cutaneous femoral nerve. 30th Annual ESRA Congress, Dresden 2011.

6. Narouze S. Ultrasound guided percutaneous cervical and upper thoracic sympathetic chain neuroelectrode implant for the treatment of Complex Regional Pain Syndrome. Pain Med 2010; 11:298.

7. Ansarinia M, Rezai A, Tepper S, Mohajer P, Steiner C, Stanton-Hicks M, Narouze S. Sphenopalatine Ganglion (SPG) Stimulation during Acute Migraine and Cluster Headaches. International Headache Congress (IHC). Philadelphia 2009.

8. Narouze S, Rezai A, Tepper S, et al. Sphenopalatine Ganglion Stimulation for the Acute Treatment of Intractable Migraine. Pain Med 2009; 10: 226.

9. Narouze S, El-Sharkawy H. Ultrasound- guided T2 Sympathetic Block with the Anterior Approach. Pain Med 2009; 10: 225.

10. Narouze S, Saad R, Nagem H, Kapural L. Occipital Nerve Stimulation with Self-anchoring Leads for the Management of Refractory Chronic migraine Headache. Pain Med 2009; 10: 221.

11. Narouze S. Ultrasound-guided Lateral Atlanto-axial Joint Injection for the Treatment of Cervicogenic Headache. Pain Med 2009; 10: 222.

12. Vydyanathan A, Narouze S: Dorsal nerve of the penis electric stimulation for penile pain. Pain Med 2009; 10: 226-227.

13. Kapural L, Zovkic P, Narouze S. Cooled radiofrequency of dorsal ramus of L5 for denervation of the sacroiliac joint: Technical report. Pain Med 2009; 10: 220-221. 
14. Ansarinia M, Rezai A, Stanton-Hicks M, Machado A, Tepper S, Steiner C, Stump J, Deogonokar M, Francisoco A, Narouze S. Stimulation of Sphenopalatine Ganglion (SPG) for Treatment of Acute Cluster Headaches. North American Neuromodulation Society meeting, Las Vegas 2008.

15. Narouze S, Casanova J, Kapural L. Sphenopalatine ganglion radiofrequency ablation for the management of chronic cluster headache. Headache 2008; 48: S1-S15.

16. Girgis G, Narouze S: Intramedullary cystic granuloma complicating chronic intrathecal opioid infusion: A Case Report. (MARC) Midwest Anesthesia Resident Conference, Indianapolis 2008.

17. Ryan D, Narouze S: Recurrent tunnelled epidural catheter infection in CRPS patient. Midwest Anesthesia Resident Conference (MARC), Indianapolis 2008.

18. Vydyanathan A, Narouze S: Dorsal nerve of the penis electric stimulation for penile pain. A Case Report. Midwest Anesthesia Resident Conference (MARC), Indianapolis 2008.

19. Hogan, PW, Andrews, G, Yonan, S, Narouze S: Asymptomatic Epidural Abscess Following Epidural Steroid injection for the treatment of acute herpes zoster neuralgia. Midwest Anesthesia Residents Conference (MARC), Indianapolis 2008 .

20. Shaparin N, Narouze S: Inadvertant Discogram during Lumbar Transforaminal Injection: A Case Report. Midwest Anesthesia Resident Conference (MARC), Indianapolis 2008.

21. Narouze SN, Zakari A. Ultrasound-guided placement of permanent percutaneous femoral nerve electric stimulation leads for the treatment of intractable femoral neuropathy. International Neuromodulation Society (INS), Mexico 2007.

22. Narouze SN, Vydyanathan A Ultrasound guided stellate ganglion block successfully prevented esophageal puncture. Reg Anesth Pain Med 2007; 32:A37.

23. Narouze SN, Gutenberg L. Radiofrequency denervation of the lateral atlantoaxial joint for the treatment of cervicogenic headache. Reg Anesth Pain Med 2007; 32: A-8.

24. Narouze SN, Govil H, Mekhail N. Continuous Cervical Epidural Catheter for Rehabilitation after Shoulder Surgery. Reg Anesth Pain Med 2007; 32:A-77. 
25. Narouze SN. Supraorbital nerve stimulation for the treatment of intractable chronic cluster headache (F31). Headache 2007; 47(5):763.

26. Narouze SN, Abdou A. Selective sacral nerves stimulation for pudendal nerve entrapment syndromes. Pain Med 2007; 8(1):A117.

27. Narouze SN, Kapural L, Mekhail N. The efficacy of sphenopalatine ganglion block in the management of chronic cluster headache. Pain Med 2006; 7(2):A127.

28. Narouze SN. Supraorbital nerve stimulation for the treatment of intractable postherpetic trigeminal neuralgia. Reg Anesth Pain Med 2005; 30(3):A6.

29. Narouze SN, Katyal S, Casanova J. The efficacy of propofol in the treatment of intractable chronic daily headache. Anesth Analg 2005; 100, S-316.

30. Narouze SN, Casanova J. The efficacy of lateral atlanto-axial intra-articular steroid injection in the management of cervicogenic headache. Anesthesiology 2004; 101: A1005.

31. Narouze SN, Tabet JC, Casanova J. Lumbar intrathecal granuloma complicating a low-dose intrathecal morphine infusion. Eur J Anaesth. 2004; 21(32): 199, A-799.

32. Narouze S, Farag E, Tetzlaff J. Anesthetic management of Charcot-MarieTooth (CMT) disease. Eur J Anesth 2003; 20:A384.

33. Kapural L, Narouze S, Rajagopalan S, Mekhail N. Efficacy and Complication Profile of Surgically Implanted Versus Percutaneously Implanted Spinal Cord Stimulation Systems. Anesthesiology 2002; 96:A928.

34. Narouze S, Zakhari E, and Basali A. Genitofemoral and Ilioinguinal neuropathy after open versus laparoscopic inguinal herniorraphy. ASRA Annual Fall Meeting, Phoenix 2002.

35. Narouze S, Basali A, and Tetzlaff J. Horner's syndrome and Trigeminal nerve palsy after epidural analgesia for labor and delivery. ASRA Annual Spring meeting, Phoenix 2002.

36. Narouze S, Ayad S, Demian Y, and Tetzlaff J. Subarachnoid catheter placement after wet- taps for analgesia in labor. Influence on the risk of headache in obstetric patients. Anesthesiology 2001; 95:A1040. 


\section{Review Articles and Book Chapters:}

1. Headache and Craniofacial Neuralgias. Encyclopedia of neurological sciences. $2^{\text {nd }}$ ed., Elsevier 2012.

2. Joint injections. Essentials of Pain Medicine, $3^{\text {rd }}$ ed., edited by Benzon et al. Elsevier 2011.

3. Cervicogenic Headache. Essentials of Pain Medicine, $3^{\text {rd }}$ ed, edited by Benzon et al. Elsevier 2011.

4. Orofacial Pain. Essentials of Pain Medicine, $3^{\text {rd }}$ ed, edited by Benzon et al. Elsevier 2011.

5. Sympathetic blocks. Spinal Injections and Peripheral Nerve Blocks, $1^{\text {st }}$ ed. Edited by; Honorio Benzon, Marc Huntoon, and Samer Narouze. Elsevier 2011.

6. Head and neck blocks. Spinal Injections and Peripheral Nerve Blocks, $1^{\text {st }}$ ed. Edited by; Honorio Benzon, Marc Huntoon, and Samer Narouze. Elsevier 2011.

7. Ultrasound guided cervical spine injections. Spinal Injections and Peripheral Nerve Blocks, $1^{\text {st }}$ ed. Edited by; Honorio Benzon, Marc Huntoon, and Samer Narouze. Elsevier 2011.

8. Cranial neurostimulation. Interventional and Neuromodulatory Techniques for Pain Management, $1^{\text {st }}$ ed. Edited by; Robert Levy, Salim Hayek. Elsevier 2011.

9. Role of Sphenopalatine Ganglion Neuroablation in the Management of Cluster Headache. Current Pain and Headache Reports 2010.

10. Ultrasound-guided Interventional Procedures in Pain Medicine: A Review of Anatomy, Sonoanaotmy and Procedures. Part II: Axial structures. Reg Anesth Pain Med 2010; 35:386-96.

11. Ultrasound-guided Interventional Procedures in Pain Medicine: A Review of Anatomy, Sonoanaotmy and Procedures. Part I: Non-axial structures. Reg Anesth Pain Med 2009; 34:458-74.

12. Ultrasound guided cervical facet intrarticular injection. Atlas of ultrasound guided procedures in interventional pain management, $1^{\text {st }}$ ed. Edited by; Samer Narouze, Springer 2011. 
13. Ultrasound guided cervical nerve root block. Atlas of ultrasound guided procedures in interventional pain management, $1^{\text {st }}$ ed. Edited by; Samer Narouze, Springer 2011.

14. Ultrasound guided caudal, ganglion impar and sacroiliac joint injections Atlas of ultrasound guided procedures in interventional pain management, $1^{\text {st }}$ ed. Edited by; Samer Narouze, Springer 2011.

15. Ultrasound guided transversus abdominus plane (TAP) block. Atlas of ultrasound guided procedures in interventional pain management, $1^{\text {st }}$ ed. Edited by; Samer Narouze, Springer 2011.

16. Ultrasound guided cdeliac plexus block and neurolysis. Atlas of ultrasound guided procedures in interventional pain management, $1^{\text {st }}$ ed. Edited by; Samer Narouze, Springer 2011.

17. Ultrasound guided occipital stimulation. Atlas of ultrasound guided procedures in interventional pain management, $1^{\text {st }}$ ed. Edited by; Samer Narouze, Springer 2011.

18. Ultrasound guided groin stimulation. Atlas of ultrasound guided procedures in interventional pain management, $1^{\text {st }}$ ed. Edited by; Samer Narouze, Springer 2011.

19. Ultrasound guided atlanto-axial and atlanto-occipital joint onjections. Atlas of ultrasound guided procedures in interventional pain management, $1^{\text {st }} \mathrm{ed}$. Edited by; Samer Narouze, Springer 2011.

20. Ultrasound assisted cervical discography and intradiscal procedures. Atlas of ultrasound guided procedures in interventional pain management, $1^{\text {st }}$ ed. Edited by; Samer Narouze, Springer 2011.

21. MILD procedure: to do or not to so. ASRA Newsletter August 2011.

22. Renewed interest in Sphenopalatine ganglion. ASRA Newsletter May 2011.

23. Differential epidural and TAP block. ASRA Newsletter May 2010.

24. Trigeminal neuralgia. ASRA web site. Spring 2010.

25. Cervicogenic headache. ASRA web site. Spring 2009.

26. Certification for Ultrasound-guided regional anesthesia: yes or no. ASRA Newsletter Feb 2009.

27. Ultrasonography in Pain Medicine: Research update. ASRA Newsletter Nov. 2008. 
28. Ultrasonography in Pain Medicine: A Sneak Peak at the Future. Pain Practice 2008.

29. Complications of head and neck procedures. Tech Reg Anesth Pain Manage 2007; 11:171-177.

30. Pain Management in Chronic prostatitis. Current Clinical Urology Series, Chronic Prostatitis/Chronic pelvic Syndrome, edited by Daniel Shoskes. Humana Press 2007.

31. Cervicogenic Headache: Diagnosis and Management. ASA Refresher Course Publications 2007.

32. Medical Management of Chronic Shoulder Pain. Disorders of the Shoulder $2^{\text {nd }}$ ed. Edited by Joseph P. Iannotti and Gerald R. Williams Jr., LWW 2007.

\section{Book Editor}

1. Atlas of ultrasound guided procedures in interventional pain management. Narouze, Samer N. (ed.) 1st Edition. Springer 2011.

2. Interventional headache management: nerve blocks and beyond. Narouze, Samer N. (ed.) 1st Edition. Springer 2012 (in press).

3. Spinal Injections and Peripheral Nerve Blocks, 1st Edition. Elsevier 2011. Edited by; Honorio Benzon, Marc Huntoon, and Samer Narouze.

4. Essentials of Pain Medicine, 3rd Edition. Elsevier 2011 Edited by, Benzon et al. Co-editor: Samer Narouze. 